\title{
DESIGN AND DEVELOPMENT OF RAPID BATTERY EXCHANGE SYSTEMS FOR ELECTRIC VEHICLES TO BE USED AS EFFICIENT STUDENT TRANSPORTATION
}

\author{
A Thesis \\ Presented to \\ The Faculty of the \\ California Polytechnic State University \\ In Partial Fulfillment \\ Of the Requirements for the Degree of \\ Master of Science in Engineering
}

By

Jonathan Austin BeVier

July 2009 
(C) 2009

Jonathan Austin BeVier ALL RIGHTS RESERVED 
TITLE: Design and Development of Rapid Battery Exchange Systems for Electric Vehicles to be used as Efficient Student Transportation

AUTHOR: Jonathan Austin BeVier

DATE SUBMITTED: July 20th, 2009

COMMITTEE CHAIR: Dr. Linda Vanasupa, Professor - Materials Engineering COMMITTEE MEMBER: Dr. Daniel Walsh - Asst. Dean of Engineering COMMITTEE MEMBER: Dr. Lanny Griffin - Chair, Biomedical Engineering 


\begin{abstract}
Design and Development of Rapid Battery Exchange Systems for Electric Vehicles to be used as Efficient Student Transportation
\end{abstract}

By

Jonathan Austin BeVier

Rapid battery exchange systems were built for an electric van and pedal assist electric bike as a method of eliminating the need to recharge the vehicles batteries in order to increase the feasibility of using electric propulsion as a method of efficient student transportation. After selecting proper materials it was found that the systems would need a protective coating to ensure consistent operation. 1020 cold rolled steel samples coated with multiple thicknesses of vinyl resin paint, epoxy resin paint, and powder coating were subjected to environmental wear tests in order to determine if the type and thickness of common protective coatings has an effect on the durability of the system over its lifetime. The tests consisted of a 2400 hour extended salt spray test, coating delamination testing, and modified impact testing. The extended salt spray test, delamination test, and deformation tests of the coatings all found that the type of coating and the thickness of the coating to have a significant effect on the measured outputs. The significant effect shown in the deformation test could not determine the proper material without the aid of microscopic studies of the surface geometry change due to the induced deformation. Powder coating the rapid battery exchange systems would result in proper performance if coupled with epoxy paint for repairs. Testing of the Rapid battery exchange system indicated that the use of mechanical aiming was not suitable for the application, a further adaptation of the system indicated that the system may be better suited toward personal bicycles as there was a large increase in transportation efficiency. 


\section{ACKNOWLEDGEMENTS}

This project would not have been possible without the funding and support of General Hydroponics, Sebastopol, California. I would like to thank Dr. Art Mc Carley of the Electrical Engineering Department at the California Polytechnic State University, San Luis Obispo for the donation of the electric van used in this project. I would like to thank James Follansbee, owner of Auto Life Center, for the time, efforts, and equipment that he provided me with for this project. I would also like to thank Charles Botsford of Aerovironments Inc. for the time, equipment, and service that he provided me with during the project. Lastly I would like to thank my advisor Dr. Linda Vanasupa of the Materials Engineering Department at California Polytechnic State University, San Luis Obispo. Her patience, guidance, and support have been more than helpful. 


\section{TABLE OF CONTENTS}

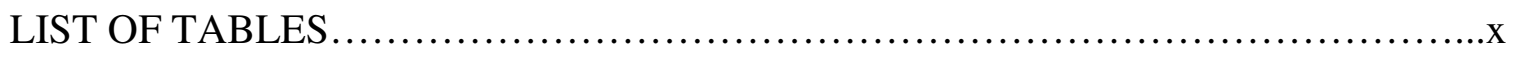

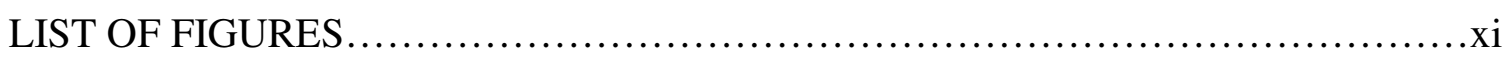

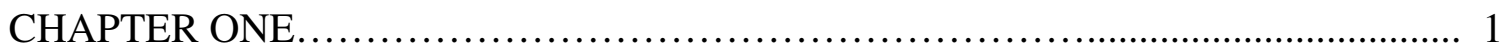

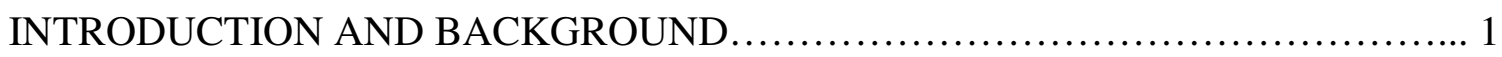

1.1 The Rise of the Electric Car...........................................

1.2 Advancement of Transportation Modes and Their Energy Sources...............2

1.2.1 Horses- Edible Food..............................................2

1.2.2 Steam Power - Wood \& Coal........................................

1.2.3 Internal Combustion Engines - Petroleum Based Fuels..................4

1.2.4 Natural Gas.......................................................6

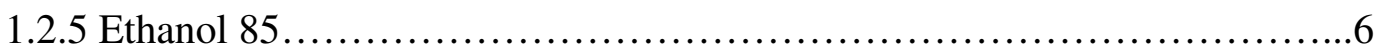

1.3 Modern Energy Sources for Transportation.............................. 7

1.3.1 Petroleum Based Fuels............................................8

1.3.2 Natural Gas...................................................8

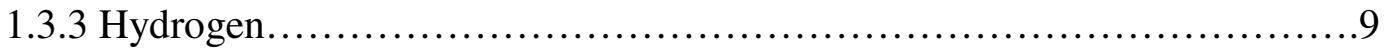

1.3.4 Electricity................................................. 9

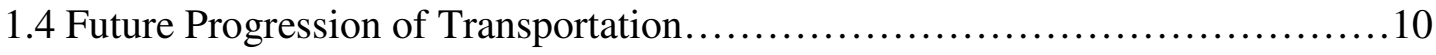

1.4.1 Photovoltaics as an Energy Source for Electric Propulsion................11

1.4.2 Geothermal and Wind Energy as Sources for Electric Propulsion...........12

1.5 Broader Impacts of Altering Transportation.............................. 13

1.6 The Need for Change in Transportation Methods.......................... 15

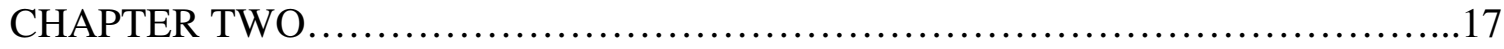




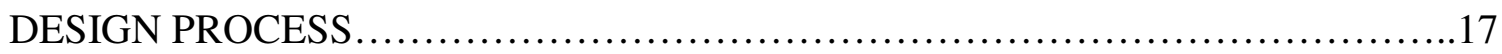

2.1 Current Transportation Models...........................................17

2.2 Various Electric Propulsion Charging Models...................................19

2.2.1 Rapid Charging .......................................................

2.2.2 Metropolitan “Muni” Trolley Bus Model...............................22

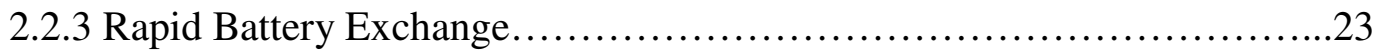

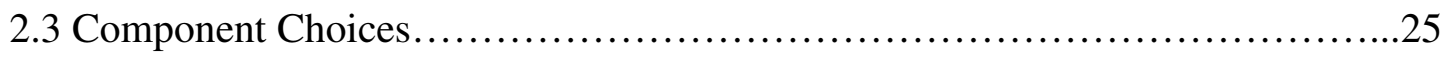

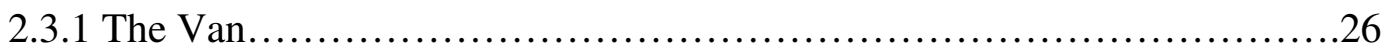

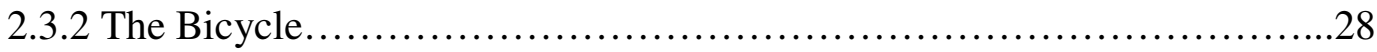

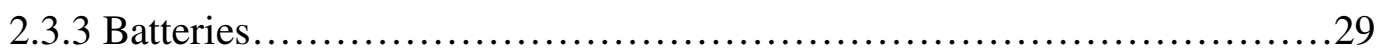

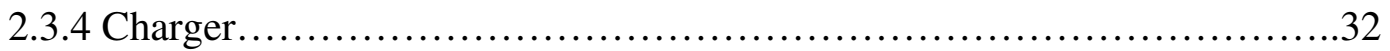

2.3.5 Materials to Build the Actual System.....................................34

2.4 Conceptual Designs of the System........................................34

2.5 Designs for Rapid Battery Exchange System Protection.........................39

2.6 Manufacturing the Rapid Battery Exchange Systems...........................40

2.6.1 The Van's System....................................................

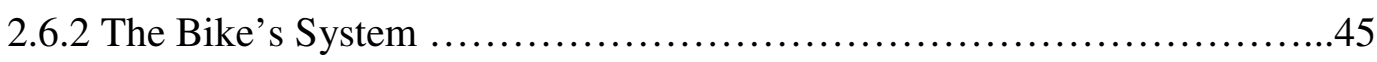

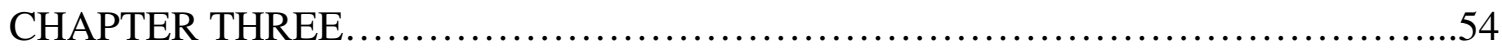

RESEARCH OBJECTIVES ...................................................

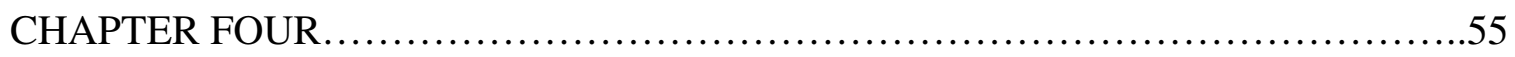

EXPERIMENTAL MATERIALS AND METHODS...............................55

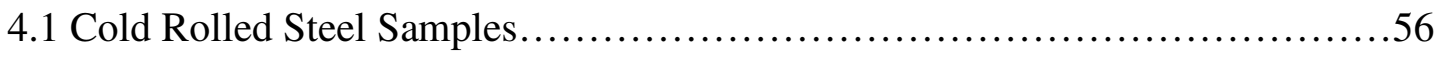

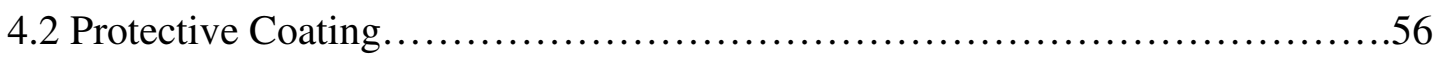




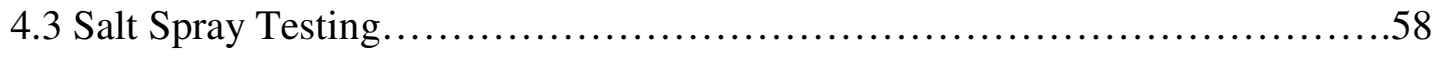

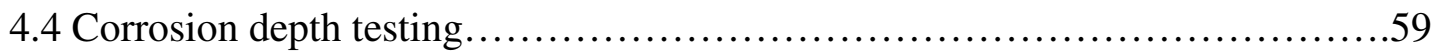

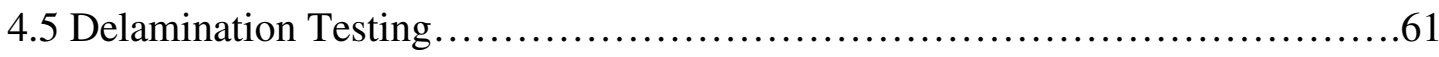

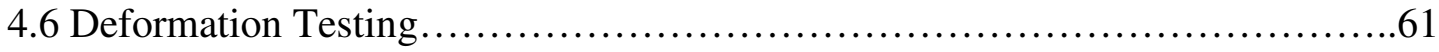

4.7 Rapid Battery Exchange Testing ........................................62

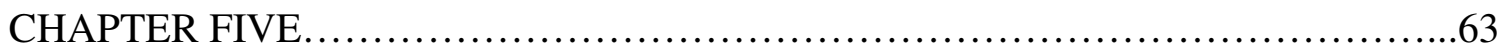

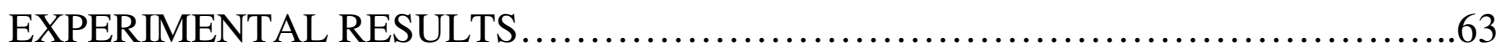

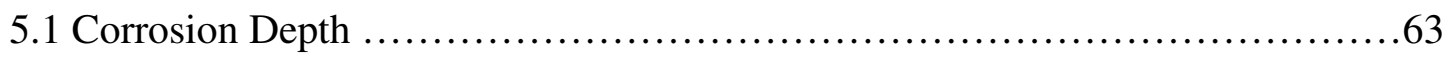

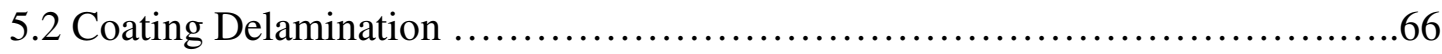

5.3 Coating Deformation .................................................. 70

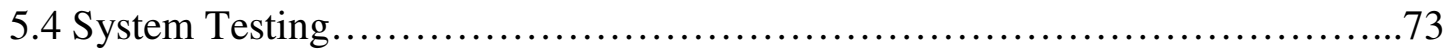

5.4.1 Van System Testing................................................ 74

5.4.2 Bike System Testing ............................................... 75

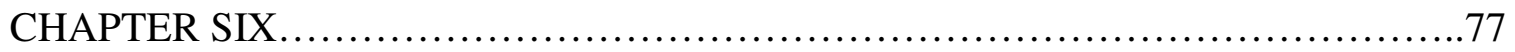

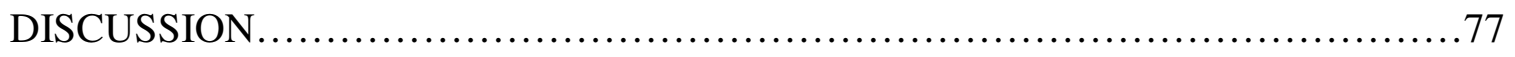

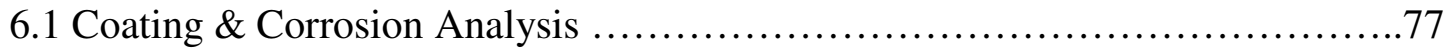

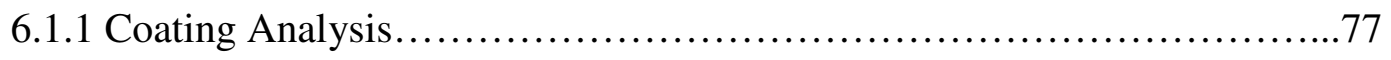

6.1.2 Corrosion Testing .................................................. 80

6.1.3 Effect of Coating on Corrosion....................................... 82

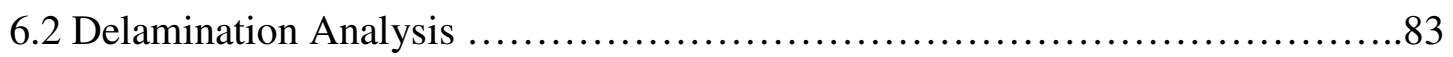

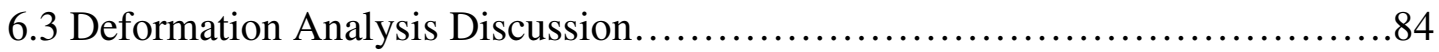

6.4 Rapid Battery Exchange - Van System....................................86

6.5 Rapid Battery Exchange - Electric Bike System.............................91 


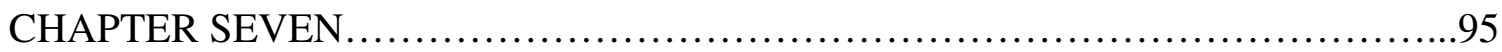

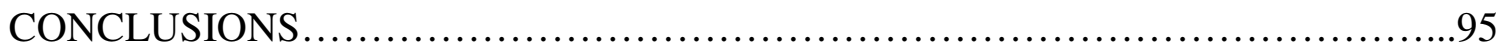

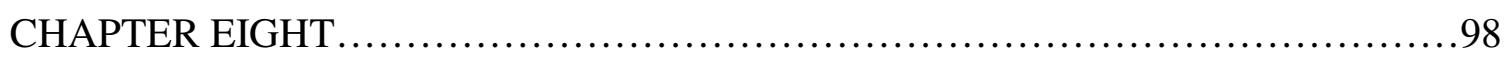

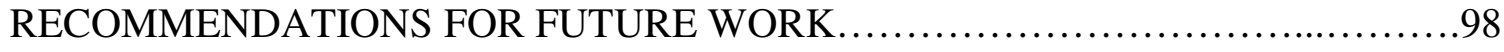

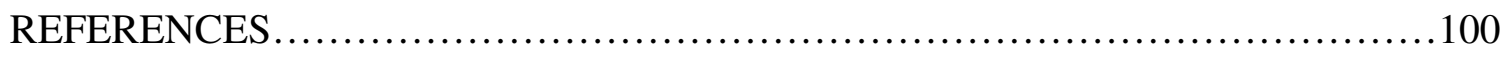

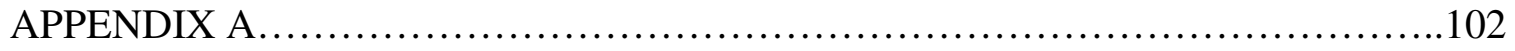

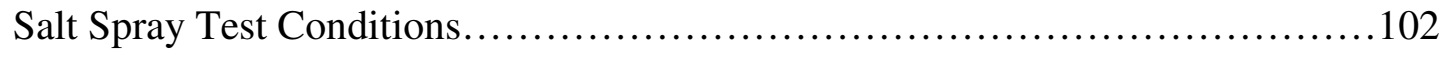

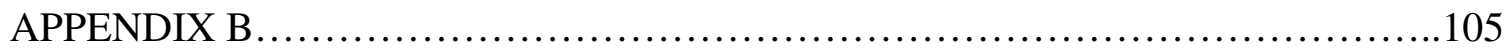

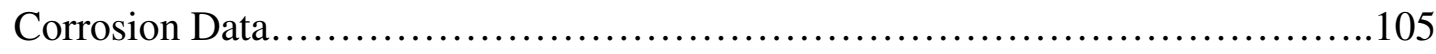

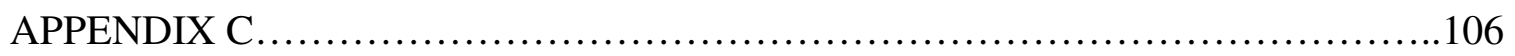

Corrosion Statistical Significance........................................... 106

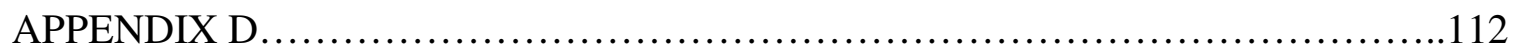

Delamination Data....................................................... 112

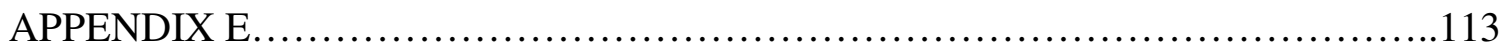

Delamination Statistical Significance.........................................113

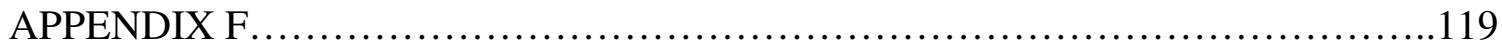

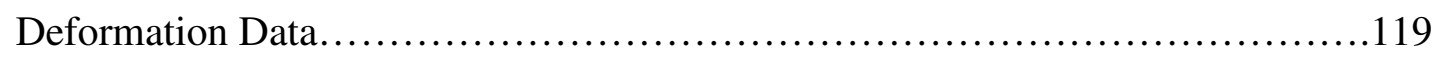

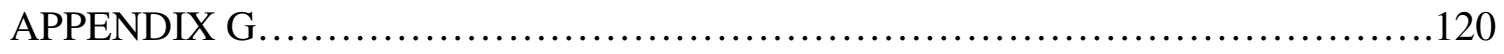

Deformation Statistical Significance........................................120 


\section{LIST OF TABLES}

Table I. Hypotheses Made in the GLM Model for Corrosion Depth Analysis............64

Table II. Summarized P-Values for Corrosion Results...............................65

Table III. Hypotheses Made in the GLM Model for Coating Delamination

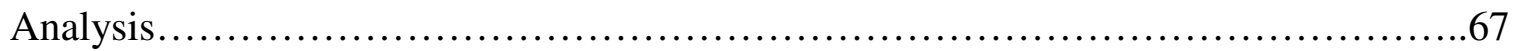

Table IV. Summarized P-Values for Delamination Results.............................68

Table V. Hypotheses Made in the GLM Model for Coating Delamination

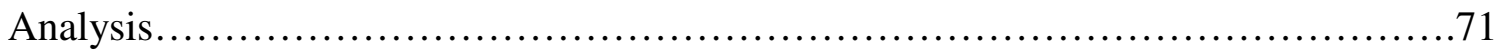

Table VI. Summarized P-Values for Deformation Results............................72

Table VII. Plastic Composition in Various Powder Coating Thicknesses...................80

Table A1. Salt Spray Test Conditions for 100 Day Test............................102

Table B1. Measured Corrosion Depth of Salt Spay Test Samples......................105

Table D1. Measured Coating Delamination.......................................112

Table F1. Deformation Distances of Impact Testing.................................119 


\section{LIST OF FIGURES}

Figure 1. Commercial Cost of solar is estimated to decrease severely over the next

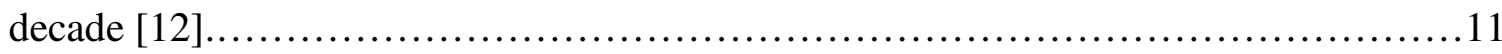

Figure 2. The typical uses for benzene, its counterparts, and their derived acids, the method of obtaining these plastics is not limited to this process map..................14 Figure 3. Forklift battery exchange systems are manual in operation, recent versions

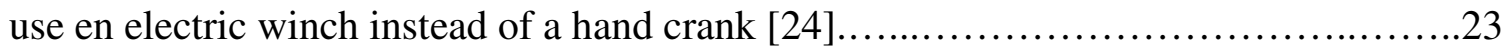
Figure 4. Mercedes Benz electro transport system that utilizes a hand operated battery exchange system, circa 1971 [25].

Figure 5. A 1991 GMC electric G-Van utilized by PG\&E was the vehicle that the rapid battery exchange system would be designed for ...

Figure 6. Prima runner pedal assist electric bike used for the project prior to modifications

Figure 7. Panasonic Cylindrical cells look like tubes while prismatic cells are square allowing for a larger range of applications [26]...

Figure 8. AeroVironments Inc. ABC 150 electric vehicle test station and charger

Figure 9. Hydraulic design that mimics the initial design of the system, long distances for the battery to travel result in low efficiency .36 Figure 10. A rework of design methodology resulted in the development of a more efficient applicable design 
Figure 11. Simple conceptual designs of how the rapid battery exchange system would work on the electric bike, the different components are: battery (yellow), battery attachment piece (blue), exchange track on bike (red)

Figure 12. A custom fabricated pallet moving mechanism for moving pallets over $3500 \mathrm{lbs}$ was to be the donor component of the exchange system....................41

Figure 13. Steel pallet rack prior to modification to hold batteries

Figure 14. The shaft down the center of the two rails was the drive source for the pallets; the new system doesn't require a drive source so it was removed. 42 Figure 15. Tighter fit linear bearings were used to stabilize the battery so that it would operate in a functional matter.

Figure 16. The modified pallet moving system was attached to its support table for testing.

Figure 17. The battery carrier system that was intended to be installed below the vehicle. .44

Figure 18. Topeak MTX A-Type rear bicycle rack, the body is made of aluminum with a plastic insert where adapters slide in [30]. .46 Figure 19. Topeak Fixer 6 MTX rear basket adapter that was used for mounting the battery on the electric bike system. .46 Figure 20. Fuse clip that serves as terminal connectors for the various components of the electric bike, a similar model to this one was used. .48

Figure 21. Four leads on the rack allow for AC plug in for rapid charging .49

Figure 22. An AC extension cord and DC wires protrude from the base of the rack.....49 
Figure 23. A 48 volt battery management system was soldered and connected to the different positions on the battery. BMS is seen here just after completion

Figure 24. The negative terminal wire for the battery exchange system overloaded causing sparking and melting of the surrounding plastic .51 Figure 25. High current 30A Anderson connectors are used to ensure worry free operation.

Figure 26. A battery ruminator switch with a key was utilized due to its ability to handle vast amounts of electrical current..... .52

Figure 27. Support pieces for the bottom of the battery ensured minimal movement.....52 Figure 28. Completed rack and battery for the bicycle rapid battery exchange system. .53

Figure 29. Sections of an epoxy test sample prior to being analyzed.

Figure 30. Bakelite mounted samples are prepared and are ready for microscopic analysis to determine corrosion depth

Figure 31. Interaction plot shows the difference in corrosion depth for different thicknesses of the various types of coatings. .64 Figure 32. Interaction plot shows the difference in delamination surface area for the different thicknesses and types of coatings. Figure 33. A $0.5 \mathrm{~mm}$ vinyl resin paint sample exhibited exfoliation corrosion at the lighter colored areas of the sample.

Figure 34 . $0.5 \mathrm{~mm}$ coating thickness epoxy paint samples exhibit bubbling and delamination of the paint layer after 2400 hour salt spray test. 
Figure 35. A $0.5 \mathrm{~mm}$ powder coated sample exhibits almost no corrosion, just the

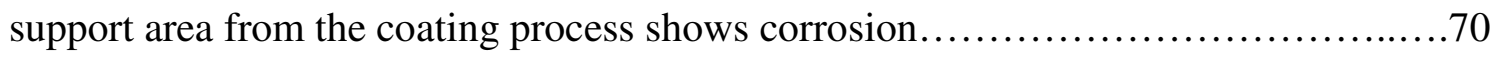

Figure 36. Interaction plot shows the difference in deformation distance for the different thicknesses and types of coatings................................... 71

Figure 37. Indentation of $1 \mathrm{~mm}$ thick coated of A) epoxy resin paint, B) vinyl resin

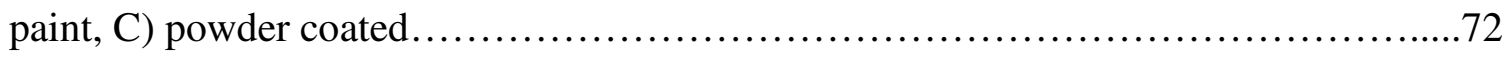

Figure 38. The various aspects of this project were built and tested at the same time,

this saved time for testing however did not consider design setbacks...................73

Figure 39. During testing of the rapid battery exchange system a collision occurred between the battery and the carrier starting a dangerous fire $\ldots \ldots \ldots \ldots \ldots \ldots \ldots \ldots \ldots \ldots \ldots$

Figure 40. Shape played a large role in the damage done to the battery, the square battery on the right is the revised geometry $\ldots \ldots \ldots \ldots \ldots \ldots \ldots \ldots \ldots \ldots \ldots \ldots \ldots \ldots . \ldots \ldots$

Figure 41. The typical structure of a lithium type cell with separators, anodes, and

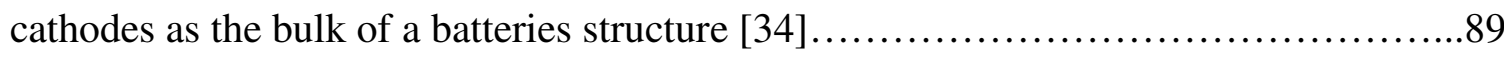

Figure 42. The connector portion of the battery showing the difference from the old attachment style (red wire) and the new attachment style (blue wire) $\ldots \ldots \ldots \ldots \ldots \ldots . . .92$ 


\section{CHAPTER ONE}

\section{INTRODUCTION AND BACKGROUND}

\subsection{The Rise of the Electric Car}

A rapid shift is occurring that will affect everyone in the not-so-distant future; our methods of transportation are rapidly evolving to more environmentally friendly machines from the dinosaurs of the past. Electric propulsion, a not-so-new yet far more efficient method is finally taking its rightful place in the transportation industry.

While it may seem like there currently aren't many electric vehicles on the roads, they are coming. Auto makers have all begun a shift in transportation by implementing hybrid and pure electric technology into many of their vehicles; it is only a matter of time before pure electric becomes the dominant source of transportation as the number of hybrids sold increases by approx $30 \%$ per year [1]. Massive shifts in what society values have brought on changes that push for vehicles to be more efficient and environmentally friendly. Movies like "Who Killed the Electric Car" and "An Inconvenient Truth" have brought our rapid industrialization into perspective and have contributed to the progression and development of future methods of transportation.

Throughout the history of humankind and industrial progress, we as people have developed transformational technology. Newer technologies' increase in popularity has brought with them the downfall of older iterations. Simple examples are how compact discs replaced analog tapes, the pc replaced the typewriter, and how the horse buggy was replaced by the car. These transformational and destructive events occur on all levels, 
from the devastation of different species to the collapse of a star. In the case of the electric car, the collapse of the economy coupled with the societal desire for energy independence have fueled the need for an efficient form of transportation that will drive consumers from place to place, not drive the consumers into economic and environmental debt.

The cost of this transition may be high as we see it today but it will help prevent irreversible damage to the environment that would have taken place over the next 40 years. We must work to achieve a sustainable future; electric propulsion is technology that the world should embrace as an efficient means of transportation for all varieties of living conditions and environments.

\subsection{Advancement of Transportation Modes and Their Energy Sources}

How we get from A to B has significantly progressed over the course of human history. Reform, innovation, and technology have developed as transportation measures were required to reach further and further distances, displacing, if not eliminating, the previous forms of transportation. Some of these steps still need improvement, and some will always remain with us.

\subsubsection{Horses - Edible Food}

Horses were the first non human powered form of transportation that was utilized by the human race. Since about 2000BC horses have been used as transportation, it wasn't for about 4000 years until steam was used to power a method of transportation. Horses were effective means of transportation due to their ability to carry heavy loads, 
either by cart or on their back. People still utilize this method in certain parts of the world for various reasons. The disadvantages of horses is the requirement of edible food and the fact that horses, like humans, generate a lot of excess heat as their bodies naturally metabolize carbohydrates. By generating waste heat you are in turn lowering the efficiency of the transportation, not something settlers of the planet were too concerned with at the time. The availability of consumable food was also not as much of an issue back then as horses could eat grass for their energy, today there wouldn't be enough grass to support country wide transportation by horse.

\subsubsection{Steam Power - Wood \& Coal}

In the late $18^{\text {th }}$ century steam power was first implemented and utilized as a method of propelling a boat by paddle. This idea was later implemented on land transportation with the locomotive in the early $19^{\text {th }}$ century. Transportation by boat and train were mainly used as public transportation as it required a lot of wood or coal to produce enough heat that could boil massive amounts of water to generate steam for a piston type motor, the cost had to be recouped from numerous people to make it worthwhile[2]. This method, along with horses, were used until the middle of the $19^{\text {th }}$ century when motorcycles, planes, and automobiles were invented (some early motorcycles and cars were steam powered, initiating the transition). The problem with steam is that a vehicle must carry thousands of pounds of wood or coal in order to generate the heat necessary to boil the steam for long distances. The amount of excess heat generated by burning the wood or coal is enormous, bringing the efficiency of this transportation between one and ten percent. While this may be a low efficiency, steam 
was what brought electricity into the first houses in America and brought the development of the internal combustion motor. More modern developments utilizing condensers, multiple expansion systems, recirculation, and cogeneration bring the efficiency between 80-95 percent of the input energy. Aside from needing a complex piping system steam has one major flaw, it uses coal and wood to provide heat, two sources that produce massive amounts of $\mathrm{CO} 2$ when combusted. Again, this is not something that people were keen to when they were developing these systems for use in the $19^{\text {th }}$ century.

\subsubsection{Internal Combustion Engines - Petroleum Based Fuels}

In the mid $19^{\text {th }}$ century Karl Benz developed a vehicle that could operate with an internal combustion engine, this expansion to a new petroleum based fuel source spurred most of the development of the internal combustion engine. For reference, gasoline which is distilled from oil has about twice the energy density, kilowatt hours per kilogram $(\mathrm{kwh} / \mathrm{kg})$, that coal has, making it one of the most concentrated sources of energy ever used in transportation. The availability and ease of drilling and purifying oil is what drove the market expansion of personal automobiles. Petroleum based fuels were and still are drilled and refined by the millions of barrels a day to meet up with the demand that has formed over the years. The introduction of this new fuel quickly spread to other applications, trains worked for longer periods of time and used less fuel than before, ships started importing goods from overseas, and planes were progressively developed to carry people around the world with minimal effort. Gasoline was cheap at the pump for the average consumer and everyone was happy. Again people disregarded the environmental 
impacts because it wasn't something that science had caught up to until recently. Now, over a century later, most of the general public of the United States knows that gasoline gets burnt and produces $\mathrm{CO} 2$ much like coal and wood. The problem lies in the fact that everyone is utilizing a car to get from place to place; it has become the necessity of the world to own a vehicle. There are a recorded 250 million operating cars in the United States, one for every person over the age of 18 [3].

While the efficiency of these vehicles lies between 15 and 30\%, most vehicles on the road operate at $18-20 \%$ efficiency. This is roughly double that of steam, the upside is that gasoline produces a fourth the $\mathrm{CO} 2$ that coal does when burnt; the downside is that burning it is polluting the air, both with noise from the motors exhaust system and from the $\mathrm{CO} 2$ emissions. Internal combustion engines also generate massive amounts of excess heat as the output relies on the burning of a fuel source, another indicator of lower efficiency and a source of infrared radiation.

New technologies have increased the efficiency of motors by implementing exhaust recirculation along with complex fuel injection management systems. The increase in efficiency in these methods comes from increasing the percentage of fuel burnt during the cycle, not the overall efficiency of the drive train components. Drive train components have also been modernized to achieve maximum efficiency but there is still a considerable loss in these components. Maintaining optimum operation coupled with advanced exhaust collectors and converters reduce the overall greenhouse gasses emitted by the vehicle during operation. 


\subsubsection{Natural Gas}

Natural gas is a source of fuel that not too many people think about in terms of transportation; in reality most public transit systems (bus systems) utilize at least one or two natural gas burning vehicles in their fleet. Natural gas is a relatively new source of fuel for transportation and has not been implemented into many vehicles; those in which it has been implemented have far fewer greenhouse gas emissions than oil and coal. Natural gas is also primarily methane, which, when released without burning, has a greater negative impact on the environment as it is 21 times more effective at preventing infrared radiation from escaping the planet[4]. The problem here lies in the fact that natural gas goes through a very rigorous treatment process prior to being used as fuel, which means the actual burned natural gas is about two thirds as polluting as gasoline[5]. Another problem is storing it; it must be stored in pressurized containers in order to keep it in a liquid state, maintaining efficiency for fuel transportation and use. This is not the solution to reducing the $\mathrm{CO} 2$ output associated with transportation; however it may be a stepping stone while more efficient energy sources develop.

\subsubsection{Ethanol 85}

Ethanol is a source of fuel that has emerged relatively recently as farmers were looking to do something with their crops of corn other than use it as a food source. This fuel source is a mixture of $85 \%$ ethanol and $15 \%$ gasoline; it was designed to be a fuel that people can generate on a large scale. There are many problems associated with E85: the vehicles must be specially built to operate on this instead of gasoline, the vehicles get $25 \%$ less mileage per unit of fuel used due to its decreased energy density [6], the amount 
of land required to produce it is too large to benefit the fuel source, and the amount of energy from gasoline utilized from cradle to grave is more than the energy put out by the ethanol. What this basically says is that there is more pollution from generating and burning ethanol than drilling for oil, refining it, and then burning it. This is by no means a decent replacement for gasoline as a fuel source.

\subsection{Modern Energy Sources for Transportation}

There are a variety of sources of fuel that modern transportation methods can utilize on a large scale. The first that we have discussed already is petroleum based fuels; this is currently the most used method as most vehicles are explicitly designed to operate with this type of fuel. The second is natural gas, many car manufacturers are putting efforts into developing and producing natural gas vehicles, Hondas natural gas civic was named “America's Greenest Car of 2008”[7]. The third source is hydrogen, while it may be similar to electric vehicles in operation of the drive train; a hydrogen car has the ability to store an abundant amount of fuel for operation as the fuel is under extreme pressure, making it denser. A fourth source of energy is electricity, it may currently be supplied by power plants that burn coal, natural gas, or diesel fuel but it is readily available for implementation in all transit systems.

The factors that come into place when it comes to energy sources for cars are availability, cost, demand, and convenience. All of the previously mentioned forms of energy are available for the market however each has their own issues associated with the decision factors. 


\subsubsection{Petroleum Based Fuels}

These fuels encompass everything we do on a daily basis; it is one of the most readily available sources of energy for use in transportation. The problem is that it produces $19.54 \mathrm{lbs}$ of $\mathrm{CO} 2$ per gallon of gasoline that is burnt, and we are running out. As a society we are currently attempting to lower our $\mathrm{CO} 2$ output to fight global warming and the climate changes associated with it, while this method may be readily available it's at-the-pump cost depends on the condition of the consumer market, making this a highly variable source of energy in terms of cost. The one thing that gasoline does not have is convenience, it is rather inconvenient in our fast paced society to pull off the road and spend 5-10 minutes at a gas station to refuel.

\subsubsection{Natural Gas}

As mentioned before this fuel produces half as much $\mathrm{CO} 2$ per unit burned as gasoline, a major problem is that there are limited fill up stations and even more limited vehicles that operate with this type of fuel, making it a less than optimum choice as a less polluting alternative to gasoline. The cost is about $30 \%$ lower than that of gasoline [8], meaning it is cheaper to fill up, a factor that everyone is motivated by. The final problem is that when it comes time to fill up the tank you must be at a special station that fills the tanks in 3 minutes, if you don't have a station like this and are using natural gas from the utility company then you have to wait between 6 and 9 hours for the tank to fill up. This is a longer time than it takes some electric vehicles to charge. 


\subsubsection{Hydrogen}

The recent development and implementation of hydrogen as a fuel source for vehicles may have something to do with the fact that when the car uses hydrogen and oxygen to produce electricity through reverse hydrolysis. Reverse hydrolysis is a reaction that involves the combining of hydrogen and oxygen, from this reaction electrons are released, these electrons flow to an electric drive system that moves the vehicle. The only output of this type of system is water drops, a cleaner exhaust than that of a petroleum based fuel vehicle. While water is a contributor to global warming it is a step in the right direction. The issues and limitations with hydrogen are that you have to put two different gasses into the vehicle in order to ensure proper operation. There are also very limited hydrogen cars around, not a single one in production for purchase (the Honda FCX clarity is available for lease only). The cost of the components inside these vehicles is also something that will sway consumers, the system inside of the FCX clarity is reported to cost over $\$ 100,000$, to top it all off hydrogen is only available at special laboratories and public works departments, making recharging impossible unless you work at one of these facilities.

\subsubsection{Electricity}

Almost everything we use requires electricity nowadays, utilizing electricity as a means to fuel transportation would be a practical use of the current infrastructure available to most consumers. At 10-17 cents per kilowatt-hour[9] this source of energy would cost the same as a gallon of gas (for equivalent kwh) but due to electric vehicles $80-95 \%$ efficiency the distance the car could travel would increase by six to eight times 
as far[10]. The problem with electric cars is the fact that the vehicles require a battery that weighs a third of the total car weight and costs $50 \%$ of the total vehicle cost[11]. Due to the high demand for personal transportation if all vehicles started using the grid to charge there would be a massive electrical draw, increasing the stress put on the utilities provider's infrastructure. However, this would be the most convenient method of transportation as it would allow users to plug their vehicles in at home or at work and charge them with minimal or no inconvenience of refueling at designated stations.

\subsection{Future Progression of Transportation}

With our current options in transportation energy sources there are many paths for the future of transportation. There is no doubt that the transportation of the future will have reduced the $\mathrm{CO} 2$ output of a vehicle, whether it result from cleaner energy sources such as photo-voltaics, geothermal generators, wind, or from reduced $\mathrm{CO} 2$ emissions from the tail pipe of a vehicle using a consumable, or convertible fuel.

The utilization of electric propulsion is the path that transportation seems to be going with the rapid introduction of numerous hybrid drive systems and pure electric cars. It is important to understand that going with the simplest form of energy that is available to us will be beneficial to society later as renewable energy sources become more economically friendly to the consumer. 


\subsubsection{Photovoltaics as an Energy Source for Electric Propulsion}

Photovoltaic (PV) systems are one of the least environmentally impactful methods (when implemented) of obtaining electricity. The cost of PV systems is $25 \%$ of what it used to be 15 years ago; this means the resulting price for each kilowatt hour of energy produced by today's panels is $1 / 4$ of that of 1994 . The expansion of solar over the next 15 30 years will drive this price down far beyond today's prices. The cost of a PV kWh is around 20-30 cents, 15 years ago this was a dollar per kWh, over the next 15-30 years we can expect solar to drop down to $2-5$ cents per $\mathrm{kWh}$ which means it would be cheaper than operating a traditional fuel driven power plant, figure 1.

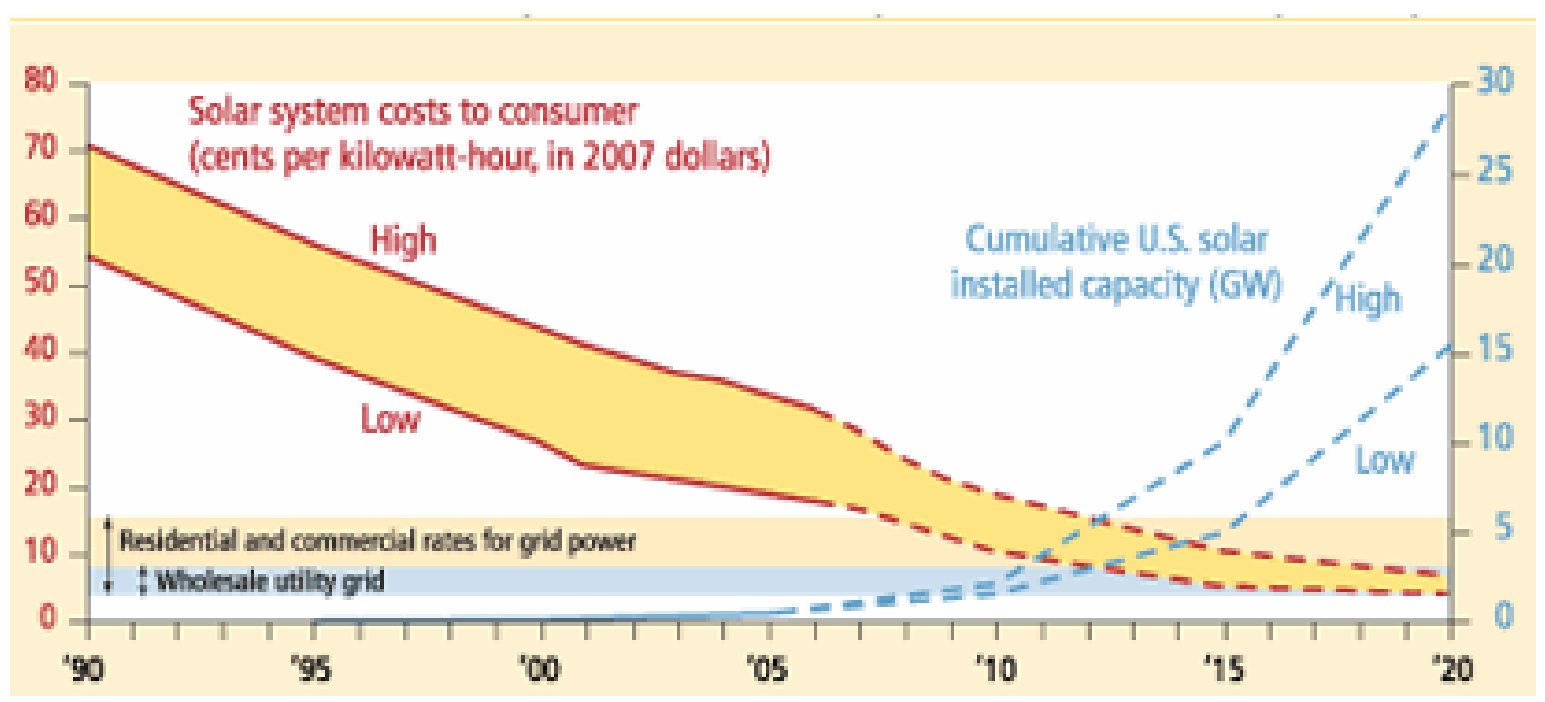

Figure 1. Commercial Cost of solar is estimated to decrease over the next decade [12].

The development of newer high efficiency PV systems would decrease the cost even further. The result would be a carbon free or carbon neutral system that could be used as an abundant energy source for electric cars. 


\subsubsection{Geothermal and Wind Energy as Sources for Electric Propulsion}

Expanding both geothermal and wind power systems over the next 30 years could have an effect on the environment over this period which is why expansion should be done in moderation with more monitoring than photo-voltaics. These sources provide a larger quantity of energy with a smaller surface area footprint on the environment.

Geothermal requires the drilling of lines deep into the earth's crust where there are areas of high heat; there are a limited number of locations that can produce this amount of heat efficiently. Geothermal also requires drilling through gas pockets in the crust; these pockets can be an abundant source of methane that, as mentioned, will retain the IR radiation provided by the sun.

Wind power is a source that we may not fully understand just yet. The current problems with wind power are that it requires so many turbines to generate a respectable amount of energy compared to the output from a power plant, [13] they are noisy, and they are ugly to some part of the population. The problem with future progression of wind energy to power electric propulsion for transportation is that we may not understand the impact we have on the environment by limiting the wind flow with the use of turbines, we just aren't sure that what we are doing in Wyoming's wind farms isn't altering or destroying a beneficial ecosystem in another country or continent.

These power sources are all limited in delivering power due to their availability and current utilization. The benefit and cost reduction they provide will allow electric propulsion to be the environmentally friendly mode of transportation of the future. 
Careful planning of energy costs will allow us to understand how our utilization can modify the future cost of transportation.

\subsection{Broader Impacts of Altering Transportation}

The rise of the electric car will eventually bring the death of the petroleum fuel based vehicles; this must be recognized in order for people to be accepting of the change that will occur. While the change in methods of propulsion is an important factor in the progression of efficient transportation there are some side effects that it may cause, particularly with regards to the production of petroleum based products like plastics, medications, and chemical solvents.

The automobile industry is the largest source of oil consumption in the world. [14] By changing the source of the power, the oil is no longer needed, creating a surplus. This surplus means that the price of oil will go down drastically (gradually if the electric vehicle transition is not an immediate switch). In order to maintain profits oil companies must either produce less or increase prices, it is likely with the way that oil prices are currently controlled that oil production would decrease and the price would increase as the oil companies try to create a demand. The cost to build the previously mentioned oilbased products will increase severely if this occurs. Adopting a new energy system would therefore be detrimental to the oil companies if they wanted to maintain oil's current pace.

Petroleum has been used in the development of solvents for almost a century. Methyl ethyl ketone, ethane, benzene, etc are all solvents that are considered basic 
chemical building blocks. All of these are used in the production of everyday plastics, figure 2 , that are utilized in everything from clothing to drugs.

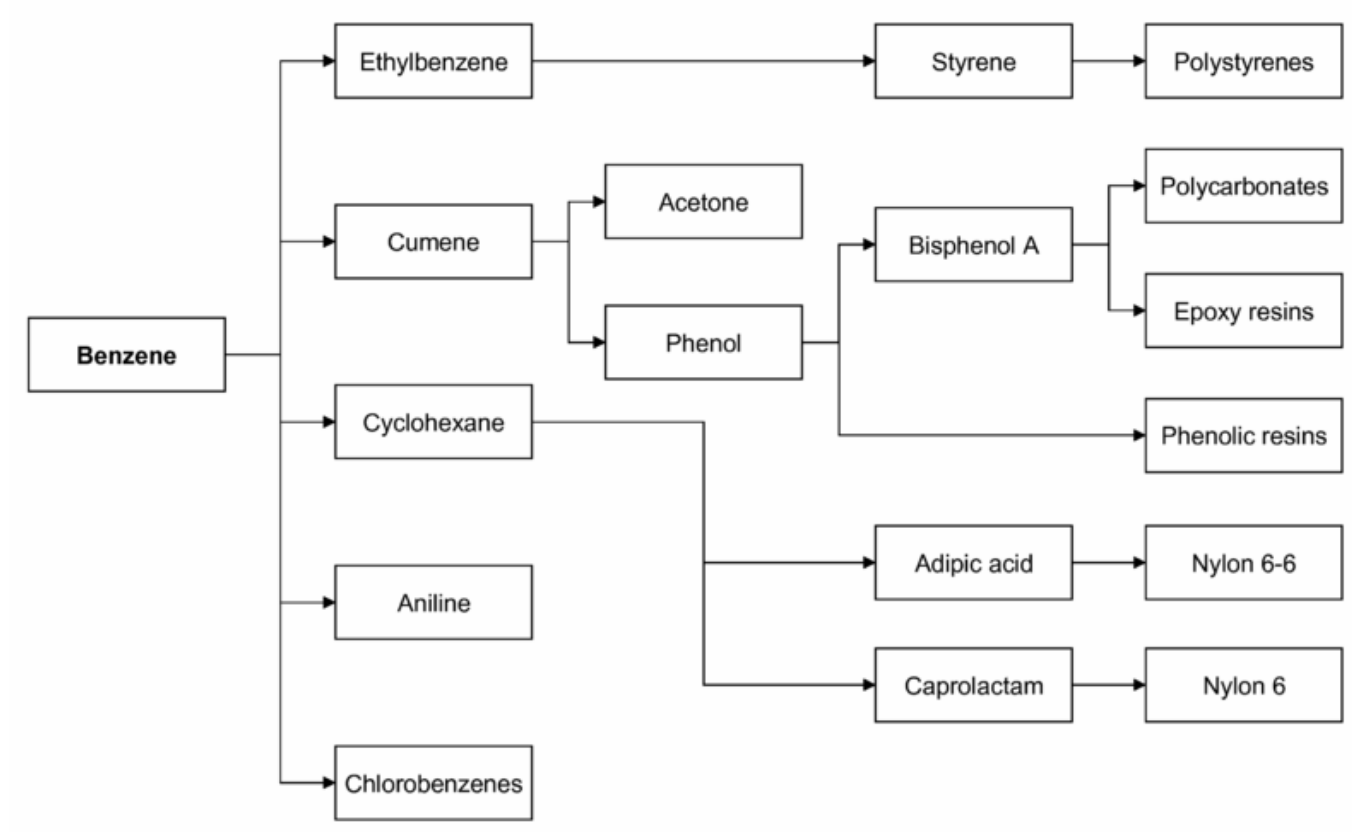

Figure 2. The typical uses for benzene, its counterparts, and their derived acids, the method of obtaining these plastics is not limited to this process map [15].

New sources for the development of solvents and plasticizers include corn oil, soybean oil, natural gas, and chemical synthesis from non petroleum based products. Not only would the expansion into grow-able sources for these products stimulate the economic need for petroleum byproduct replacements, they would remove the dependence on crude oil. These sources would allow for a crude-oil-free transition that would limit the impact on people's daily life. Solvent free processes will more than likely be developed on a larger scale than they are today. 


\subsection{The Need for Change in Transportation Methods}

As mentioned before the current methods of transportation rely heavily on the consumption of polluting fuels that have high energy densities. By utilizing these types of fuels we are introducing carbon dioxide as well as a large assortment of other greenhouse gasses such as water vapor and nitrous oxides into the environment. Over the last century the production of automobiles has increased astronomically and the result is the smog laden valleys that we have today. Because this damage is so extensive the Kyoto protocol was developed. The Kyoto protocol was designed to stabilize and reduce the greenhouse gas concentrations in the atmosphere to a level that would prevent anthropogenic interference with earth's climate, or prevent the planets environmental conditions from destabilizing. This was developed for the United Nations Framework Convention on Climate Change (UNFCCC), 183 countries have signed this document, 13 have yet to sign, and the United States has yet to ratify [16].

The UNFCCC has published various documents making it clear that there must be a 95\% reduction in CO2 emissions of 1990's emissions output value. In 1990 the United States generate five billion metric tons of $\mathrm{CO} 2$, today we generate six billion. A 95 percent reduction of 1990s values would be 250 million allowable metric tons of CO2 per year, 5.75 billion metric tons less than our current yearly output. A reduction this large is so far out of reach that drastic measures, such as mass implementation of alternative transportation systems, need to be taken to achieve this goal in a 40 year time span.

While transportation does not make up our total yearly $\mathrm{CO} 2$ output it is still significant at $30 \%$ of the total national CO2 output[17]. The normal consumer/commuter 
makes up about $20-30 \%$ of the transportation $\mathrm{CO} 2$ output with food transport and shipping services totaling $70-80 \%$ of the $\mathrm{CO} 2$ output associated with transportation.

Currently $60 \%$ of the students attending cal poly utilize the least efficient methods of commuting to school, more than $60 \%$ utilize these methods for traveling around town. The typical automobile uses the equivalent of 600 watt hours over the course of a mile, [18] this is the equivalent to 633 grams of $\mathrm{CO} 2$, a value that is unsustainable and will lead the planet into further ecological overshoot. To be in ecological overshoot means the population of the planet is producing more $\mathrm{CO} 2$ than the planet can naturally absorb. Currently we are producing 1.4 times as much $\mathrm{CO} 2$ as the planet can absorb per year.

A reduction needs to be made and changes need to be implemented that severely decrease the $\mathrm{CO} 2$ levels of the current transportation methods, currently UPS and FedEx (the largest shipping services and heaviest polluters worldwide) are looking at pure electric and hybrid drive trains for their delivery trucks. This is just the start of automotive transportation changes, in the future all transportation will need to be reduced significantly further to achieve a sustainable output for the planet. 


\section{CHAPTER TWO}

\section{DESIGN PROCESS}

\subsection{Current Transportation Models}

The design process for my project was driven by the needs of current and future cal poly students, and of the school itself. The needs for this project were to have a form of transportation that is economical, efficient, is readily available for students to use, and to reduce the impact of vehicles on campus. Current methods of transportation can be classified into three categories: public transportation, vehicles, and bicycles. The issues associated with each are as follows.

- Public transportation is not a quick method of getting to school as it requires knowledge of the different transit routes, walking time to the pickup point, waiting for the bus, and riding the bus to the various pickup junction points around town or at school. While this may be a more efficient form of transportation than driving a car the efficiency is lost in the time it takes to arrive to campus. For people that live outside the city limits this method can take up to an hour longer than driving a vehicle [19]. The downfall to the public transportation system is the fact that when busses are full or late people have no method of getting to school on time. This is why most people choose to drive to school or in some cases, car pool.

- Personal vehicles are a fast and quick method of getting to school; they allow students and teachers to have more time for themselves before class. The problem with personal vehicles is that they are inefficient, they require a lot of space, and 
their impact on campus is large compared to other forms of available transportation. The resulting issue with personal vehicles is cost, when you consider all of the factors. They are expensive to fill up with fuel, they are expensive to maintain, and they are expensive for both the school and the driver to park on campus [20]. The few roads going through campus sustain extensive wear and tear every year, primarily because of personal vehicles and the school is who foots the bill for the repair. The school's parking lots are getting increasingly expensive to park in and are limited in accessibility; all general parking lots only have one entrance and one exit. This leads some students to consider riding bicycles to school as the costs associated with driving to school are not worth the benefit.

- Bicycles are an excellent form of transportation when it comes to efficiency, and are a readily available method of transportation for students who own them. However, bicycles fall short when it comes to ease of use, the speed at which they get someone to school, and the inability of use in severe weather. These are the factors that determine if someone is willing to bike to school. These issues, coupled with the fact that Cal Poly SLO has the worst possible location when it comes to being biker friendly. The school is in an isolated corner of the town, it is built into the side of a hill on the geographically higher end of town, and it is surrounded by high speed traffic zones. This means if someone living past the center of town wants to get to school it will be a long ride that is labor intensive and dangerous for bikers, not something that generally motivates someone who 
owns a bicycle. This doesn't consider someone who lives outside of town as riding on the side of the freeway is illegal and extremely unsafe.

The aforementioned issues with current methods of transportation that are available to members of the student body and faculty of Cal Poly SLO generate a demand for a better method of transportation. Both electric vehicles and pedal assist electric bicycles fulfill these needs and this is the reason they were the choices for the system.

\subsection{Various Electric Propulsion Charging Models}

The problem with electric vehicles is quite simple, they don't have the range that conventional gasoline vehicles have, a problem that is diminishing as battery technology and manufacturing is quickly progressing. This range issue is coupled with the fact that batteries can take as long as 5-24 hours to recharge [20]. The only way to deal with these issues is to develop a method of getting a usable amount of energy into the car or bike in a quick and effective manner. There are various methods of doing this some of which include rapidly charging the battery, hooking the vehicles up to the grid so it had a constant power source, and changing the battery. All of these methods have issues associated with them and are outlined below

\subsubsection{Rapid Charging}

Rapid charging is the process of charging a battery in a relatively quick period of time, for most battery manufacturers this time is considered to be about an hour. Batteries are rated in terms of their capacity, or "C" ratings. For a battery to be fully charged in an hour it must charge at " $1 \mathrm{C}$ ", or 1 times its capacity over the period of an hour. For 
example, a battery that is 240 volts nominal voltage and has a capacity of 50 amperehours must be supplied with 50 amps at $>240$ volts in order to be $95 \%$ charged in the period of an hour, the same battery would have to charge at $100 \mathrm{amps}$ at $>240 \mathrm{~V}$ in order to charge in the period of half an hour. There are various problems associated with rapid charging which include the batteries and components not being able to handle the amperes traveling through them, the electrical grid not being able to supply the energy required for charging, and the need for expensive and complex chargers.

- Batteries and the various components completing the circuit between the battery and the charger have to have minimal electrical resistance in order to operate with a rapid charging system. This is because rapid charging is the process of moving a massive amount of energy in a short period of time, if there is any electrical resistance along the path of travel then heat is going to be generated. If large capacity batteries, utilizing rapid charging, are required for long distance operation then the components (wires, battery management system, and interface contacts) need to have large electrical contact surface areas for to allow the electrons to flow freely. This size increase in components for the rapid charging system means increased cost for the system. This is also true for decreasing the time it takes to charge the batteries, if a shorter time is required then the components need to be larger to accommodate the excess energy. Batteries themselves also need to be able to absorb this energy at this fast pace. Most batteries currently on the market have a substantial amount of internal electrical resistance, meaning if they 
were to encounter a rapid charging system they would heat up, the amount of heat depends on the level of resistance and the charging current.

- The electrical grid is a precious commodity that people are tied to in terms of functioning on a daily basis [22]. Having a single electric vehicle with a moderate size battery, 45 kilowatt hours (kwh), require a rapid charge in the period of 30 minutes would put a $90 \mathrm{kwh}$ strain on the electrical grid, the equivalent to 90 homes. With a bit of math we can see that with a 480 volt AC input line this would require about 188 amps being drawn over the period of 30 minutes $(90000 \mathrm{~W} / 480 \mathrm{~V}=187.5 \mathrm{~A})$, this one vehicle would require a special $\$ 600$ dollar breaker from US breaker inc. to operate at 50\% its capacity, not to mention the charging location having access to a 480V line from the grid. Any faster than 30 minutes would increase the cost tenfold if purchasing the breaker from the same company.

- Chargers for rapid charging are neither inexpensive nor are they simple in any means of functioning. Chargers suited for this application fall within 400$2000 \mathrm{lbs}$, meaning they are expensive to ship, and cost anywhere between 50,000 and 300,000 dollars. For home use this is out of the question, systems like this would need to be at recharging stations with slow chargers at home as slow chargers that recharge a car in 8 hours only cost 3000 dollars and are usually built into the cars. Rapid chargers take up about as much space as an office desk would and require special electrical components prior to being installed. They also operate with advanced computer programming and 
sometimes require external power supplies. These complex devices do have one benefit, they require no maintenance.

\subsubsection{Metropolitan “Muni” Trolley Bus Model}

The San Francisco Municipal Transportation system (Muni) uses electric busses that operate on overhead wires, allowing them to operate continuously without the need for a battery. This type of system eliminates the cost for a battery and charging system however it is limited by the fact that it requires a network of overhead wires to operate, a large infrastructure cost that certainly bypasses the cost of small scale battery charging systems [23]. Although, having overhead power lines does have an advantage; the system is much more efficient because the busses are lighter, allowing more passengers than a conventional electric or gasoline bus. The problems are that this type of system is plagued with systemic power loss as the wires have to be powered constantly and if the power goes out, the busses don't operate. Also, when an accident occurs or if the roadway is blocked for some reason the availability of re-routing is diminished.

Manufacturers are fixing these shortcomings by installing small batteries or diesel generators into the busses in order to allow them to drive short distances without the need for wires. The problem is that these modifications are only a temporary fix and will ultimately decrease the efficiency of the vehicle, meaning an increase of the amount of $\mathrm{CO} 2$ emitted per passenger mile.

Many countries use this type of system as a means of cheap transportation with zero emissions. This type of system is more or less designed for major metropolitan areas that have the pedestrian throughput to justify the infrastructure development. 


\subsubsection{Rapid Battery Exchange}

Changing the battery of electric vehicles has been explored by manufacturers of various equipment and vehicles as a means to continue operation with minimal time delay for renewing a machines power source. Forklifts that operate with electric motors have battery packs made up of lead acid batteries that can weigh anywhere between 200$2000 \mathrm{lbs}$ (depending on size and type of lift). These vehicles cannot be plagued with charging issues so manufacturers developed rapid battery exchange systems in order to keep the units operating, figure 3.

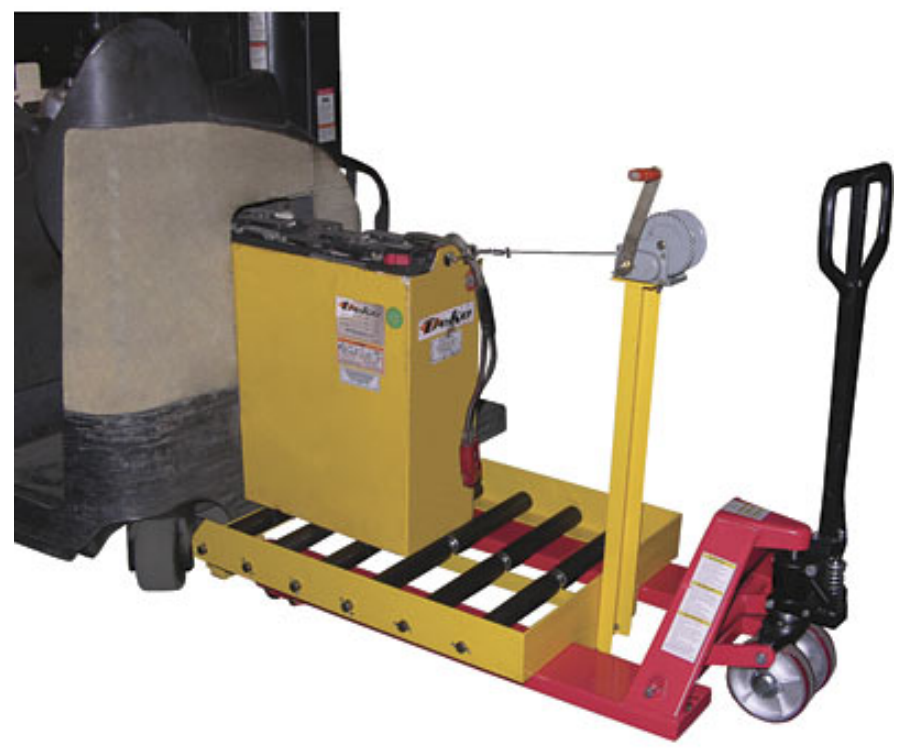

Figure 3. Forklift battery exchange systems are manual in operation, recent versions use en electric winch instead of a hand crank [24].

This type of system has one disadvantage, it is operated by hand, making it a

laborious process that requires time that could have been otherwise used productively.

Major auto manufacturers learned the same thing in the 1970's when they attempted to develop a system that would allow electric transport vehicles to operate constantly, figure 4. 


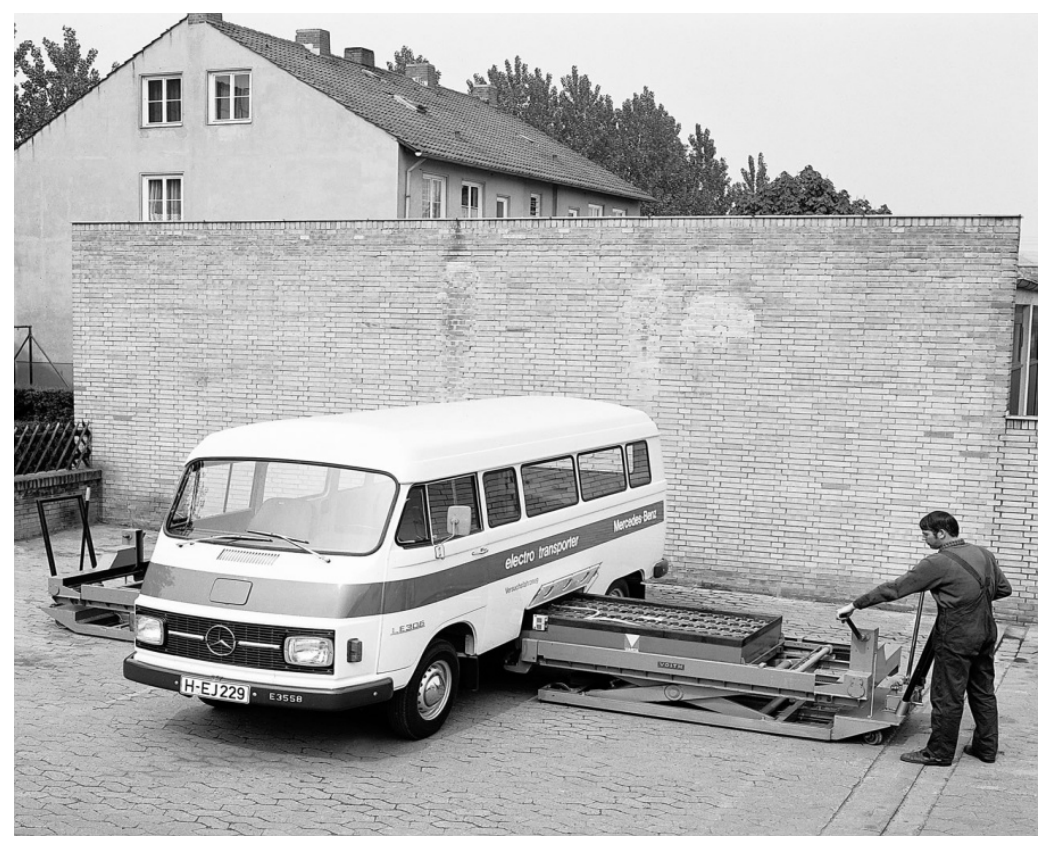

Figure 4. Mercedes Benz electro transport system that utilizes a hand operated battery exchange system, circa 1971 [25].

The benefit of this type of system is that the battery doesn't have to undergo a rapid charging cycle, allowing smaller, less expensive components to be used, a plus when it comes to mass production. Vehicles operating with this type of system would benefit from the availability of power, no longer having to wait for their battery to charge, allowing users to continue on with their errands.

The major issue with this type of system is the fact that you have to maintain a stock of batteries at any exchange location in order to keep up with the demands of users meaning a high cost of batteries associated with each station. There is no way to eliminate this if the system is intended to be used in a commercial scale. 


\subsection{Component Choices}

Based on the previous information the rapid battery exchange model is the optimum choice for this project, the intended outcome of this system would be a small scale transportation system with the ability to expand if desired. By using a rapid battery exchange system the project could be made small enough for one vehicle and could limit the battery exchange process to a period of two times per hour. This will allow the vehicle to maintain its route delivering students to their homes or helping move student projects around campus. The overhead cost of doing a "muni" style transportation system was too large for the scale of this project; rapid battery charging would also limit the vehicles ability to operate in a continuous matter.

The disadvantage of this small scale system is that the battery and components will have to be able to rapidly charge in order for the system to exchange a battery multiple times per hour. While this is a setback it can be overcome by using special components and chargers that are available.

The electric vehicle being used was a 1991 electric GMC G-Van, figure 5, that was graciously donated by the head of the Electrical Engineering department at Cal Poly, Dr. Art McCarley; the only work the van needed was to fit it with batteries. 


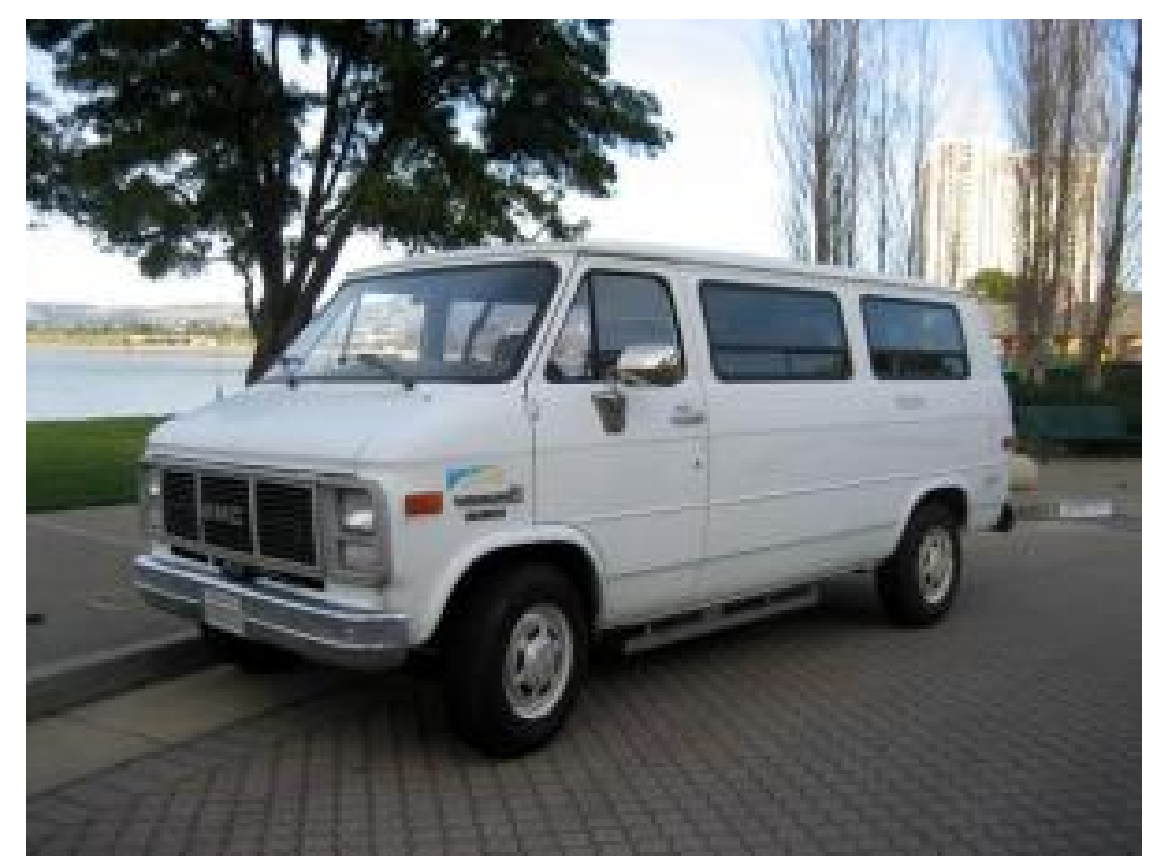

Figure 5. A 1991 GMC electric G-Van utilized by PG\&E was the vehicle that the rapid battery exchange system would be designed for.

It should be noted now that the pedal assist electric bicycle model was done as an addition to this project to demonstrate proof of concept due to complications that arose with the functionality of the electric van. The electric bicycle was purchased from a coworker in northern California as a personal project during the testing of the van that developed into a direct application of the rapid battery exchange system.

\subsubsection{The Van}

These vans were part of a limited production run as a cooperation between General Motors and Vehma International, a Canadian auto parts company. 500 of these vans were made for an evaluation run of the vehicles, 45 of which were used to get the vehicles DOT approved. This particular van was used by PG\&E as a field technician van. The vans were powered by a $45 \mathrm{kw}$ separately excited DC motor that had the capability 
for brake regeneration when coupled with a chloride mark V-A controller. The van had the regular amenities of cars in the early 90's, air conditioning, heater, radio, power accessories (including windows). These were powered directly off of the battery or were driven by a secondary motor in the center of the vans undercarriage.

This dual motor setup is a relatively inefficient design; there was a lot of heat loss as all components of the accessories, controller, and motor were air cooled. Running two motors in order to power the accessories was also not the best design choice as pure electric components could have been purchased to power the accessories. The batteries in particular were very inefficient, they were flooded 6 volt nickel cadmium (NiCad) cells made by Peugeot for vehicles and boats in the 1980s. The batteries were cooled with two fans in order to prevent damage to the cells. These cells are inefficient because of their plate's ability to swell and cause excess heat and possibly damage to the vehicles.

The exterior of the van was in good condition for being in Nipomo, a beach community that can have excessive corrosion issues. The interior of the car was set up for five people, including the driver, a third row seat was to be purchased to expand the seating capacity of the van if need be.

This vehicle weighed in at $7000 \mathrm{lbs}$ when it was loaded with the $2150 \mathrm{lb}$ battery pack, the unique thing about this van was the fact that it used a heavy duty suspension system and had an 11 inch ground clearance in between the axles without the original batteries in place. 


\subsubsection{The Bicycle}

The bicycle used was a Prima Runner pedal assist electric bike that had been produced in Italy by Prima power bikes for the past nine years, figure 6 .

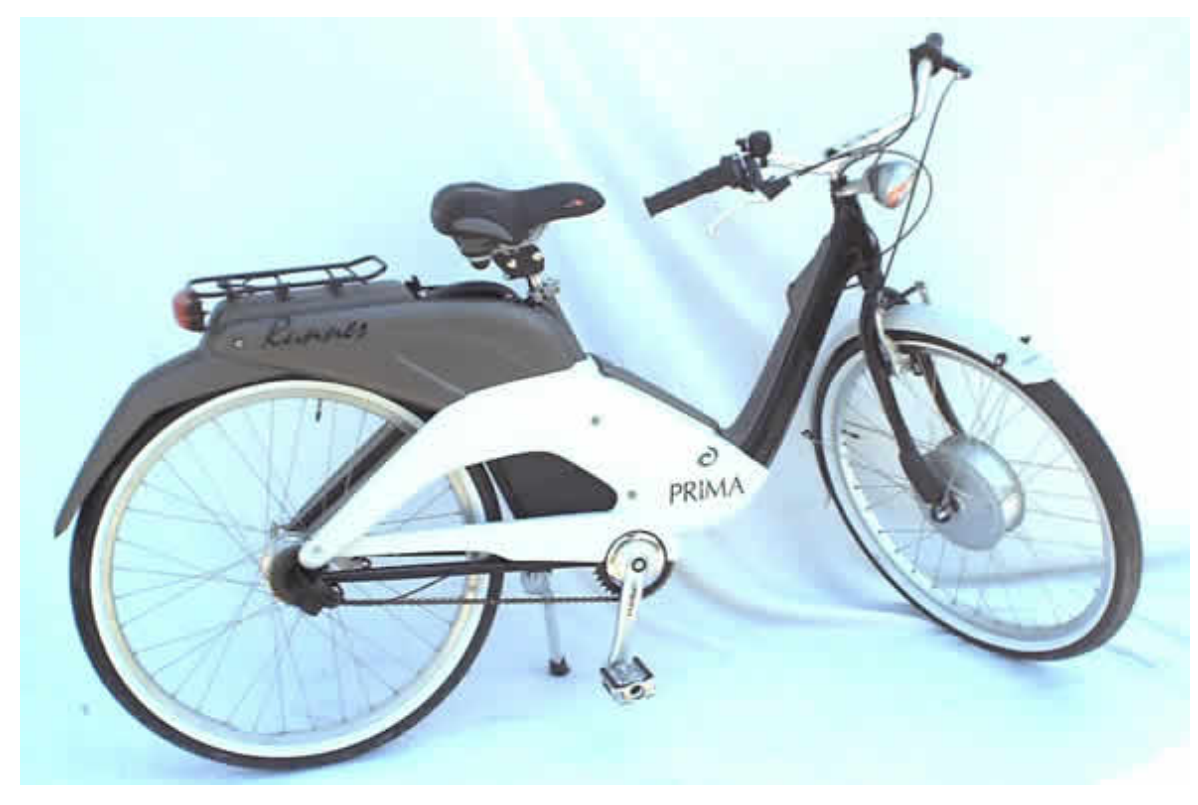

Figure 6. Prima runner pedal assist electric bike used for the project prior to modifications.

The model name has changed over the last few years to "Runaway". These bikes are sold at various electric bicycle dealerships across the country. The bikes retail cost was 1600 US dollars, it had range of 20 miles on its low speed eco mode (10 mph) and 15 miles in sport mode (15 $\mathrm{mph})$.

The bike was originally powered by a 10 amp pedal assist controller and a 250watt ABB hub motor. The motor size was modified slightly to produce 450 watts and a more efficient throttle style 20 amp controller was installed after the bike was purchased. More efficient tires were put on the bike in order to reduce drag caused by tread. This bike also included a body that utilized front and rear fenders as well as a rear 
rack and a small lockable storage compartment. This body was quickly removed as it was excess weight and could only slightly increase the bikes appeal to the common rider. The rear fender was left on as the rear rack was incorporated into it as well as the fact that it could keep mud off away from the rider's clothes.

The bike also originally came with a dynamo style light that was powered off of the wheel as it rotated; this was removed as well due to the unnecessary drag that it caused on the system, as well as the unappealing noise it generated while in operation. The main issue with this bike is that it weighed $70 \mathrm{lbs}$ before modifications; a lighter bicycle would have been more desirable as it would have increased the overall efficiency of the bike.

\subsubsection{Batteries}

As previously mentioned the batteries are the weakest link of electric propulsion. This, coupled with the need for rapid charging, made finding a suitable battery for the system difficult. In order to make a rapid battery exchange system the battery had to be lightweight, be able to power the van for a period of 30 minutes, be able to recharge at greater than $2 \mathrm{C}$, and last longer than 5 years. These design criteria left only a few options for use, all of which were lithium based.

Lead acid, nickel metal hydride, nickel iron, and nickel cadmium batteries were not chosen because they're energy density was too low, making them heavy without containing enough energy to power the vehicle for the required time. Lithium Sulfur and lithium manganese batteries have high energy densities but they have a life span of less 
than 3 years making them less than optimal choices for prolonged use. Nickel hydrogen and super charge ion battery were not chosen because while they have an energy density that would be suitable for this project they are extremely rare and hard to obtain, making them a less than optimal choice.

The batteries that were chosen as possible candidates for the rapid battery exchange system were lithium ion polymer, lithium iron phosphate, and lithium titanate batteries. The selection of batteries includes classifying them as prismatic or non prismatic, figure 7.

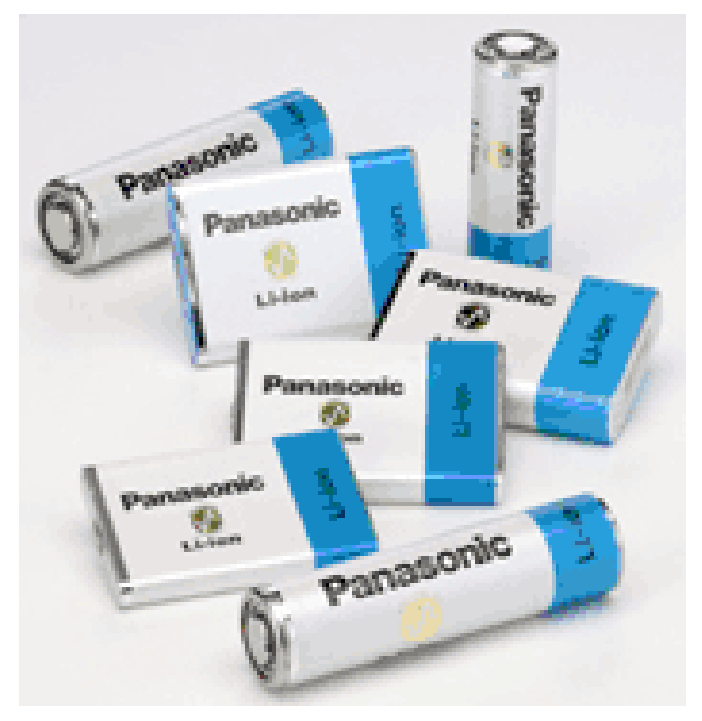

Figure 7. Panasonic Cylindrical cells look like tubes while prismatic cells are square allowing for a larger range of applications [26].

All exhibit energy densities in the $150-200 \mathrm{Wh} / \mathrm{kg}$ range, meaning that a battery pack that can operate the van would weigh an acceptable amount which may increase the strain on the exchange system. 
- Lithium ion polymer batteries - These prismatic cells are lighter weight than lithium ion cells with metal cases. They are more flexible and cost less. More shapes can be suited with lithium ion polymer cells because they are flexible due to their polymeric casing. The electrode sheets and separator sheets in these cells are laminated together to make them flexible. If overcharging occurs, this cell has the tendency to explode or ignite on fire.

- Lithium titanate batteries - These are non prismatic cells that only come in a $35 \mathrm{kWh}$ size that weighs $400 \mathrm{lbs}$ per pack. The high cost and limited availability due to limited production makes the cost of each of these batteries over 100,000 dollars apiece. The energy density of these batteries is similar to that of lithium ion polymer batteries.

- Lithium Iron phosphate batteries - These are prismatic cells and non prismatic cells that are lighter weight and similar energy density to lithium ion polymer batteries. These batteries feature a doped nano-phosphate cathode, allowing for a higher surface area meaning the batteries can be discharged at a higher rate than lithium polymer batteries. These batteries don't require the use of cobalt, unlike lithium polymer batteries, making them more environmentally friendly.

From the contenders the lithium iron phosphate batteries were chosen because of the fact that they were safer, more cost efficient, and more environmentally friendly than the lithium polymer and titanate batteries. The pack that was needed to drive the vehicle for 30 minutes was approximately $24 \mathrm{kWh}$ which would weigh around 450-500 lbs with 
the battery management system. The pack needed to operate the bicycle would weigh less than $30 \mathrm{lbs}$ and would allow the bike to operate for over an hour.

A battery management system (BMS) is a circuit board system that controls the charging and discharging of each cell in the entire battery. The BMS can be the source of a large headache in the electric vehicle world as they are the weakest link of the battery. Metal-oxide-semiconductor field-effect transistors (MOSFETs) are the components on a BMS that are prone to having issues because they limit the power output of the battery, sometimes the current draw from the controller on an electric bike or vehicle can exceed the output capability of these MOSFETs, causing the system to shut down until the power draw is re-cycled (the car or bike is turned off then on again). This is important to mention because the BMS was a large source of trouble in vehicle testing on both the bicycle and the car.

\subsubsection{Charger}

A high output charger was required for this system to operate continuously. Based on the size of the battery, a compatible charger was to be capable of delivering $48 \mathrm{kw}$ of peak power continuously for a period of 30 minutes. To operate efficiently the charger should only be utilizing $50 \%$ of its maximum power at any given time, stressing a charger for short periods of time can lead to failure of the charger due to heat buildup and component stress [27].

High output chargers are hard to come by, especially high output chargers that are compatible with lithium iron phosphate technology as they require a specific charging cycle in order to obtain a their maximum life and charge. Aerovironments Inc. is a company that has been working in this field for a few decades by supplying chargers to 
airports for their luggage transport systems. A prototype ABC-150 vehicle test system was donated by Charlie Botsford, an employee of Aerovironments Inc., to act as a charger for the battery system, figure 8 .

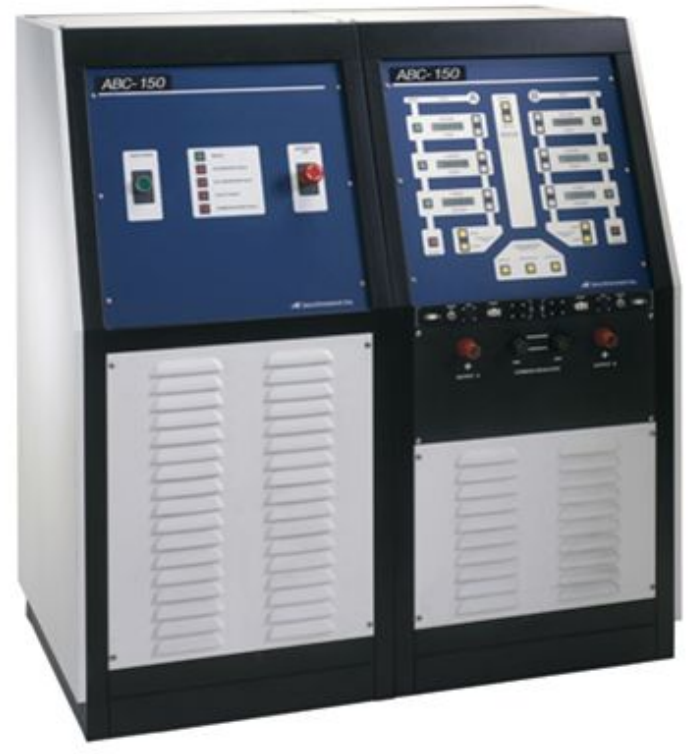

Figure 8. AeroVironments Inc. ABC 150 electric vehicle test station and charger [28].

Due to this power supply being a test system it can be programmed to function as a charger; however there was no method to monitor the power delivery to the battery. Therefore a supplemental battery charge regulator was needed in order to monitor the power draw. One was purchased from an industrial lab surplus dealer in New Mexico.

The electric bike would not need a large scale charger as its capacity allowed the bike to run for a period greater than an hour. A Zivan NG1 charger that outputs $48 \mathrm{~V}$ at 15 amps was used for the electric bike. 


\subsubsection{Materials to Build the Actual System}

Various materials that were corrosion resistant were available to build this system such as aluminum and stainless steel; other steels that aren't corrosion resistant were also available. The determining factors that I used in selecting a material were the ASTM standards for automotive part testing and CES Edupack for the $\mathrm{CO} 2$ footprint associated with the primary production and milling of the material, cost was not considered in the choice.

6061 T6 Aluminum, a machinable aluminum with good strength properties, had the highest primary production $\mathrm{CO} 2$ footprint of $11.4 \mathrm{~kg}$ of $\mathrm{CO} 2$ per $\mathrm{kg}$ of material; however it had the lowest machining $\mathrm{CO} 2$ footprint of $0.41 \mathrm{~kg}$ of CO 2 per $\mathrm{kg}$ of material removed. 304 Stainless steel, an inexpensive strong stainless steel with decent corrosion resistance had a primary production $\mathrm{CO} 2$ footprint of $5.1 \mathrm{~kg}$ of $\mathrm{CO} 2$ per $\mathrm{kg}$ of material with the highest machining $\mathrm{CO} 2$ footprint of $.811 \mathrm{~kg}$ of $\mathrm{CO} 2$ per $\mathrm{kg}$ of $\mathrm{CO} 2$ produced. ASTM standards for corrosion testing indicated that automobiles must utilize cold rolled steel for their undercarriage components, this steel had the lowest $\mathrm{CO} 2$ footprint with 2.6 $\mathrm{kg}$ of $\mathrm{CO} 2$ per $\mathrm{kg}$ of material with a machining $\mathrm{CO} 2$ footprint. $652 \mathrm{~kg}$ of $\mathrm{CO} 2$ per $\mathrm{kg}$ of material removed. The choice I made was to go with the ASTM standard as it indicated proper use for the project and because the $\mathrm{CO} 2$ footprint was the lowest of the materials that I researched in regards to primary production and machining of the material.

\subsection{Conceptual Designs of the System}

The actual design of the system was the most important part of the design process as it would determine the speed and efficiency in which the system functioned. The 
critical design requirements for the system were that it be easy to use, be environmentally conscious, and be able to withstand the environment it would be placed in. A fourth critical design requirement was that it require no external electrical input in order to operate (operation is not hooked up to the grid). The battery charger would still be hooked up to the grid as this is the only way the charge could effectively operate.

The purpose of this system is to exchange the battery, possibly the heaviest individual component of an electric vehicle. Consideration has to be given when attempting to carefully move an object as heavy as this, especially when there is no access to electricity. Minimal movement of the heaviest component would be optimal as it would increase the functionality of the system by limiting mechanical movement; aiming the battery into its location would also have to be manual as there is would be no access to consistent electricity.

The placement of the battery exchange system on the vehicle would determine the available methods in which the vehicle could operate. Because the van had 11 inches of ground clearance and the weight of the battery would keep the center of gravity of the van lower, the location of the system was chosen to be the bottom of the vehicle between the front and rear wheels. This led to various designs and complications with each design. The three most developed designs are listed below.

- Cantilever system - Two beams running parallel to the length of the van are placed on the bottom side of a platform. The cantilever point is slightly forward of the center point between the van's wheelbase. The system uses the weight of the van to push down on the cantilever assembly, a platform 
with a battery, battery release mechanism, and battery holder would come lift up, disengage the battery, the battery would fall into a catch device, the new battery would go in and initiate the trigger release mechanism, lowering the battery release triggers, this complex system was adapted to the hydraulic system.

- Hydraulic system - A set of hydraulic actuators, positioned underneath the front wheels of the van, would collapse from the weight of the van, moving the fluid from the inside of the actuators to actuators positioned underneath a platform. This platform holds the battery and the unlocking mechanism, the battery was a pyramid shape and aimed itself automatically. The unlocking mechanism is two cones that also self aim and dislodge the existing battery via two hooks, figure 9 .

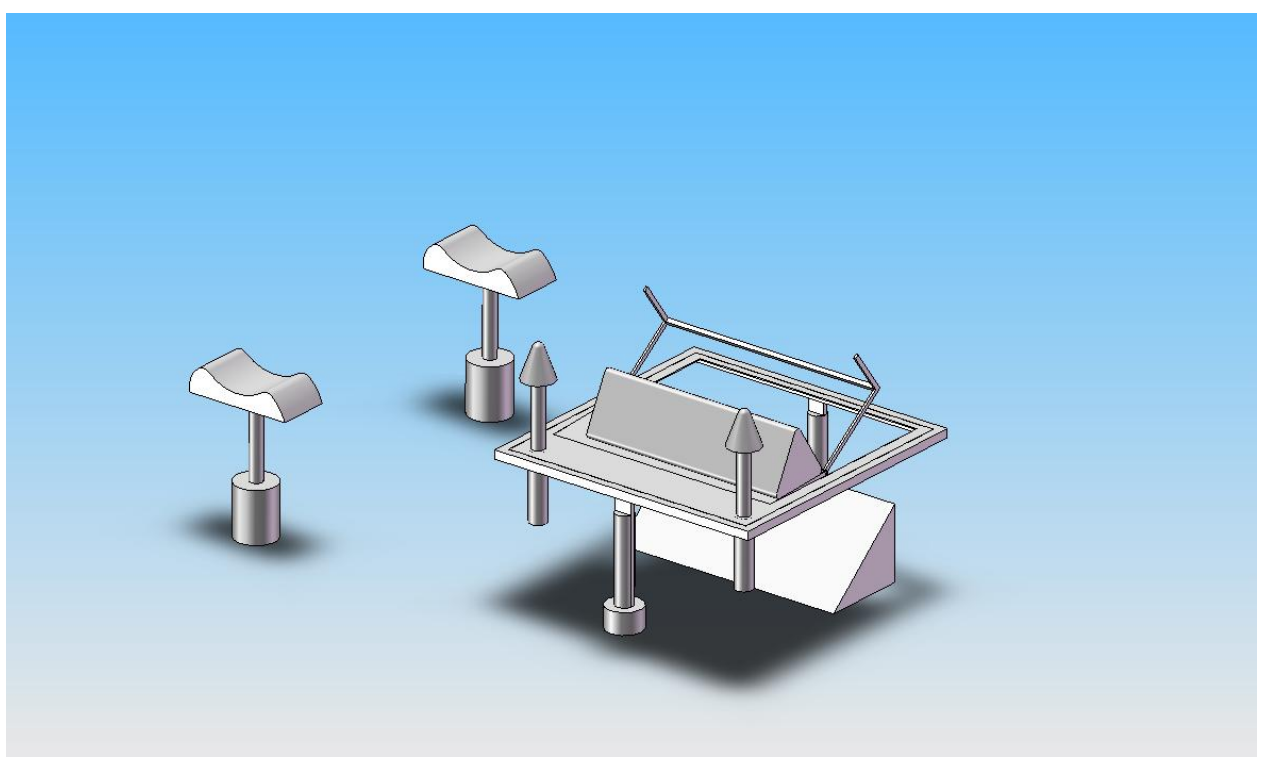

Figure 9. Hydraulic design that mimics the initial design of the system, long distances for the battery in the design resulted in low efficiency. 
- Newton's cradle system - This system involved a set of tracks on a plate bolted to the ground that held a battery in place. Two speed bumps on either side of the system allowed the front suspension of the van to clear the system before the exchange occurred. A small carrier would hold one battery on the van while the van drove and prior to the exchange. Once the van got over the speed bumps 4 linear actuator locks on the motor disengaged allowing the battery to sit on the tracks. Once the old battery was sitting on the tracks the battery would contact the other battery, stopping the battery. The van would then continue rolling and the new battery would be positioned in the carrier before the rear wheels went over the speed bump, the carrier locks would then be re engaged, the rear wheels would go over the speed bumps and the van would drive off with a new battery. The locks would also be the contact leads for the propulsion system, figure 10.

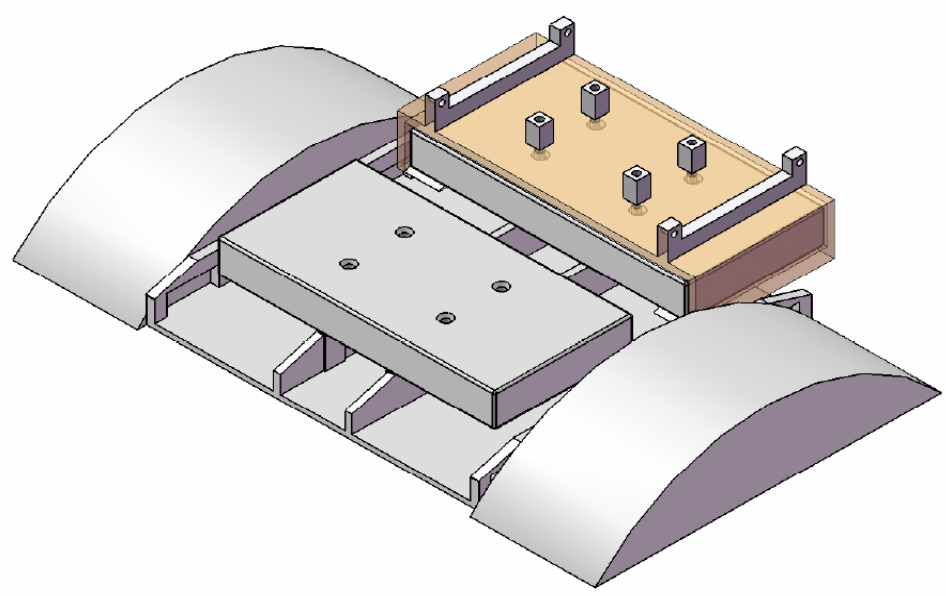

Figure 10. A rework of design methodology resulted in the development of a more efficient applicable design. 
The Cantilever system was one of the first designs for this project and was abandoned when a small model was made and it was quite noticeable that the system worked too fast and components were likely to break without using dampeners, adding to the cost and complexity. The hydraulic system was discarded when it was realized that the pressure exerted by the front wheels (1400lbs) is slightly greater than is required for the system to operate $(1200 \mathrm{lbs})$, allowing for a limited factor of safety. This problem would only occur if both batteries were on the tray at the same time; the tray would otherwise weigh $700 \mathrm{lbs}$ and would be a functional system. The Newton's cradle system was the combination of looking at how a VCR worked and how to conserve the momentum of the van as it operated with the system. The result was a system that had minimal moving parts and needed minimal alignment in order to function properly.

The electric bicycle's system is very similar in functionality, there was only one system designed for the bicycle as it was to act as proof of concept. The battery has a fixture mounted to the bottom of the battery case that allows it to secure itself in a track that is attached to a rack on the electric bike. In the fixture there are contacts for the bicycles controller and a charging cables, this allows the user to simply slide the battery onto the rack and turn the battery on, figure 11 . 


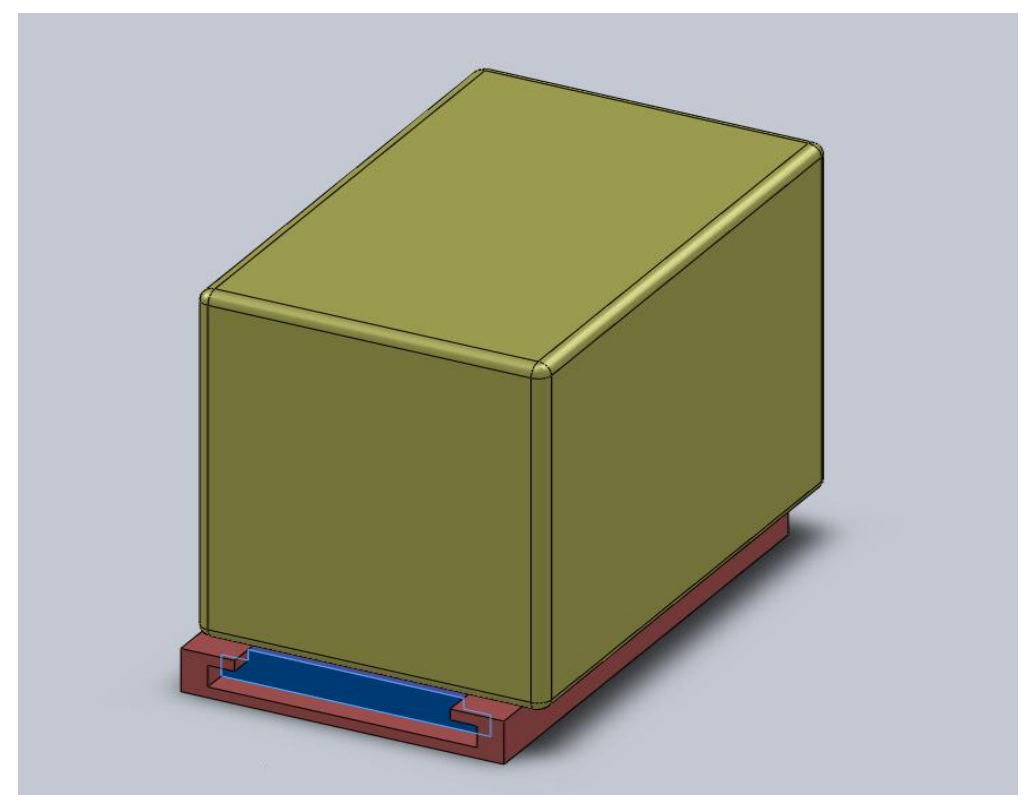

Figure 11. Simple conceptual designs of how the rapid battery exchange system would work on the electric bike, the different components are: battery (yellow), battery attachment piece (blue), exchange track on bike (red).

A locking mechanism would be installed on the front of the battery that allows the battery to stay attached to the rack when the bicycle is in operation. The battery would otherwise detach from the rack and the bicycle during riding and the bike would not function.

\subsection{Designs for Rapid Battery Exchange System Protection}

Both of the previously discussed systems needed to be able to withstand exposure to the environment as they were to be used constantly. Because of this, a suitable protective coating had to be utilized to prevent system failure or system degradation. The coating needed to be durable, inexpensive to apply and maintain, and it needed to prevent corrosion and impact damage. Epoxy resin paint, powder coating, and vinyl resin paint were chosen as candidates as preliminary research showed they were all widely used 
environmental protection coatings. These coatings were to be tested by exposing them to a corrosive environment for an extended period of time, measuring delamination inflicted by the corrosion, and impacting the coatings to determine the effects of paint deformation at a microscopic level in order to better understand the materials behavior at a macroscopic level.

\subsection{Manufacturing the Rapid Battery Exchange Systems}

Having a functional design and the proper components for the system are only half of what goes into making the system work, a prototype must be made in order to determine if the system will work as it was designed to. Obtaining system components is also another task that is a difficult portion of developing systems. A lot of manufacturing went into both systems and the revisions associated with problems that arose during operation. The simplified process for each system is described below.

\subsubsection{The Van's System}

At my employer there were a few things that were available to me: a McMaster Carr account, a supply of funding, and an automated pallet moving system that was no longer being used, figure 12 . 


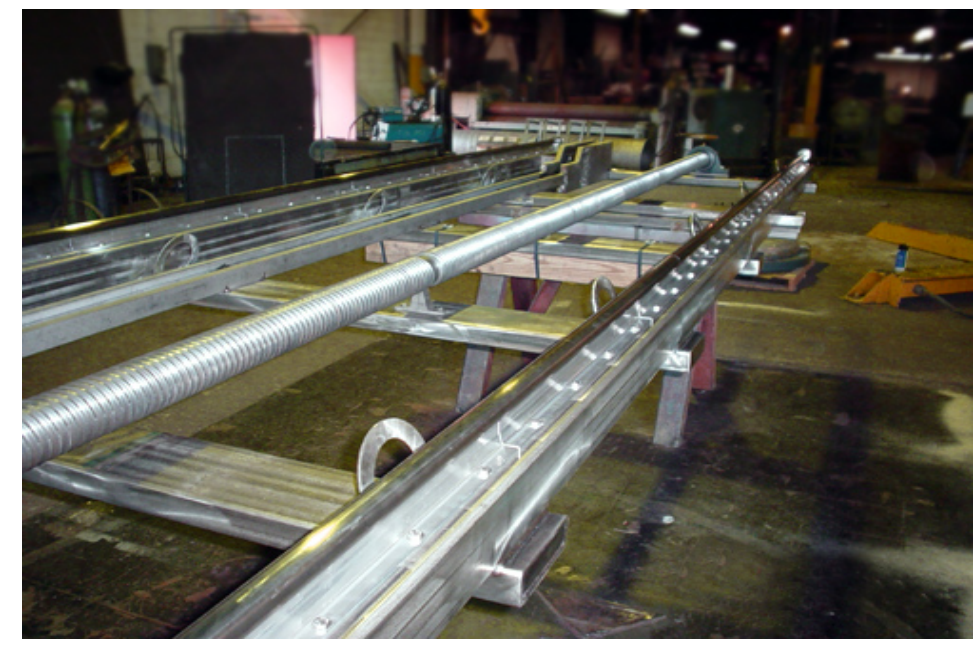

Figure 12. A custom fabricated pallet moving mechanism for moving pallets over $3500 \mathrm{lbs}$ was to be the donor component of the exchange system.

This pallet system required some small modifications to make it functional, such as modifying the pallet rack, figure 13 , to be the battery holding containers.

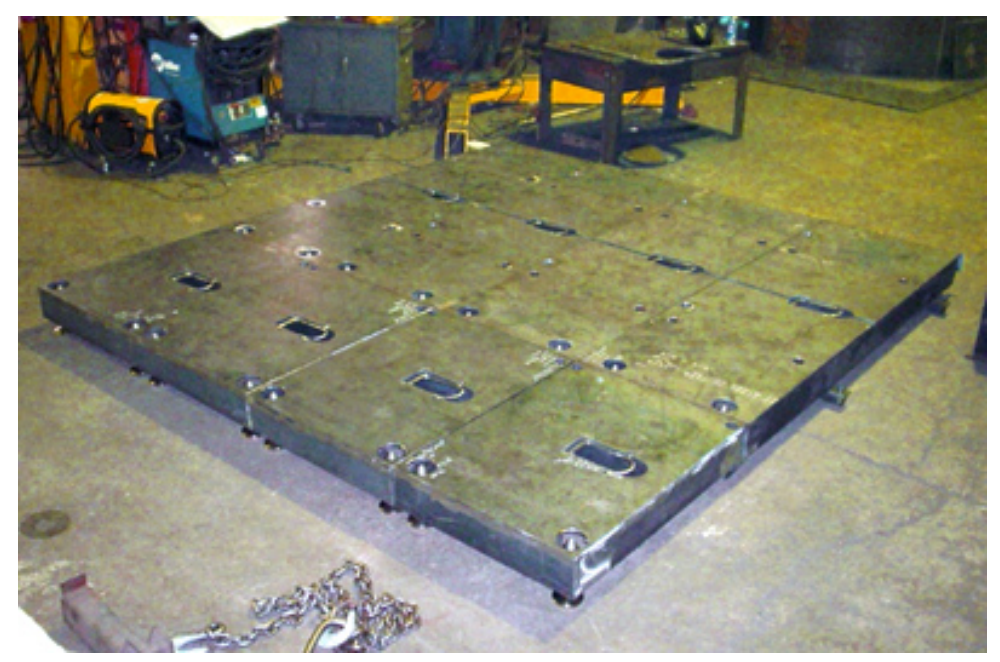

Figure 13. Steel pallet rack prior to modification to hold batteries

The pallet racks internal structure had to be removed prior to utilizing it as a battery box. The top of the pallet rack was unbolted and the internal structure was removed by simply cutting it out with an acetylene torch. The remaining bits were ground down with a hand grinder to provide a flat finished battery box. 
The original pallet mover relied on a center drive shaft that was threaded and turned by a motor to move the pallet assembly. Since the batteries were to be free moving, the shaft was removed, figure 14.

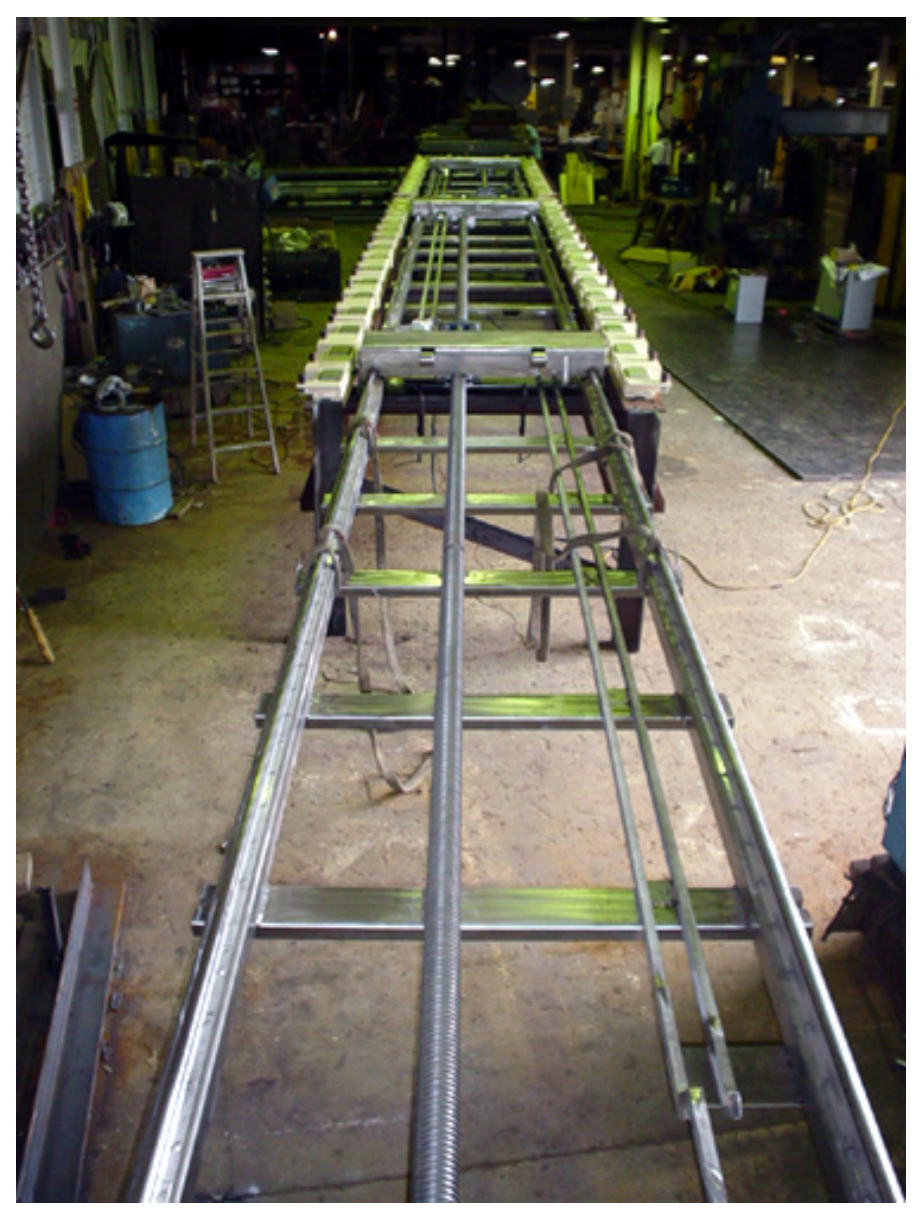

Figure 14. The shaft down the center of the two rails was the drive source for the pallets; the new system doesn't require a drive source so it was removed.

Doing this slightly destabilized the batteries as they relied on the center shaft for support. To fix this, new linear bearings, figure 15 , were installed onto the battery box to make the interaction tolerances tighter resulting in a stable, smooth operating contact. 


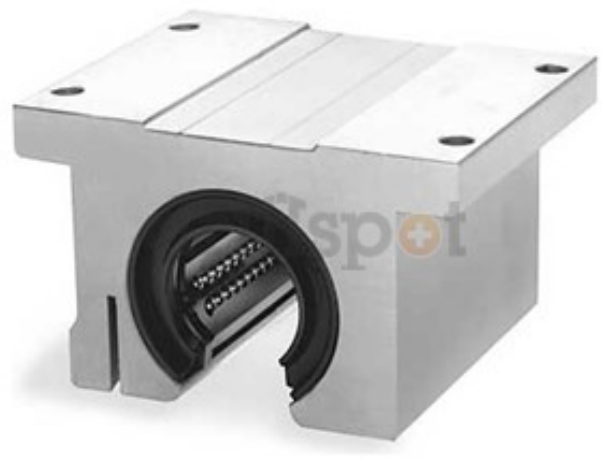

Figure 15. Tighter fit linear bearings were used to stabilize the battery so that it would operate in a functional matter [29].

Once the system was where we wanted it as far as the base components we bolted it onto its old steel support table, figure 16.

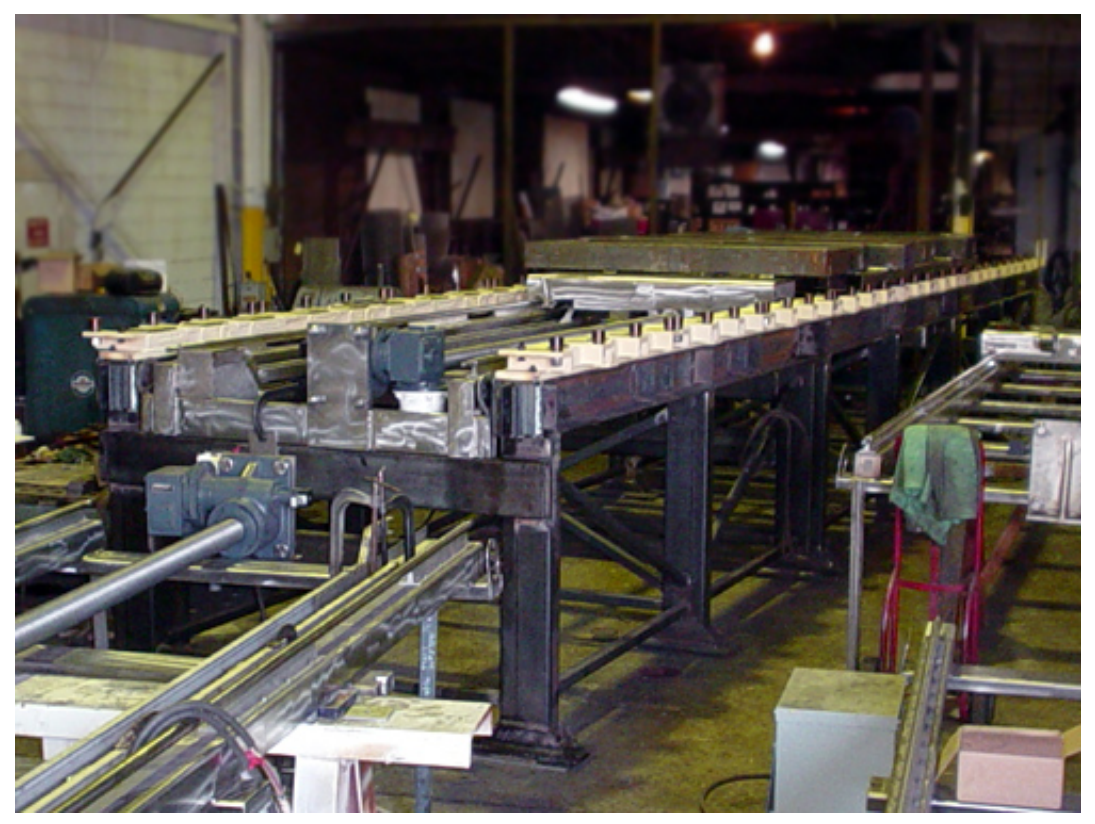

Figure 16. The modified pallet moving system was attached to its support table for testing. 
A carrier was made with 1" square tubular cold rolled steel with a steel plate acting as a battery scoop to mimic the design shown in figure 17.

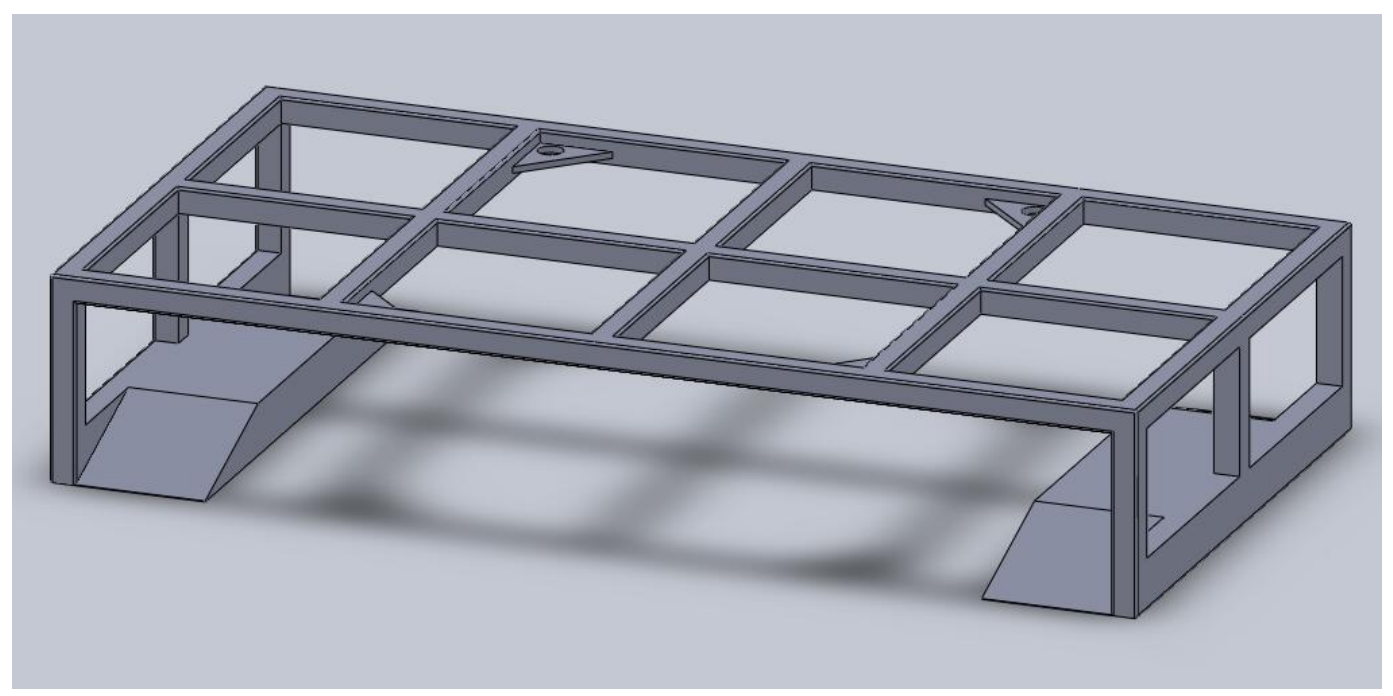

Figure 17. The battery carrier system that was intended to be installed below the vehicle.

Mounting points for 4 linear actuators and the actuator controller were positioned on the top corners of the carrier as seen in the figure. The linear actuators were not installed as the batteries were not fully assembled with contacts or with a case lid.

Once the carrier was finished it was temporary fitted with linear bearings with less than optimal bearings on them in order to check the fit of the rack. The fit of the carrier was originally slightly off and as the system was MIG welded together; a hammer was used to break the weld bead and the carrier's position was adjusted. The batteries were assembled into an open battery container in a less than optimal fashion for testing.

This overall design was chosen as it was brought to my attention that I could use a system placed closer to the ground as long as there was a mechanism that lowered the 
carrier from the car. By doing this there was no need for the speed bumps as the car could clear the entire battery assembly by just rolling over it.

Modifications made to the car were minimal as the vehicle was already set up for a battery system that allowed for easy removal. Attaching the vehicle's controller leads to the linear actuators would have been implemented in order for the wires to contact the battery. Attaching the carrier to the vehicle would have also taken place if complications had not arisen.

\subsubsection{The Bike's System}

The design for the bike was simpler than the vans as it involved moving the system by hand and was based on a smaller platform, making adjustments easier and quicker to complete. The utilized design was similar to figure 11 and allowed the battery to fit into a guide channel that would prevent the battery from moving side to side. A latch was to be used on the front of the system to hold it from falling off the bike. During the initial design of the system I chose acrylic plastic as there was an abundance of it in 1 " thick sheet at cal poly, this design quickly changed when I found manufactured bike racks with channel systems already in place.

Many bike manufacturers make racks that have proprietary bags and other accessories that go with them. I decided to look for a premade one to save both time and money. After investigating in local stores, I had failed to find a system I saw at school; it was then that I found the rack available online. I ordered the rack that would fit my bike after taking a few measurements and ordered a few basket mounting systems that would 
be utilized for the batteries. The rack is a Topeak MTX A-type rear rack, figure 18, the basket attachment piece is a fixer 6 , figure 19; when the rack and accessories arrived and system assembly began.

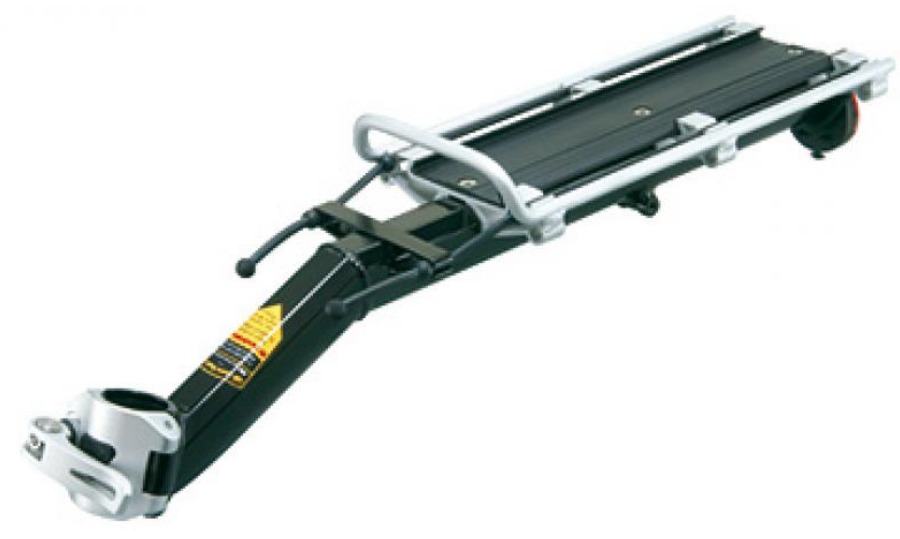

Figure 18. Topeak MTX A-Type rear bicycle rack, the body is made of aluminum with a plastic insert where adapters slide in [30].

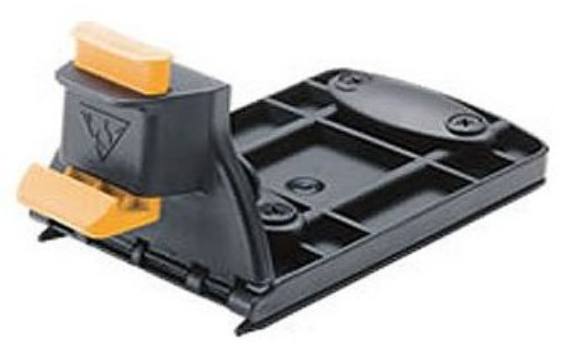

Figure 19. Topeak Fixer 6 MTX rear basket adapter that was used for mounting the battery on the electric bike system. 
The rack fit fine on the bike after the seat was raised a bit. This rack was a seat post mounted rack that rested on top of the original rack I had on the bike. I did this because I wanted the extra support as this would be where the battery would sit. I noticed there was a bit of lateral movement that the rack experienced just with me moving it around, this occurred because the system only mounted at the seat post. I machine two 2in $x$ 0.5in x 0.25 in pieces of Delrin to affix the new rack to the old rack I left attached to the bike in an effort to increase the racks weight capacity. This resulted in a firmly secure rack assembly that had minimal movement in any direction.

Designing a way to get the battery to attach securely was a bit more difficult. A cold rolled steel ammunition box was purchased from SLO camp n pack for holding batteries that would power the bike. The battery box was quite large as the battery being used was a section from the original van's battery and smaller batteries could not be formed. The box was powder coated black by central coast powder coating prior to modifications in order to limit thinning of the coating due to sharp or thin edges that may have resulted from altering the box. The Fixer 6 rack adapter was slightly modified then positioned and mounted onto the battery box; adjustments to positioning were made in order to ensure a balanced battery. The latch adapter from the fixer 6 (yellow piece that can be removed from the base), seen in figure 19, was heavily modified to fit the battery box in order to ensure the battery stayed on the bike during operation. The battery box now slid onto the rack and locked into place.

In order for the system to be an actual rapid battery exchange there needed to be electrical components built into the rack and battery box that contacted when the box slid 
onto the rack. A spring loaded coupling device (sprung fuse holder), figure 20, and aluminum spacers were used to make these connections.

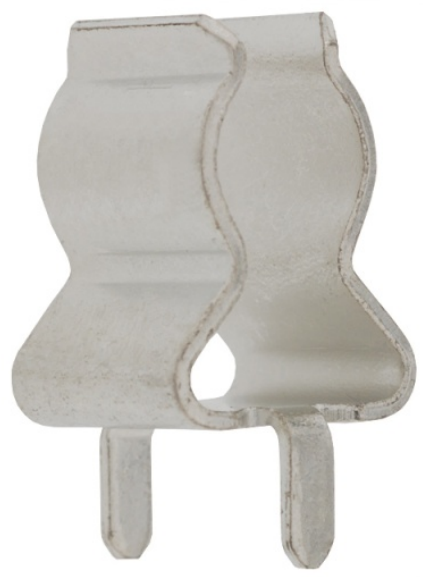

Figure 20. Fuse clip that serves as terminal connectors for the various components of the electric bike, a similar model to this one was used.

The front portion of the fixer 6 adapter was modified in order for this connector system to work. The leading edge of the fixer 6 adapter included the mechanism required for proper aiming of the adapter; modifications were made so that this remained relatively intact. The fuse adapters were modified to obtain the fuse holding portion, the portion making the connection. These were attached to the fixer 6 adapter with aluminum screws; aluminum was used as it is easier to modify in the case that something doesn't fit and has a higher electrical conductivity than steel. Four fuse adapters were used for each battery built. It was my intention to allow this bike to have rapid charging and rapid exchange capabilities, a power cord would be attached to two of the future leads, figure 21, allowing it to plug into an $\mathrm{AC}$ power source freely. 


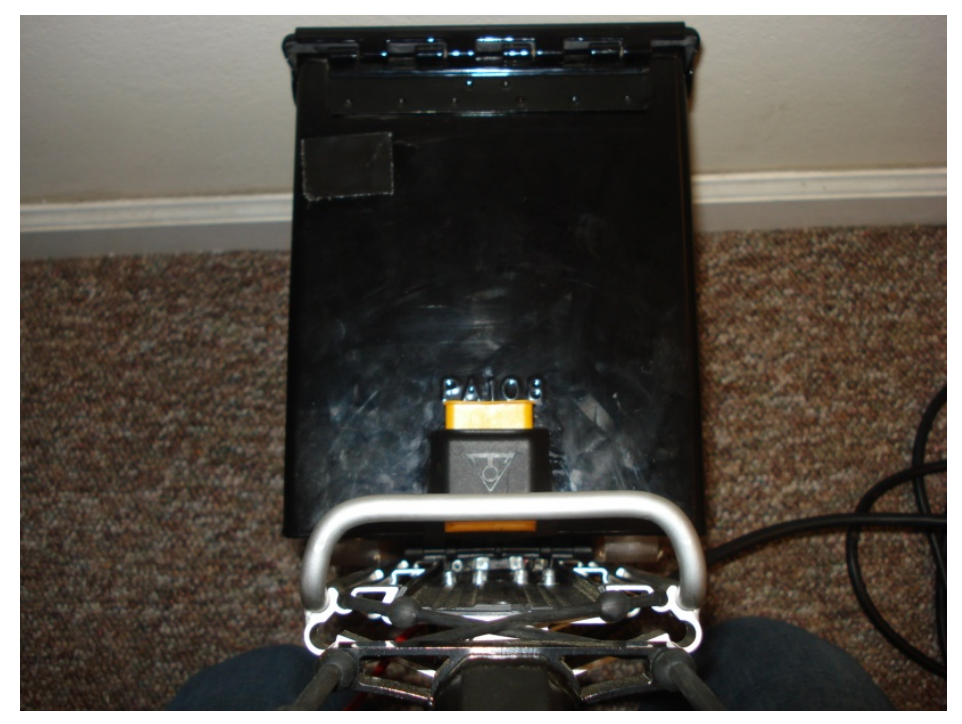

Figure 21. Four leads on the rack allow for AC plug in for rapid charging.

The modified fixer 6 adapter was removed from the battery box and was positioned on the rack where holes were drilled for placement of the aluminum spacers, the piece that fits into the modified fuse adapters. The aluminum spacers were attached with aluminum screws, leads from the bicycles controller and an AC extension cord were positioned in their respective locations beneath the rack, figure 22.

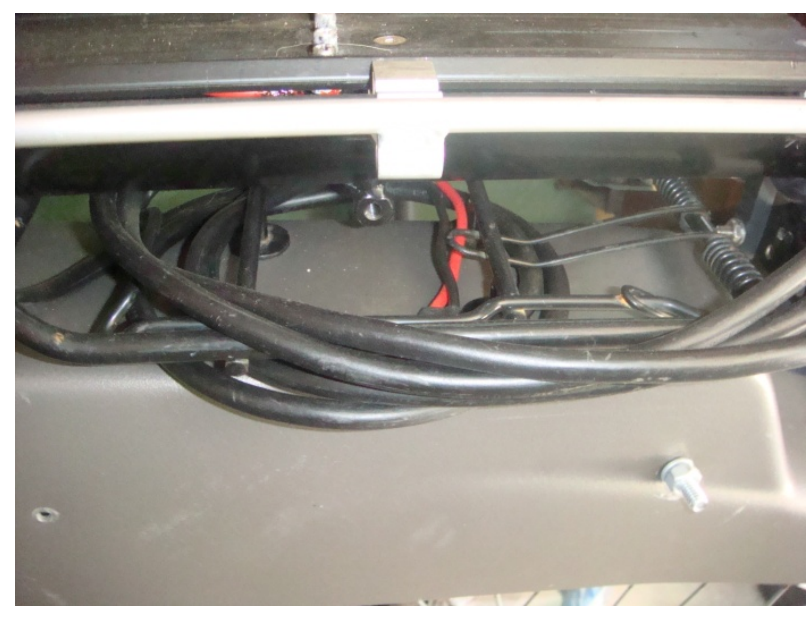

Figure 22. An AC extension cord and DC wires protrude from the base of the rack. 
A BMS was made from a kit for a $48 \mathrm{~V}$ battery system in order for the battery to discharge and charge at a rate that would not damage the cells of the battery, figure 23.

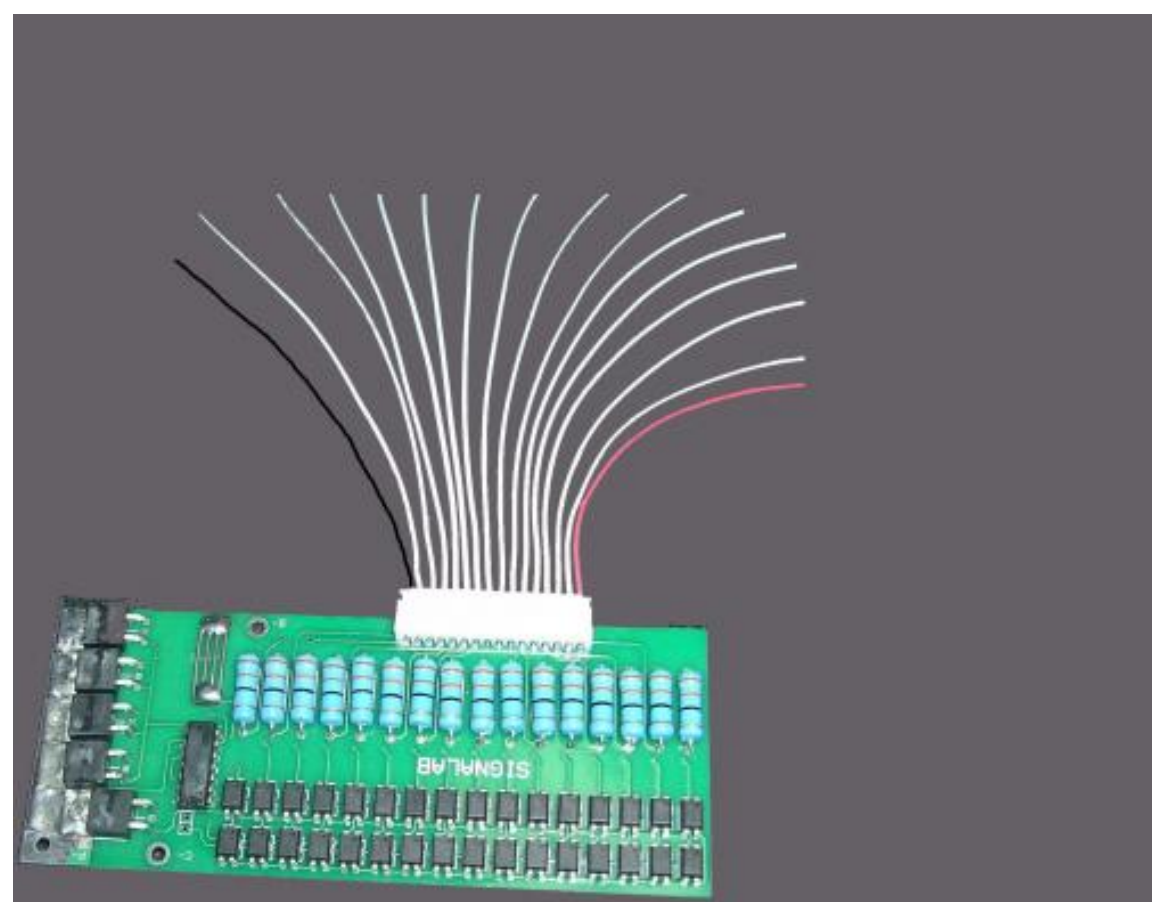

Figure 23. A 48 volt battery management system was soldered and connected to the different positions on the battery. BMS is seen here just after completion.

Wires from the battery and the charger in the battery box were run to each of their respective fuse holders; the power wires for the electric bike were revised when the original setup resulted in some unwanted sparking due to current overload, figure 24 . 


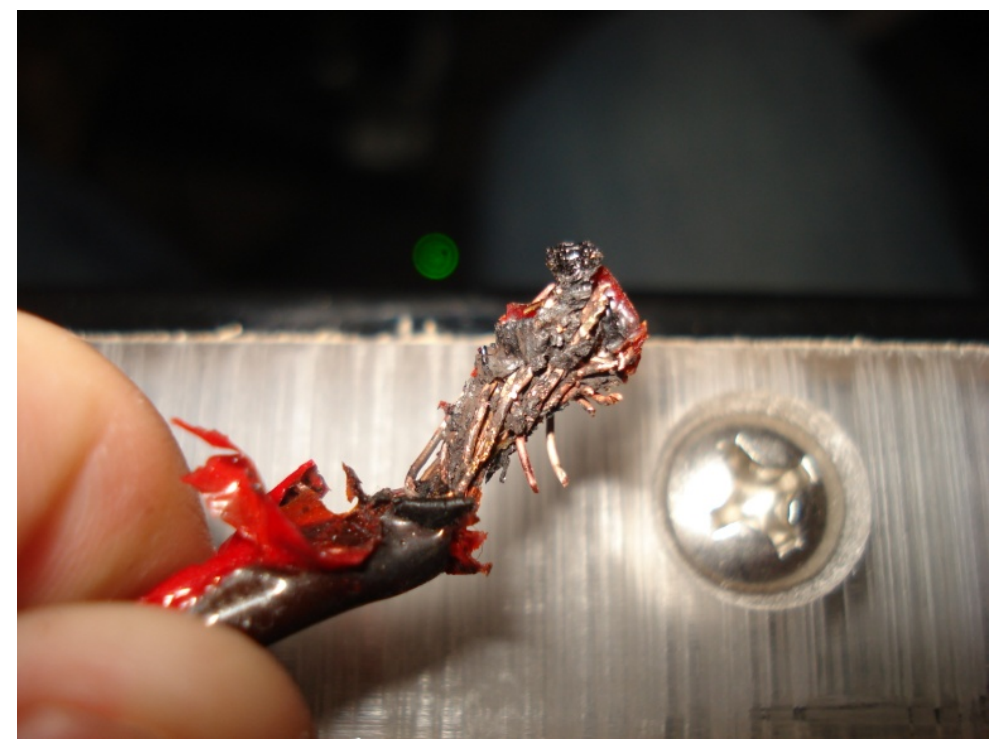

Figure 24. The negative terminal wire for the battery exchange system overloaded causing sparking and melting of the surrounding plastic.

A hole was drilled in the bottom of the battery box and a grommet was utilized to ensure the wires to have safe access into the box. Inside of the box, high current Anderson connectors, figure 25, were used to connect the wires from the fixer 6 adapter to the components inside the battery.

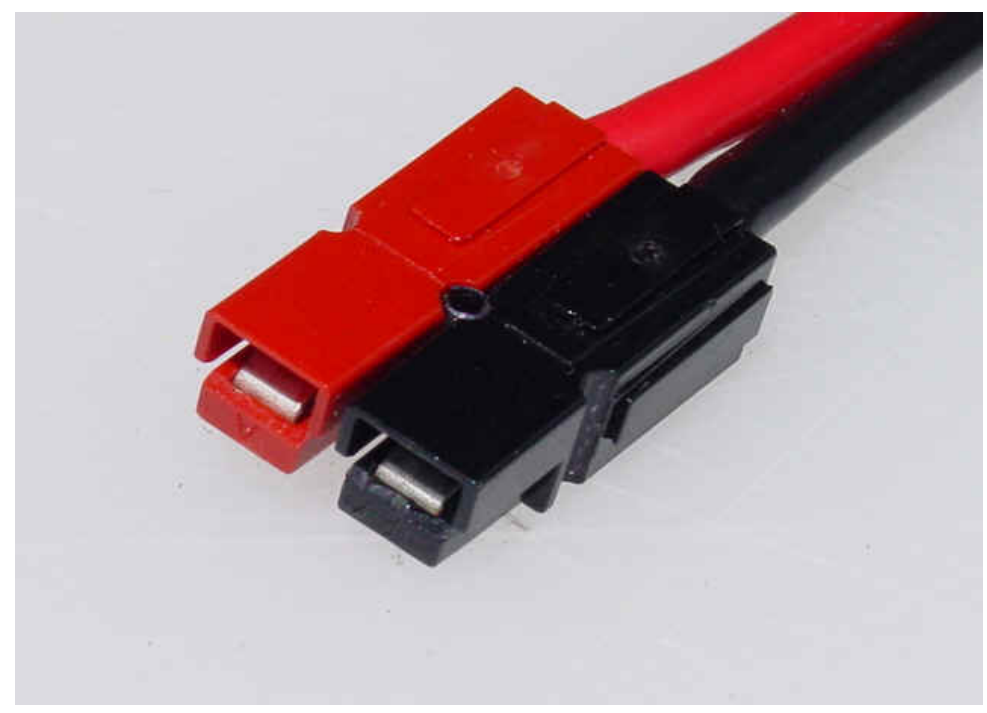

Figure 25. High current 30A Anderson connectors are used to ensure worry free operation. 
Originally a 20A switch was used for turning the battery on and off, a high current (2000A) battery isolator switch, figure 26, soon replaced the original switch when it could not handle the current demands of the bike.

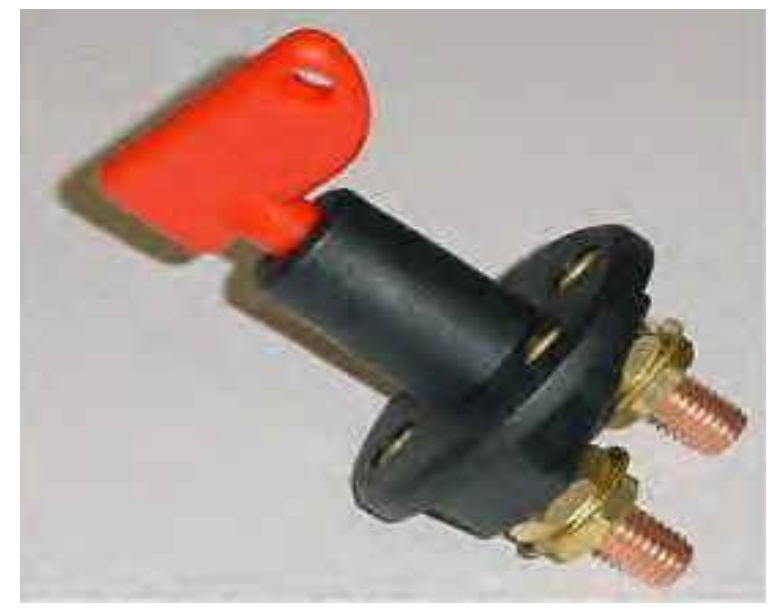

Figure 26. A battery ruminator switch with a key was utilized due to its ability to handle vast amounts of electrical current.

During preliminary testing of the bike there was a noticeable wobble of the battery, two pieces of polycarbonate were cut to be $\sin x$ 1in x. 5in support the sides of the battery while in operation, figure 27 , this eliminated the wobble.

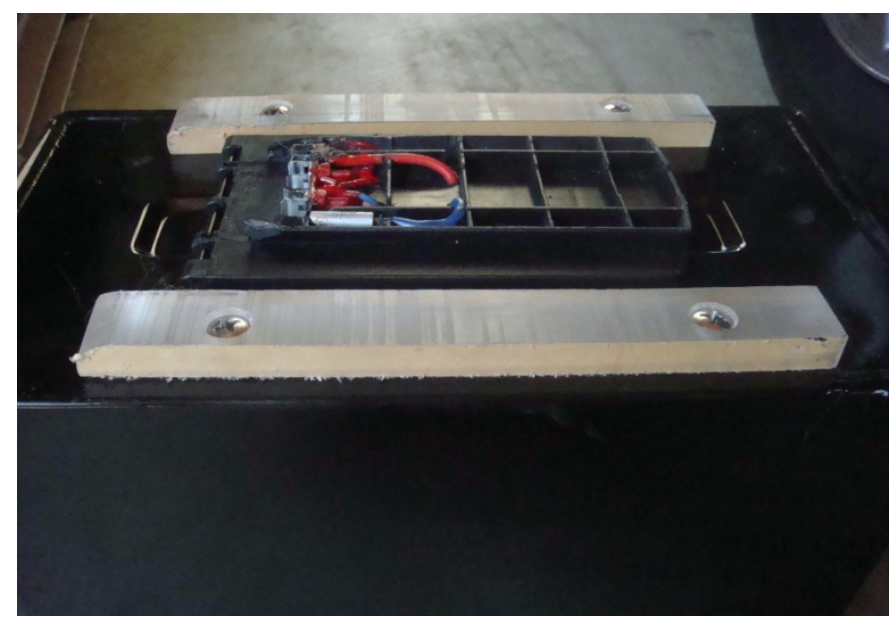

Figure 27. Support pieces for the bottom of the battery ensured minimal movement. 
Actual system testing soon followed on the completed system, figure 28.

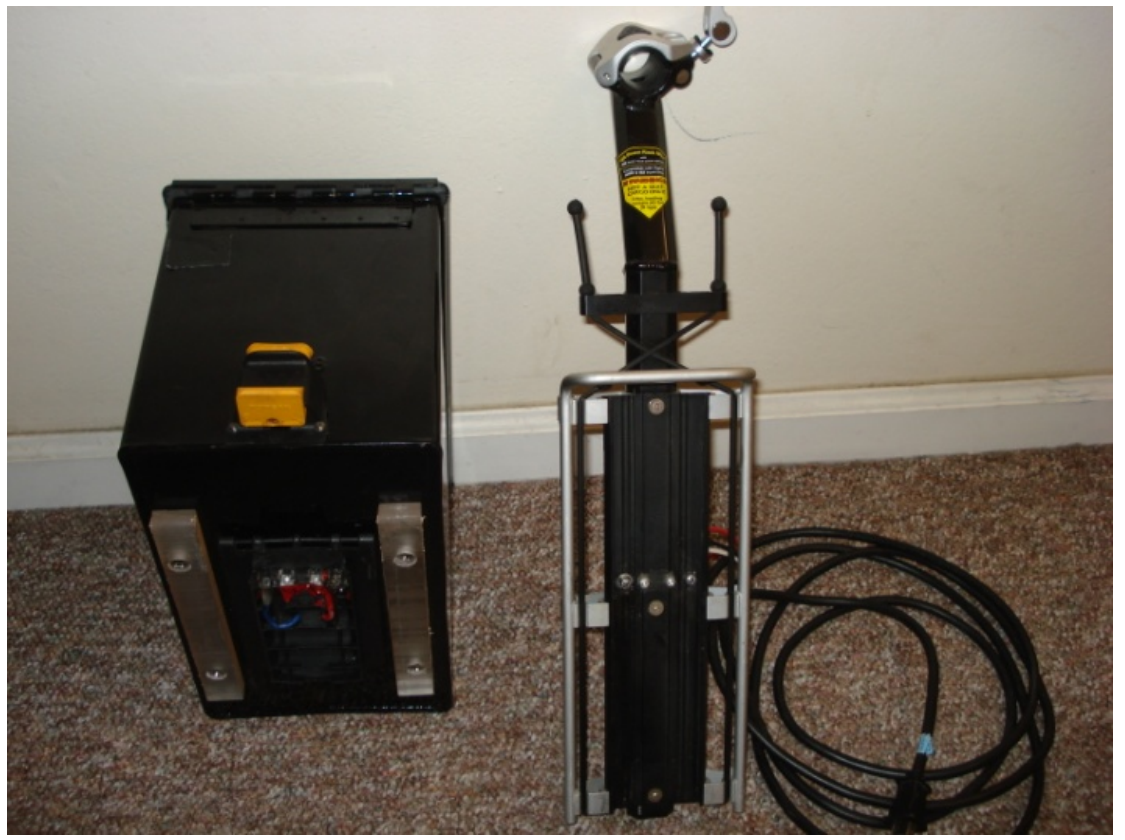

Figure 28. Completed rack and battery for the bicycle rapid battery exchange system. 


\section{CHAPTER THREE}

\section{RESEARCH OBJECTIVES}

The primary objective of this design project is to develop a system for rapidly exchanging the battery of an electric vehicle, using limited or no electricity to drive the exchange. This would allow the vehicle to function in a similar manner to that of a modern day gasoline powered vehicle by eliminating the requirement of a multiple hour charging cycle that currently makes electric vehicles impractical for most users. Previous attempts to bring electric vehicles in the consumer market were limited in the sense that the focus was entirely based on making the battery larger. This approach eliminates the need for larger batteries that may be needed in long distance driving.

A second objective of this project is to determine a proper method of protecting the exchange system from corrosion that can occur from the environment. This is examined by measuring the depth of corrosion of samples coated with various protective measures. The corrosion depth can give an indication of the coatings ability to prevent the intrusion of water or air that can aid in the formation of rust on the coated metal surface.

A third objective of this project in conjunction with determining corrosion characteristics is the ability of the coating to withstand delamination that may occur because of exfoliation corrosion that can form on the system if the coating is compromised. This is examined by measuring the surface area of paint removed by an air compressor following the corrosion test. The surface area can give an indication of the coatings ability to adhere to the surface of the metal in a harsh environment. 
A fourth objective of this project in conjunction with determining corrosion characteristics is the ability of the coating to prevent or withstand damage due to physical interaction of the system with either other components of the system or road debris. This is examined by measuring the deformation distance caused by various loads using a micro hardness indenter. The indentation can give an indication of the coatings ability to plastically deform without forming cracks or folds in the coating. 


\section{CHAPTER FOUR}

\section{EXPERIMENTAL MATERIALS AND METHODS}

Testing the coating of the system was the most important part of the systems as it would determine if the system would be effective at delivering batteries over the time in which it was implemented. In order to test for corrosion resistance a prolonged salt spray test was completed followed immediately by a delamination test that would remove loose material and give a better understanding of the coatings ability to resist exfoliation corrosion and adhere to the system. An impact test was done with a micro hardness machine to determine the materials ability to deform plastically without exposing the underlying metal surface to the environment.

\subsection{Cold Rolled Steel Samples}

Cold rolled steel strips were special ordered from McMaster Carr that met ASTM Standard A109M "Standard Specification for Steel, Strip, Carbon (0.25 Maximum Percent), Cold-Rolled" in accordance with the Society of Automotive Engineers specifications for proper testing. The samples were unpolished mill finish and the strips were 1.0in x 1/8in x $6 \mathrm{ft}$.

\subsection{Protective Coating}

Samples of the cold rolled strips were cut into two inch segments, a total of 120 samples were cut to form four groups of 30 samples. Each of the cut samples were smoothed on a belt sander to remove sharp edges, allow the coatings to fully adhere to each sample. The samples were then cooled in a water bath and dried immediately to 
prevent corrosion. All samples were sand blasted to remove any surface oxide present on the as-received material. After sandblasting the samples were wiped with ethanol to remove any grease or other particles in compliance with ASTM D609 "Standard Practice for Preparation of Cold-Rolled Steel Panels for Testing Paint, Varnish, Conversion Coatings, and Related Coating Products".

The 30 samples that utilized the epoxy resin paint were strung onto a ten pound test weight fishing line and were dipped in a black epoxy resin paint supplied by VHT paint. After 15 seconds the samples were removed from the paint and fan dried for 15 minutes. After the 15 minute period had elapsed the thickness of the coating was measured with a Check-line TI-007DL ultrasonic thickness gauge supplied by General Hydroponics. The thickness of the coating was measured in three spots on each side of each sample. This process was repeated four times until the thickness of the coating was $0.50 \mathrm{~mm}$ thick. At this time ten samples were removed and the process was continued until a $1.0 \mathrm{~mm}$ thickness was reached. Again ten samples were removed and the remaining ten samples continued the process until a thickness of $1.5 \mathrm{~mm}$ was achieved. All 30 samples were fan dried for a period of 24 hours and air dried for a period of seven days to allow the epoxy coating to fully cure.

The 30 samples that utilized the vinyl resin paint underwent a similar process as the epoxy resin paint. The samples were strung onto a ten pound test weight fishing line and were dipped into black vinyl resin paint manufactured by Krylon. After ten seconds the samples were removed from the paint and fan dried for 10 minutes. After the 10 
minutes had elapsed the thickness was measured and dipping continued until groups of ten samples had obtained paint thicknesses of $0.5 \mathrm{~mm}, 1.0 \mathrm{~mm}$, and $1.5 \mathrm{~mm}$.

The 30 samples that utilized powder coating underwent a different process than the painted samples. The samples were taken to Vaider Powder Coating in Rohnert Park, California where three different weights of polymer powder were chosen to obtain $0.5 \mathrm{~mm}, 1.0 \mathrm{~mm}$, and $1.5 \mathrm{~mm}$ thicknesses. The samples were strung on a stainless steel wire and were grounded with a grounding strap attached to the hanger the samples were on. A polarized powder dispenser sprayed charged polymer particles of each of the three different polymer weights onto three groups of 10 samples. Once fully coated, the

polymer samples were put into a large oven set at 405 degrees Farenheight for a period of 20 minutes. The samples were then removed and allowed to cool overnight. In the morning the thickness of the coating was measured to ensure that the correct thicknesses had been obtained.

The remaining 30 samples were left uncoated and were to be used as a control to observe what corrosion would occur had the system not been protectively coated. Impact and delamination tests were not done on these samples as they would have no measurable response variable.

\subsection{Salt Spray Testing}

The salt spray fog method was used to test the relative resistance to corrosion of coated and uncoated samples when exposed to a salt spray climate at an elevated temperature. Samples were placed into a chamber and were exposed to a continuous 
indirect spray of neutral $\mathrm{pH}(6.4-7.4)$ salt water solution, which falls on the samples at a rate of $1-2 \mathrm{ml} / 80 \mathrm{~cm}^{2} /$ hour, while the chamber maintains a temperature of $95.6 \mathrm{~F}$. This climate is held constant through the test cycle.

Salt spray testing was performed on 108 samples, nine samples of each thickness $(0.5 \mathrm{~mm}, 1.0 \mathrm{~mm}, 1.5 \mathrm{~mm})$ from each of the coating types including the control group that had 27 specimens. The salt spray tests were run using a 5\% salt solution, prepared by dissolving five parts sodium chloride, purchased from Sigma Aldrich, with 95 parts of deionized water to create a solution that meets the requirements of ASTM D1193 "Specification for Reagent Water, Type IV". This solution was housed in a 55 gallon reservoir and was replaced once at 50 days in order to maintain continuous testing.

Samples were placed on a plastic sample tray at an angle of 17.5 degrees from vertical, an angle that is preset on the sample trays to be in accordance with ASTM B117 "Standard Practice for Operating Salt Spray (Fog) Apparatus", so that condensation could run down the specimens in order to minimize condensation pooling. A Model 15 Standard Salt Fog Cabinet made by Auto Technology Company, donated for test time by Auto Life Center in Santa Rosa, California was used and was conditioned for two hours prior to inserting the samples. Three sample groups of three samples from each thickness of each coating type and control were placed into three different chambers inside of the fog to create a pseudo-replicated design. This was done due to the 2400 hour length of the fog test; three actual replications would have taken 300 days to complete. This length of time simulates 15-25 years of constant exposure to the environment [31]. Samples were not rotated or moved during the test cycle. After the test was completed the samples 
were removed from the chamber and were dried in a low temperature oven at $140 \mathrm{~F}$, samples were then placed into a plastic sample holder and were transported for analysis and further testing.

\subsection{Corrosion Depth Testing}

Three samples of each thickness of each coating were sectioned, mounted, and analyzed using a microscope to determine the average corrosion depth. Samples were cut into four sections using a wet cutting saw, figure 29.

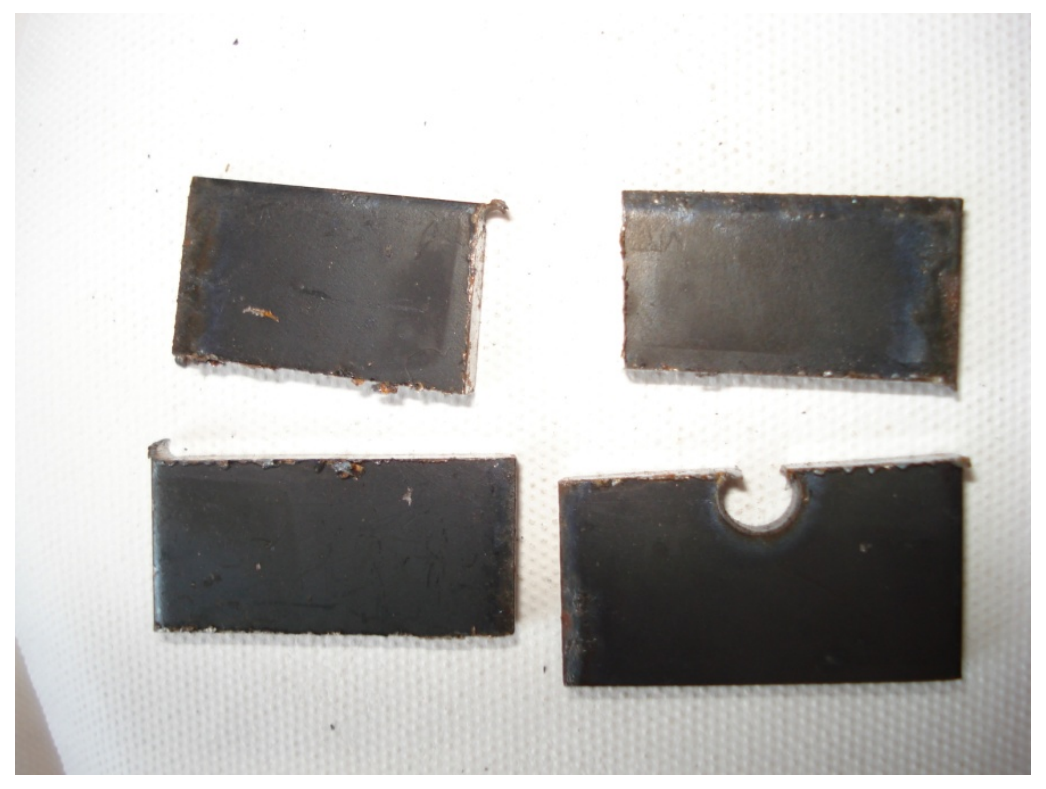

Figure 29. Sections of an epoxy test sample prior to being analyzed.

After sectioning, the samples were mounted in Bakelite, figure 30, with a LECOPR10 mounting press with specific faces facing the surface being analyzed in order to obtain the corrosion depth over the entire length of the sample. 


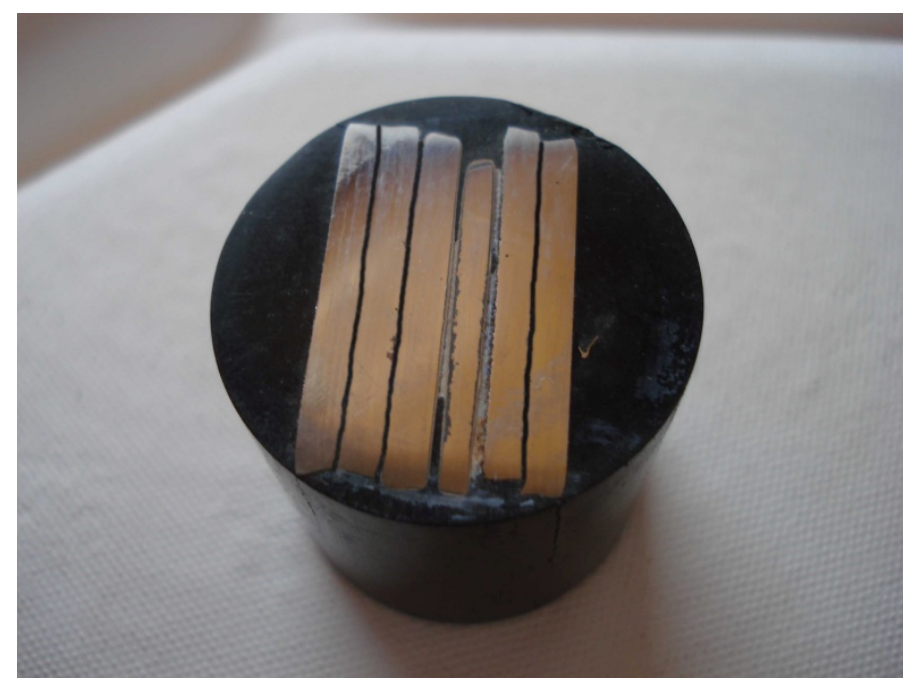

Figure 30. Bakelite mounted samples are prepared and are ready for microscopic analysis to determine corrosion depth.

Samples were sanded and polished once mounted to clearly observe the full extent of the corrosion in the sample. An optical microscope was utilized to analyze the corrosion depth. Ten measurements were made along the length of the sample where depth was measured by utilizing the digital caliper in the QCapture Pro program at each of the segments.

\subsection{Delamination Testing}

Delamination testing was completed through the use of a test fixture that introduced a stream of pressurized air onto the surface of individual test samples. Air, pressurized to 20 PSI, was applied directly to the surface of the samples for a period of 2 minutes. After the air had been applied the sample was removed and the surface area of the delaminated coating was calculated. This test was only done on samples that exhibited the ability for the coating to delaminate and was only done on one side of the test samples. 


\subsection{Deformation Testing}

Deformation testing was completed through the use of a Buehler micro hardness tester in order to determine the ability of each coating to plastically deform when impacted on the microscopic level. Three samples of each thickness of each coating were mounted in the machine then were indented at 300, 500, and 2000 grams of force; each sample received three impacts of each weight. The samples were then analyzed using QCapture Pro in order to measure the plastic deformation zones using the on screen. If the coating cracked or delaminated it was noted for the specified test. Samples were only tested on one side in order to keep track of the microscopic indentations.

\subsection{Rapid Battery Exchange Testing}

Both the van and the bike systems were to be qualitatively tested to ensure that they functioned in a safe and consistent manner. Batteries were to be loaded and discharged, the exchange systems were to complete the exchange multiple times, and the vehicles were to be tested for their performance capabilities. This was to ensure that the conceptual plan would actually work when implemented into a large scale system either at cal poly or commercially. 


\section{CHAPTER FIVE}

\section{EXPERIMENTAL RESULTS}

\subsection{Corrosion Depth}

During the salt spray test, the process conditions of temperature, total dissolved salts, $\mathrm{pH}$, volume of salt solution, specific gravity of solution, and time were held constant. The corrosion conditions for the samples tested are summarized in appendix A.

The design model used was a $2^{3}$ factorial design with three pseudo replications which resulted in 81 test samples. Corrosion depth was measured on all 81 samples along the midline of the sample to determine the effect of the salt spray test on the surface of the material.

An average value was generated from the ten measurements made in order to make the statistical analysis easier, appendix B. A general linear model (GLM) was run in Minitab to determine if the corrosion depth was dependent on the type of coating, the thickness of the coating, or the interaction effect between the thickness of the coating and the type of coating. An interaction plot was generated from the resulting analysis, figure 31. 


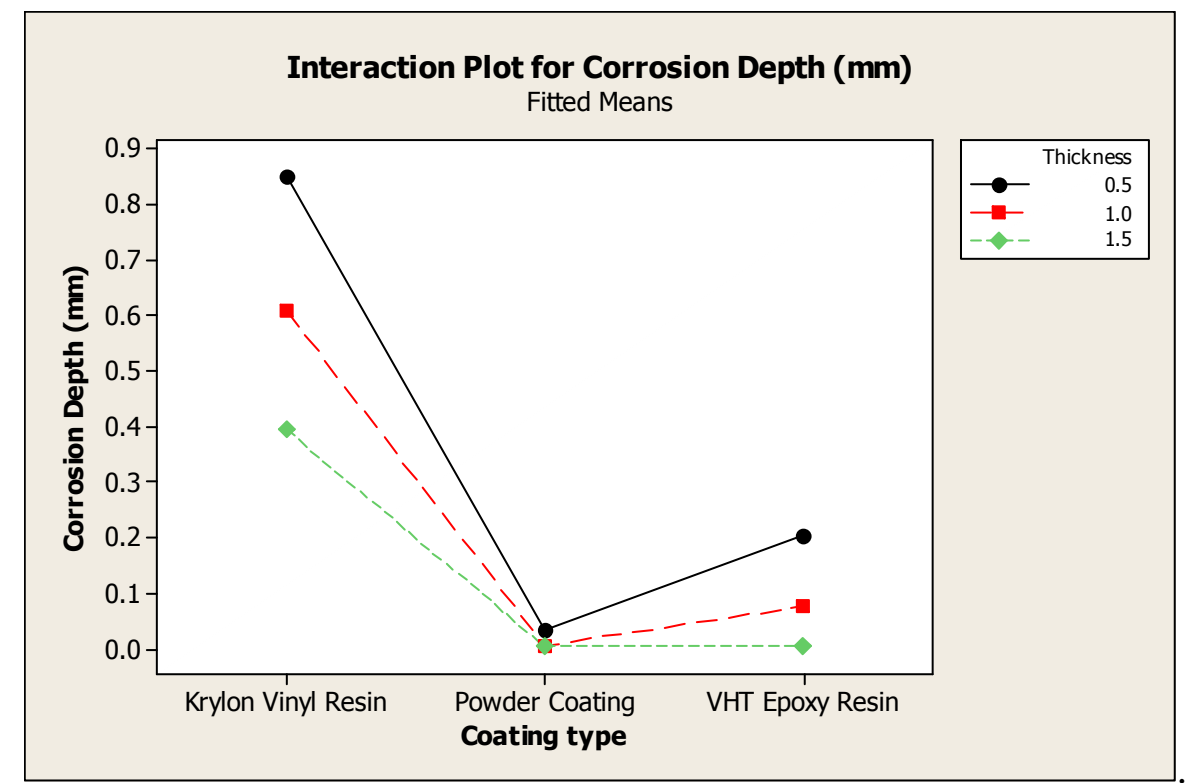

Figure 31. Interaction plot shows the difference in corrosion depth for different thicknesses of the various types of coatings.

Three sets of hypotheses are made in the general linear model and include both a null and alternative hypothesis, the null hypothesis for any test is that the change in a factor does not influence the results of the test; the alternative hypothesis is that the factor does influence the results of the test, table I.

Table I. Hypotheses Made in the GLM Model for Corrosion Depth Analysis.

\begin{tabular}{|l|l|l|l|}
\hline & Coating Type & Coating thickness & $\begin{array}{l}\text { Interaction effect (coating type } \mathrm{x} \\
\text { thickness) }\end{array}$ \\
\hline Null & $\begin{array}{l}\text { The corrosion depth } \\
\text { is not affected by the } \\
\text { type of coating }\end{array}$ & $\begin{array}{l}\text { The corrosion depth } \\
\text { is not affected by the } \\
\text { coating thickness }\end{array}$ & $\begin{array}{l}\text { The effect of the type of coating } \\
\text { on the corrosion depth does not } \\
\text { depend on the coating thickness }\end{array}$ \\
\hline Alternative & $\begin{array}{l}\text { The corrosion depth } \\
\text { is affected by the } \\
\text { type of coating }\end{array}$ & $\begin{array}{l}\text { The corrosion depth } \\
\text { is affected by the } \\
\text { type of coating }\end{array}$ & $\begin{array}{l}\text { The effect of the type of coating } \\
\text { on the corrosion depth depends } \\
\text { on the coating thickness }\end{array}$ \\
\hline
\end{tabular}

The output of the GLM, appendix C, includes the associated probability values that would indicate if there was a statistical difference between the tested factors. The 
probability values or P-value is the determined probability that the results of the test could be similar between the different levels or factors that were tested. In this test the Pvalue indicated the probability of similar corrosion depths occurring between the different thicknesses of coating, types of coating, or the combination of the two. A Pvalue of less than .005 indicates a statistically significant number, it means that there is less than a 5\% chance that the different samples (thickness or type) would share similar corrosion depth values, if the $\mathrm{P}$ value is less than .005 the null hypothesis is rejected. The actual results of all three tests indicated that there was enough evidence to reject the null hypothesis and state that the results were statistically significant, table II.

\section{Table II. Summarized P-Values for Corrosion Results.}

\begin{tabular}{|l|r|l|}
\hline Variable & $\begin{array}{l}\text { P- } \\
\text { Value }\end{array}$ & $\begin{array}{l}\text { Statistically } \\
\text { Significant? }\end{array}$ \\
\hline Coating Type & 0.000 & Yes \\
\hline $\begin{array}{l}\text { Coating } \\
\text { Thickness }\end{array}$ & 0.000 & Yes \\
\hline $\begin{array}{l}\text { Interaction } \\
\text { Effect }\end{array}$ & 0.000 & Yes \\
\hline
\end{tabular}

A qualitative test was performed in addition to the quantitative test previously discussed. The qualitative test was to observe the uniformity of the corrosion on the test samples. This qualitative test was originally going to be a quantitative method of determining the uniformity of the corrosion of the corroded samples. An extra corroded vinyl resin painted sample was analyzed with a Defelsko Positector $200 \mathrm{~B}$, a tool that measures coating thicknesses much like the unit used to measure the thickness of the coatings applied to the test samples. The coating thickness readout was somewhat erratic and unreliable; this may have occurred because the corrosion depth was not consistent and may have been over the detection limit of the device. The use of the device as a 
qualitative test showed that there was definitely some depth to the developed oxidation over the entire surface further confirming the measured depths representation of somewhat uniform corrosion over the surface.

\subsection{Coating Delamination}

The surface areas of the delaminated samples are summarized in appendix D. The design model for this system was a similar $2^{3}$ factorial design as the tested parameters were the same but only three samples of each combination of coating and thickness were tested instead of testing all of the samples, this was done to save time; a total of 27 samples were measured for this analysis.

A GLM was run on the data collected in order to determine the effect the type of coating, thickness of the coating, and the interaction effect between the thickness of the coating and the type of the coating had on the delamination area of the samples that were tested. An interaction plot was generated from the resulting analysis, figure 32. 


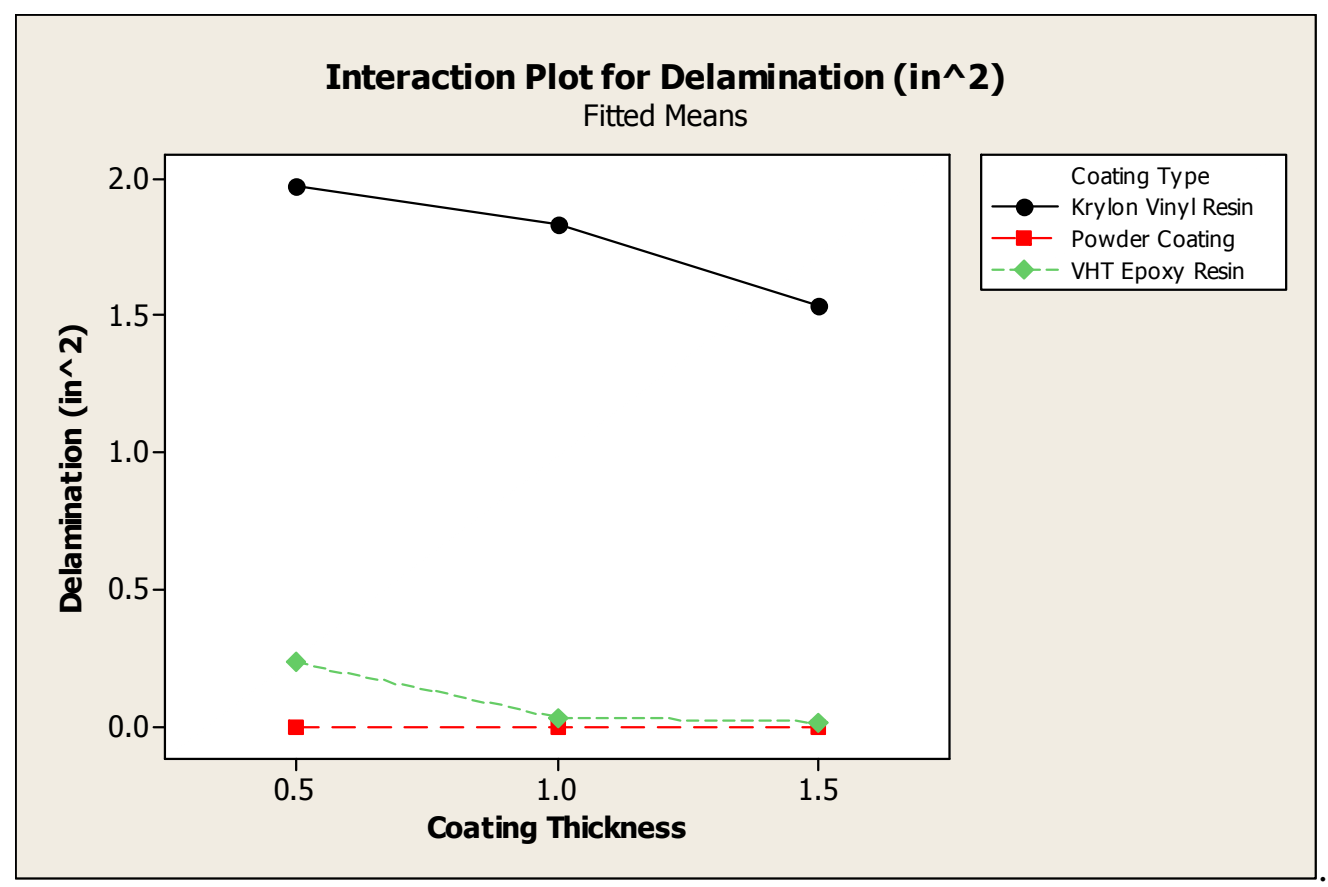

Figure 32. Interaction plot shows the difference in delamination surface area for the different thicknesses and types of coatings.

Another three sets of hypotheses are made in the general linear model used in the delamination analysis, Table III.

Table III. Hypotheses Made in the GLM Model for Coating Delamination Analysis.

\begin{tabular}{|l|l|l|l|}
\hline & Coating Type & Coating thickness & $\begin{array}{l}\text { Interaction effect (coating type } \mathrm{x} \\
\text { thickness) }\end{array}$ \\
\hline Null & $\begin{array}{l}\text { The delamination } \\
\text { surface area is not } \\
\text { affected by the } \\
\text { type of coating }\end{array}$ & $\begin{array}{l}\text { The delamination } \\
\text { surface area is not } \\
\text { affected by the } \\
\text { coating thickness }\end{array}$ & $\begin{array}{l}\text { The effect of the type of coating } \\
\text { on the delamination surface area } \\
\text { does not depend on the coating } \\
\text { thickness }\end{array}$ \\
\hline \multirow{2}{*}{$\begin{array}{l}\text { The delamination } \\
\text { surface area is } \\
\text { affected by the } \\
\text { type of coating }\end{array}$} & $\begin{array}{l}\text { The delamination } \\
\text { surface area is } \\
\text { affected by the type } \\
\text { of coating }\end{array}$ & $\begin{array}{l}\text { The effect of the type of coating } \\
\text { on the delamination surface area } \\
\text { depends on the coating thickness }\end{array}$ \\
\hline
\end{tabular}

The output of this GLM analysis, appendix E, includes P-values that indicated that there was a statistical difference between the tested factors: coating type, thickness, and the interaction effect. These $\mathrm{P}$ values are summarized in table IV, 
Table IV. Summarized P-Values for Delamination Results.

\begin{tabular}{|l|r|l|}
\hline Variable & $\begin{array}{l}\text { P- } \\
\text { Value }\end{array}$ & $\begin{array}{l}\text { Statistically } \\
\text { Significant? }\end{array}$ \\
\hline Coating Type & 0.000 & Yes \\
\hline $\begin{array}{l}\text { Coating } \\
\text { Thickness }\end{array}$ & 0.000 & Yes \\
\hline $\begin{array}{l}\text { Interaction } \\
\text { Effect }\end{array}$ & 0.000 & Yes \\
\hline
\end{tabular}

These results indicate that the null hypothesis should be rejected as there is enough evidence to say that the differences between the tested factors were statistically significant. In other words the delamination surface area was statistically different between the types of coatings and the thicknesses of each coating. While the P value indicated that there was an effect due to the thickness of the coating, this was only true for the vinyl resin paint, a Tukey-Kramer comparison in the GLM output, appendix E, shows this.

A qualitative inspection was done for the surface of the samples to determine their susceptibility to exfoliation corrosion. The vinyl resin paint samples were very susceptible to exfoliation corrosion as almost all of the material had flaked off prior to delamination testing, figure 33. 


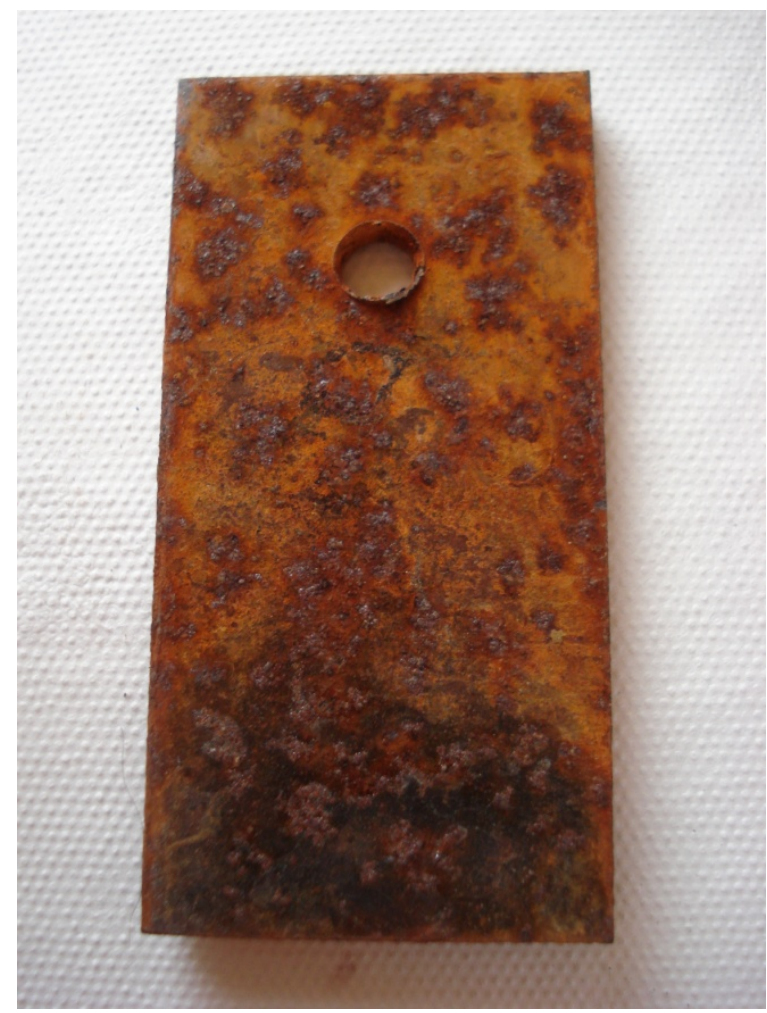

Figure 33. A $0.5 \mathrm{~mm}$ vinyl resin paint sample exhibited exfoliation corrosion at the lighter colored areas of the sample.

The epoxy resin paint was not as susceptible to exfoliation corrosion however there were some areas that exhibited minimal bubbling of the paint, figure 34 .

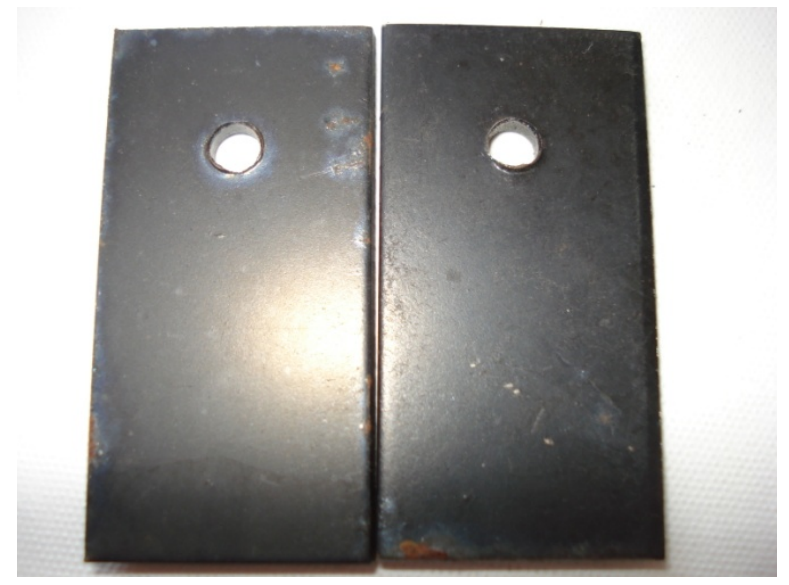

Figure 34. $0.5 \mathrm{~mm}$ coating thickness epoxy paint samples exhibit bubbling and delamination of the paint layer after 2400 hour salt spray test. 
The powder coated samples exhibited very little or no exfoliation corrosion, there was only one section of a few samples that exhibited signs of exfoliation corrosion,

Figure 35 .

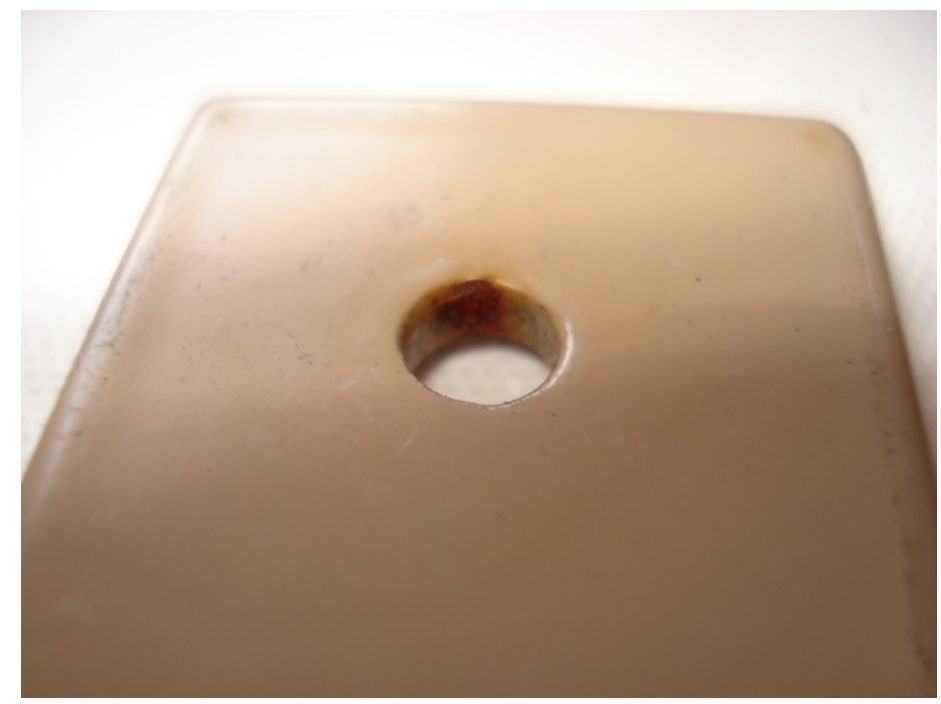

Figure 35. A $0.5 \mathrm{~mm}$ powder coated sample exhibits almost no corrosion, just the support area from the coating process shows corrosion.

These may have been minor signs of corrosion but they indicate that even extremely resistant coatings can underperform to some extent.

\subsection{Coating Deformation}

The deformation distance of the indented samples is summarized in appendix F, the design model was the same $2^{3}$ factorial as both prior tests, and a total of 27 samples were indented at the specified forces for this analysis.

A GLM was run on the indentation data in order to determine the effects of the same factors in the last two analyses (Type of coating, thickness of coating, and the interaction effect between the thickness of the coating and the type of the coating) had on 
the deformation distance of the samples tested. An interaction plot was generated from the resulting analysis, figure 36 .

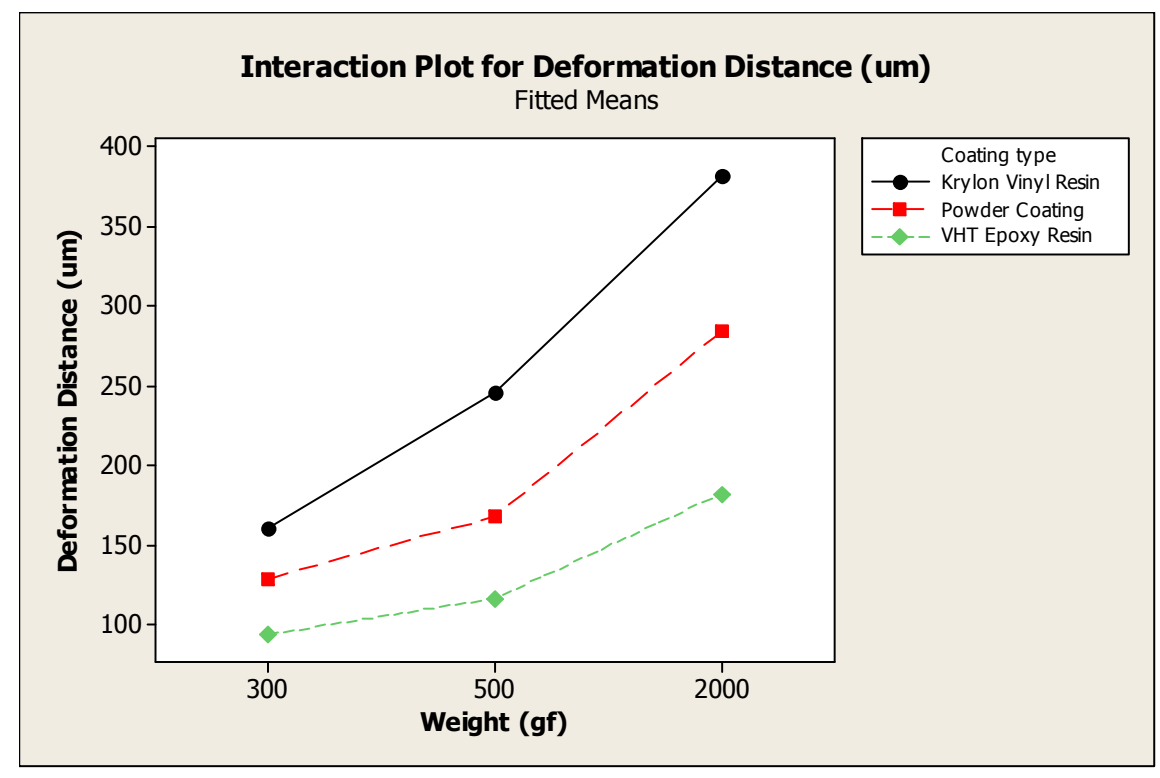

Figure 36. Interaction plot shows the difference in deformation distance for the different thicknesses and types of coatings.

Another set of similar hypotheses are made in the GLM used in the deformation analysis, Table V.

Table V. Hypotheses Made in the GLM Model for Coating Delamination Analysis.

\begin{tabular}{|l|l|l|l|}
\hline & Coating Type & Force applied $(\mathrm{g})$ & $\begin{array}{l}\text { Interaction effect (coating type x Force } \\
\text { app) }\end{array}$ \\
\hline Null & $\begin{array}{l}\text { The deformation } \\
\text { distance is not } \\
\text { affected by the } \\
\text { type of coating }\end{array}$ & $\begin{array}{l}\text { The deformation } \\
\text { distance is not } \\
\text { affected by the } \\
\text { force applied }\end{array}$ & $\begin{array}{l}\text { The effect of the type of coating on the } \\
\text { deformation distance does not depend } \\
\text { on the force applied }\end{array}$ \\
\hline Alternative & $\begin{array}{l}\text { The deformation } \\
\text { distance is } \\
\text { type of coating }\end{array}$ & $\begin{array}{l}\text { The deformation } \\
\text { distance is affected } \\
\text { by the force applied }\end{array}$ & $\begin{array}{l}\text { The effect of the type of coating on the } \\
\text { deformation distance depends on the } \\
\text { force applied }\end{array}$ \\
\hline
\end{tabular}


The output of the GLM run for this analysis, appendix G, indicated that there was a statistical difference between the tested factors; these $\mathrm{P}$ values are summarized in table VI.

Table VI. Summarized P-Values for Deformation Results.

\begin{tabular}{|c|c|c|}
\hline Variable & $\begin{array}{c}\text { P- } \\
\text { Value }\end{array}$ & $\begin{array}{c}\text { Statistically } \\
\text { Significant? }\end{array}$ \\
\hline Coating Type & 0.000 & Yes \\
\hline Force Applied & 0.000 & Yes \\
\hline $\begin{array}{c}\text { Interaction } \\
\text { Effect }\end{array}$ & 0.000 & Yes \\
\hline
\end{tabular}

These results indicate that the null hypotheses should be rejected as there is enough evidence to say that the differences between the tested factors were statistically significant. It was the case for the deformation test that all there was a statistical difference between the type of coating tested and the force at which the coatings were applied.

A qualitative test was also done for this test to examine the indentation effect on the material when it comes to consistency and rigidity of the plastic deformation. Vinyl resin paint exhibited very minimal folding or cracking surrounding the indentation site, figure 37.

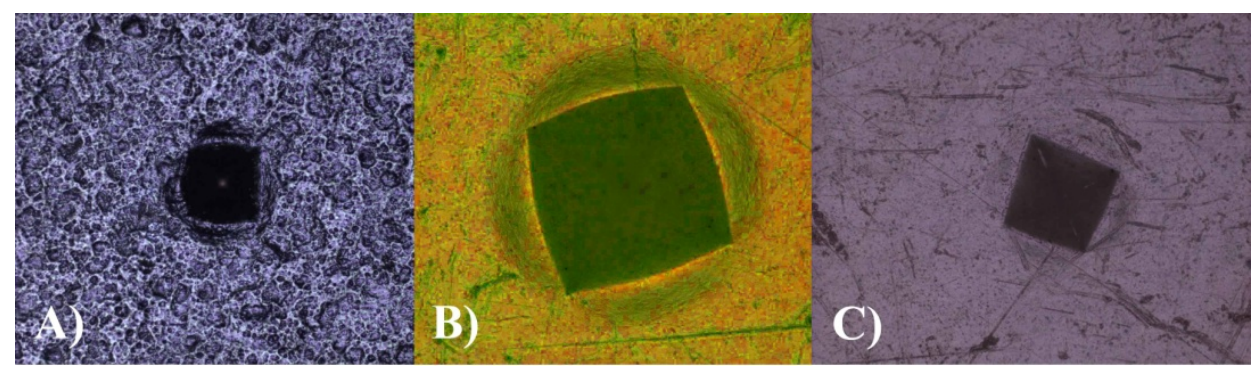


Figure 37. Indentation of $1 \mathrm{~mm}$ thick coated of A) epoxy resin paint, B) vinyl resin paint, C) powder coated

As shown above, the epoxy resin paint exhibited a tendency to fold around the indentation site; small cracks were also visible at the corners of the folds. Powder coated samples showed an even consistency surrounding the indentation site, indicating minimal folding and no cracking. This survey of the coatings ability to deform plastically without cracking or folding aided in the selection of the coating as the system would likely receive some unintended impacts over its service life.

\subsection{System Testing}

This project progressed in such a way to allow me to do analytical coating testing while building the system, a design map, figure 38, shows how the project progressed.

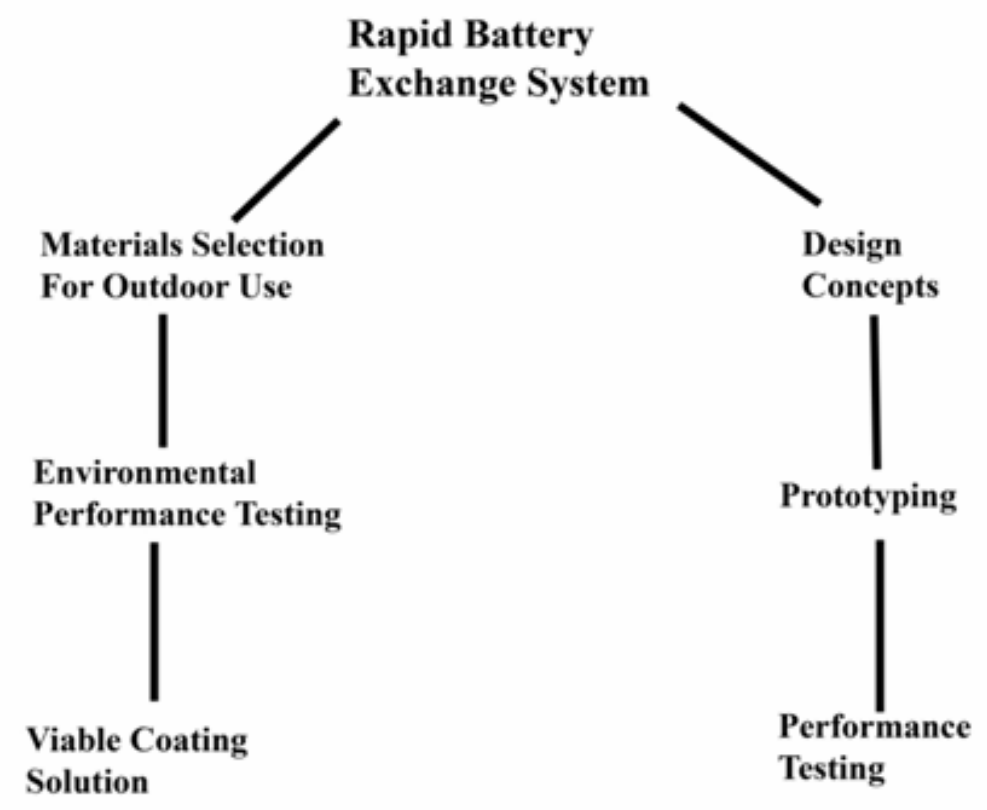

Figure 38. The various aspects of this project were built and tested at the same time; this saved time for testing however did not consider design setbacks. 
It is clear that when the system for the van was being tested the corrosion testing was just finishing. A description of the van system testing shows my progression when certain issues occurred.

\subsubsection{Van System Testing}

The van's system was designed around an idea and built around an available, affordable device. The design of this device did vary quite a bit from the conceptual design but it was a variation that had high potential of being a successful prototype. Testing the batteries of the system worked out well, the program for the charger was modified by Aerovironments in order to obtain optimal charging. Each battery (when charged at $.5 \mathrm{C}$ ) filled up in around 2.25 hours, a time that was going to be modified when the van demonstrated a decent ability to exchange batteries. The batteries were tested for their discharge capability on a 100kw solar controller which was provided by General Hydroponics. This test ensured that the batteries could provide a high enough discharge rate for use in the van.

The mechanical testing of the system was pretty brief and showed an important factor that was somewhat overlooked when altering the design of the system, proper mechanical aiming devices. When testing if the batteries would exchange in the undervehicle carrier, the carrier did not align properly on the tracks. During slow speed tests the carrier had enough time to adjust and move to compensate for battery misalignment. During a high speed test this was not the case and it resulted in a high temperature lithium fire, figure 39, which was put out safely with a few handfuls of a class D sodium chloride and graphite powder fire extinguishing kit. 


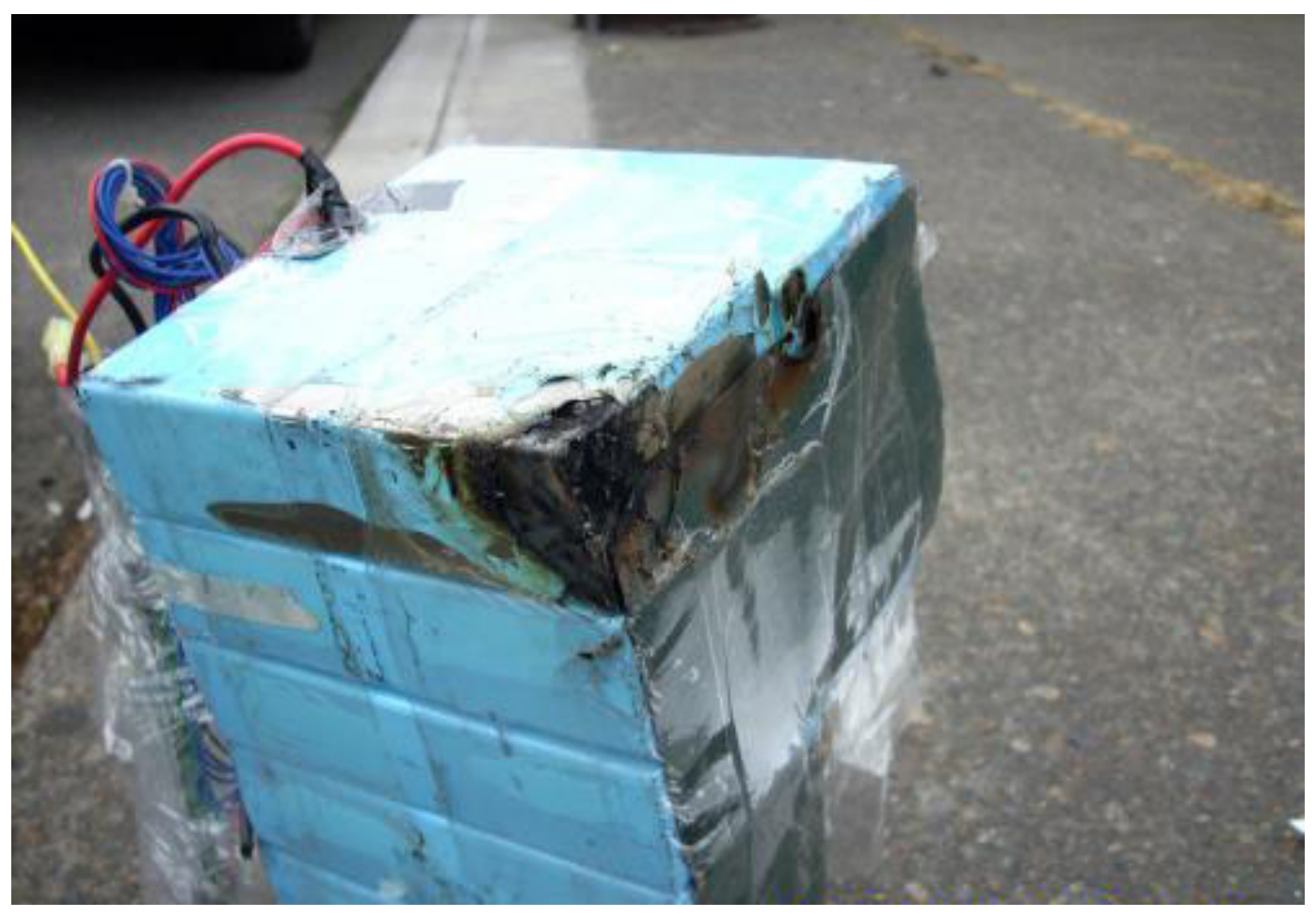

Figure 39. During testing of the rapid battery exchange system a collision occurred between the battery and the carrier starting a dangerous fire.

Further manufacturing development on the van system was halted at this point in order to reevaluate the feasibility of creating a safe functional system. I developed some new ideas for design application and implemented one of them onto my personal electric bike following the testing of the van system.

\subsubsection{Bike System Testing}

The initial tests with the bicycle rapid battery exchange system were not very successful as they resulted in a broken system as well, just not to the extent of the van's system. The battery pack fell off of the bike two or three times on its inaugural voyage; thankfully the clip that secures the battery prevented any major damage by ensuring that the battery dangled on the bike instead of falling to the ground. This allowed me to 
reposition it safely. Supports were made and placed on the battery to prevent future disconnection of the battery. This problem was partly due to the fact that the battery has a high center of gravity on the bike making this a top heavy system (it was a $27 \mathrm{lb}$ battery), this would be changed if the battery availability allowed for such modifications.

Another issue that kept occurring was the problem of ensuring a continuous connection between the contact points between the battery and the controller for the electric motor. This problem ensued until melting of the power wires occurred. At this point a revision was made to the contact terminals by soldering the wire onto the terminal instead of bolting it onto the wires; this also ended up decreasing the electrical resistance that formed during use.

To further ensure a low electrical resistant connection I made conductive graphite grease with some graphite powder and high quality semi-viscous automotive grease. This drastically decreased the resistance and resulted in a fully functional electrical connection.

Measurements of watt hours per mile are shown in the digital analysis unit on the bike. During low speed (under $15 \mathrm{mph}$ ) an average of $26.4 \mathrm{wh} / \mathrm{mi}$ was achieved over a distance of 20.2 miles. A full statistical analysis was not done on the energy usage of the bike as time did not permit it. This value for energy used is roughly $16-25 \%$ the amount of energy used by a loaded electric van. This would result in a $75 \% \mathrm{CO} 2$ savings from the electric van for the same amount of transportation. 


\section{CHAPTER SIX}

\section{DISCUSSION}

\subsection{Coating \& Corrosion Analysis}

To understand the results of the different coatings a basic understanding of the corrosion process is needed as well as an understanding of the concepts behind protective coating.

\subsubsection{Coating Analysis}

The formation of rust on cold rolled steel is an electrochemical process consisting of the transfer of electrons from iron to oxygen. The chemical equation process is as follows:

$$
\begin{gathered}
\mathrm{Fe} \rightarrow \mathrm{Fe} 2++2 \mathrm{e}- \\
4 \mathrm{Fe}^{2-}+\mathrm{O}_{2} \rightarrow 4 \mathrm{Fe}^{3+}+2 \mathrm{O}^{2-} \\
\mathrm{Fe}^{3+}+3 \mathrm{H}_{2} \mathrm{O} \rightleftharpoons \mathrm{Fe}(\mathrm{OH})_{3}+3 \mathrm{H}^{+} \\
\mathrm{Fe}(\mathrm{OH})_{3} \rightleftharpoons \mathrm{FeO}(\mathrm{OH})+\mathrm{H}_{2} \mathrm{O} \\
2 \mathrm{FeO}(\mathrm{OH}) \rightleftharpoons \mathrm{Fe}_{2} \mathrm{O}_{3}+\mathrm{H}_{2} \mathrm{O}
\end{gathered}
$$

Rust has the chemical formula $\mathrm{Fe}_{2} \mathrm{O}_{3}$; when this reaction occurs in the presence of electrolytes a simple explanation is needed For example, say we used sodium chloride, similar to the conditions in the corrosion test. The equation for sodium chloride in solution is $\mathrm{NaCl}_{(\mathrm{s})} \rightarrow \mathrm{Na}_{(\mathrm{aq})}^{+}+\mathrm{Cl}_{(\mathrm{aq})}^{-}$, what occurs is the dissolved salts create an electrolytic solution which is a solution that conducts electricity meaning the electrons 
move faster through it. This solution increases the speed of oxidation of iron to ferric oxide, making the overall process occur at a faster pace than it would normally.

The key factors in the formation of rust are the redox reaction when iron is in contact with oxygen and the further acid-base reaction that occurs with water contact, the dehydration step is not imperative and will occur at a microscopic level with the oxygen that is trapped in water.

Understanding the concept behind the protective coating process is important as well. The vinyl resin paint uses a vinyl binder with a solvent that keeps it in solution while in storage. The method in which vinyl paint dries involves the solvent evaporating and the binder undergoing oxidative cross-linking, a process that begins when the binder is exposed to oxygen (this is why a thin skin forms across the top of paint stored in cans). Cross linking is the process of bonding one polymer chain to another; this is the reason for solid sheet forming as paint dried. If it didn't undergo cross linking it would just dry into the plastic powder that was used as a component during the manufacturing process. Oxidative cross linking results in a higher molecular weight plastic than the initial powder, and can be a 1000-1500 [32]. The time associated with vinyl resin painting is about a day for applying and curing and cost was about five times less expensive than powder coating.

Epoxy paint undergoes a similar polymerization and curing process. Toluene, a solvent used in epoxy paints, evaporates a little slower than the alcohol based solvent used in the vinyl resin paint. The main difference between epoxy paint and vinyl paint is the process in which the paints cure. Epoxy normally polymerizes and cures by way of a 
chemical reaction between a resin and a hardener, mixing the two parts results in a hard plastic after the solvent that keeps them malleable slowly evaporates. Epoxy resin based paint is generally placed into two paint cans because otherwise it would not be a spreadable paint. The epoxy based paint that was used in the project was single can containing the resin, hardener, and solvent. In this case the hardener stayed inert until it was activated by the use of ultraviolet light, allowing the paint to remain fluid in the can. Once the paint is applied the hardener is activated initiating polymerization and cross linking. This process took multiple days and the result was paint with higher molecular weight chains (4000-6500) as the curing was much more extensive than the curing on the vinyl paint. The time associated with epoxy resin painting is a week as the curing process takes this long in order to provide the best protection; epoxy resin paint cost $1 / 3^{\text {rd }}$ the cost of powder coating.

The powder coating was an entirely different process. Powder coating curing takes place in an oven where the polyester and epoxy plastics are melted, resulting in the mixture flowing across the materials surface, the plastic then cross linking due to the elevated temperature for the extended time. There is no solvent in powder coating, making it a cleaner, more environmentally friendly process than the others. The result of powder coating is a melted plastic sheet with a molecular weight that depends on the weight percent of the plastics involved, the range used in this test was anywhere from 2000-3500. The specific molecular weight for the powder coating used in my testing was variable due to the composition being different for different thicknesses of coating. The weight percents of the plastics used in each thickness are described in table VII. 


\section{Table VII. Plastic Composition in Various Powder Coating Thicknesses}

\begin{tabular}{|l|r|r|r|}
\cline { 2 - 4 } \multicolumn{1}{c|}{} & \multicolumn{1}{c|}{$0.5 \mathrm{~mm}$} & \multicolumn{1}{c|}{$1 \mathrm{~mm}$} & $1.5 \mathrm{~mm}$ \\
\hline Polyester & 55 & 48 & 35 \\
\hline Epoxy & 45 & 52 & 65 \\
\hline
\end{tabular}

The time associated with powder coating is 3-5 days which includes media treatment, priming, coating, cooking, and curing. The major problem with powder coating is that it can only be applied effectively once; repairing powder coating by reheating can result in degradation of the coating. The cost of powder coating was marginal at 40 dollars for 30 test coupons; the bike system cost another 25 dollars. The estimate for the van's battery exchange system to get coated was between 850-1200 dollars.

\subsubsection{Corrosion Testing}

The salt spray method of extended environmental testing used in this study is capable of reliably producing samples that have been exposed in an even matter with the use and proper monitoring of the test conditions. The condition data in appendix A shows that there was minimal change in the actual conditions over the course of the test, meaning the corrosion test can be considered meaningful because the corrosion depth was not a factor of altered corrosion conditions. SAE test J2334 relies on altering the conditions of the corrosion environment and is said to better replicate the conditions of a lifelike environment. This test was not discovered until partway through the corrosion testing cycle, therefore a change was not made to the SAE test. The SAE test was far more in depth and required constant measuring of the samples after 20 cycles with each 
cycle taking a day to complete. While this may have resulted in a further corroded sample the corrosion method used was reliable enough for the testing required for this project.

When doing the corrosion testing on the samples I relied on the machinery to give me readouts on the status of the different experimental factors such as the specific gravity, temperature, etc. These values were to be held constant during the duration of the test and there was no method of calibrating the system being used. A factory calibration of the salt spray chamber was what I had to utilize for this test. Recalibration of the system would have been preferred in order to receive the most reliable results.

Corrosion depth is important to understand when using analytical techniques that can affect the surface corrosion of the test samples. The main tool used in the measurements and analysis of the corroded samples was metallographic analysis with an optical microscope, a non destructive test that doesn't affect the samples properties in any way. Microscopy of the samples involved analyzing the effect of the salt spray test on the coating by determining the average corrosion depth of the sample. Results of the microscopic analysis showed that the type of coating has a significant effect on the corrosion depth of the samples. The same can be said for the thickness of the vinyl resin and epoxy resin based paints. If a sample had, for example, a deep corrosion depth, it would be reasonable to expect the coating was vinyl resin based or a thin epoxy resin based coating. 


\subsubsection{Effect of Coating on Corrosion}

After observing the results of the salt spray test some justification is necessary to fully comprehend what occurred. The vinyl resin paint did not hold up to the corrosion test because the curing process only produced low molecular weight polymer chains, this is common with oxidative cross linking [33]. The short length of the chain meant there was more susceptibility to the coating forming micro cracks where oxygen and water could penetrate the coating. After a 2400 hour test minimal vinyl resin paint remained on any test samples.

Epoxy paint maintained its ability to prevent corrosion when the overall coating thickness was $1.0 \mathrm{~mm}$ or higher. The epoxy paint relied on UV light to cure and resulted in long molecular chain lengths, meaning the epoxy paint experienced extensive cross linking making the surface less susceptible to forming cracks, prohibiting oxygen and water from coming into contact with the steel sample. The issue with relying on UV light to activate the hardener is that you may get areas where the curing is uneven either due to light not getting onto the material or micro particles being present and preventing the curing process from occurring. This would allow cracks to form due to lack of polymerization of the material. There was significant bubbling in some of the $0.5 \mathrm{~mm}$ samples, meaning the thickness of the coating or the extent of curing was not enough to prevent some cracks from forming. Coatings over $0.5 \mathrm{~mm}$ would have to be used in order to fully prevent corrosion from occurring.

Powder coating fully protected the samples at the tested thicknesses because the uniformity of curing relied on heat that the samples experienced for an extended period of 
time. The use of heat means that anything on the surface of the sample would not matter as the heat would penetrate the sample from all sides making surface particles insignificant, unlike UV light. Having a completely coated surface meant that there were no cracks, eliminating the possibility of corrosion. The only corrosion that occurred was where the samples were strung from a wire during the coating and curing process; this area was unprotected before the testing began.

\subsection{Delamination Analysis}

Delamination of the paint occurred during corrosion testing, not during delamination testing. The purpose of using compressed air was to remove the material that was delaminated from the surface of the metal sample and not to attempt to delaminate the coating that was still attached to the metal. This was difficult to do because some of the delamination that occurred on the test coupons was due to bubbling underneath the surface of the coating. For the sake of consistency, the bubbled areas were not measured when measuring the delamination surface area of the test samples.

The main tool used for the measurement of the surface delamination was a digital micrometer; the areas were measured by hand then calculated. If the area of delamination was oddly shaped then some estimation occurred. This method of measurement did not alter the sample in any way or induce further coating delamination. An ASTM standard could not be found for delamination testing therefore a method described in a patent for coating nitinol films was used. A computer scanner would have been a better method of obtaining more accurate values for the surface area but that method was thought of after measurements had been made and the data analyzed. 
The results of the delamination testing found a statistical difference between the tested factors. The reason for this is similar to that of the corrosion tests. The vinyl resin coated samples, having a low molecular chain weight because of minimal chain linking, were more susceptible to corrosion. Any corrosion that forms beneath a coating can usually expand and spread out due to the accessibility to air from the crack where the corrosion initiated. This is why all of the samples lost almost all of their paint, if not all after the delamination test.

The epoxy resin paint, with a higher molecular weight, was not as susceptible to corrosion. The only samples that exhibited bubbling under the surface of the coating were the samples with a $0.5 \mathrm{~mm}$ thick coating. The surface area of the bubbling was substantial but no more than $10 \%$ of the surface area on the side of the sample being measured.

The powder coated samples had a lower molecular weight than epoxy because they were mixed with polyester, a polymer that exhibits $18-25 \%$ the molecular weight of epoxy. The key factor that separates powder coating from the other coating types is that the coating was melted onto the samples and extensive cross linking took place. Again, this doesn't allow corrosion to occur therefore no delamination was noticed except at the location where the wire was on the samples during the curing process.

\subsection{Deformation Analysis Discussion}

Deforming the samples with a micro hardness machine may not seem to have much use if you think about it but it illustrates the deformability of the different coatings at conditions that meet or exceed fast moving sharp projectiles. Indenting a small 
diamond shape into the surface may give you an indication of the hardness of the coating but it also pushes the coating material outward around the edges of the diamond, seen in figure 37. This deformation distance and the visible characteristics of the deformation itself are what make this test worthwhile.

The deformation distance measured the distance from the center of the diamond to the outermost portion of the resulting plastic deformation that occurred. This value represents the ability of the material to plastically deform; something that is necessary to ensure a coating adheres to a material when impacted by an object.

The visible characteristics of deformation were an important factor in the choice of the coating, even though it would have been difficult to quantify them. In particular I was looking to see if the coating of the material folded or cracked when indented, this would imply the material is too hard for use in this system. Too smooth of an area would imply that the material can be peeled off easily. A smoother area around the deformation with minimal variations in surface topography would be ideal as this would indicate a coating with high toughness, a desired property for protecting the battery systems.

Due to the ability of the $1 \mathrm{~mm}$ thick coatings to protect the samples it was the only thickness of coating tested during this test. Vinyl resin paint was by far the softest of the materials tested and it is clear by the size of the diamond indentation at all weights. The deformation distance of vinyl resin paint was high at each of these three weights, this means that again the polymer chain length was short enough to allow for lots of deformation without visual defects. The epoxy resin paint had the shortest of the deformation lengths, indicating that it was the hardest material tested. There were some 
folds and cracking that formed in the deformed region; this would not be an ideal choice because of its inability to resist impacts that would leave the system at risk for corrosion.

The powder coating had a deformation length that was almost in the middle of the epoxy and the vinyl paints. The visible deformation area had the formation of some small consistent folding, nothing large like epoxy, meaning that the molecular chains were long enough to prevent most of the damage but made of soft enough polymers to deform evenly along the deformation zone. Powder coating would be the ideal choice for deformation resistance as its deformation distance was less than that of vinyl indicating it was harder but deformed evenly without generating major flaws that may lead to degraded system performance.

A stylus profilometer would be a better alternative as it would measure surface roughness and produce numerical values that could be used to generate a map of the surface as a method of quantitative surface geometry analysis.

\subsection{Rapid Battery Exchange - Van System}

After building the electric van exchange system I realized that it was a harder task than the design made it seem. I modeled the system countless times in Solidworks where there is very little that can go wrong when modeling the system, interactions between the components only indicate that it won't fit, you can reduce the size in 30 seconds and then try again. This is not the same case when actually building it and I knew this going into the manufacturing process, what I was not expecting was the number of alignment issues I would have. The problem with running modeling in Solidworks is that I wasn't taking 
into account misalignment issues and I assumed that everything would remain somewhat rigid. These assumptions I made caused havoc with not only the build process but the design as well. The system was also changed significantly from the design model in Solidworks; this meant that anything that occurred during testing was going to be something different than anything I ever modeled.

This unsuccessful test with the carrier system brought two very important details to my attention: that mechanical alignment is a bad idea for a $100 \mathrm{lb}$ carrier device (it is an even worse idea for a carrier with a $400 \mathrm{lb}$ battery in it), and that the batteries being utilized for the system were not the lithium iron phosphate batteries that were sold to us, they were in fact lithium polymer batteries in large format prismatic cells typically used for lithium iron phosphate.

After explaining what happened with the battery during testing the entire battery was replaced by Shenzhen Hong De Neng Technology Co. Ltd, the company that made the original batteries. The new batteries' shape was reconfigured to be tested with the system again, figure 40 . 


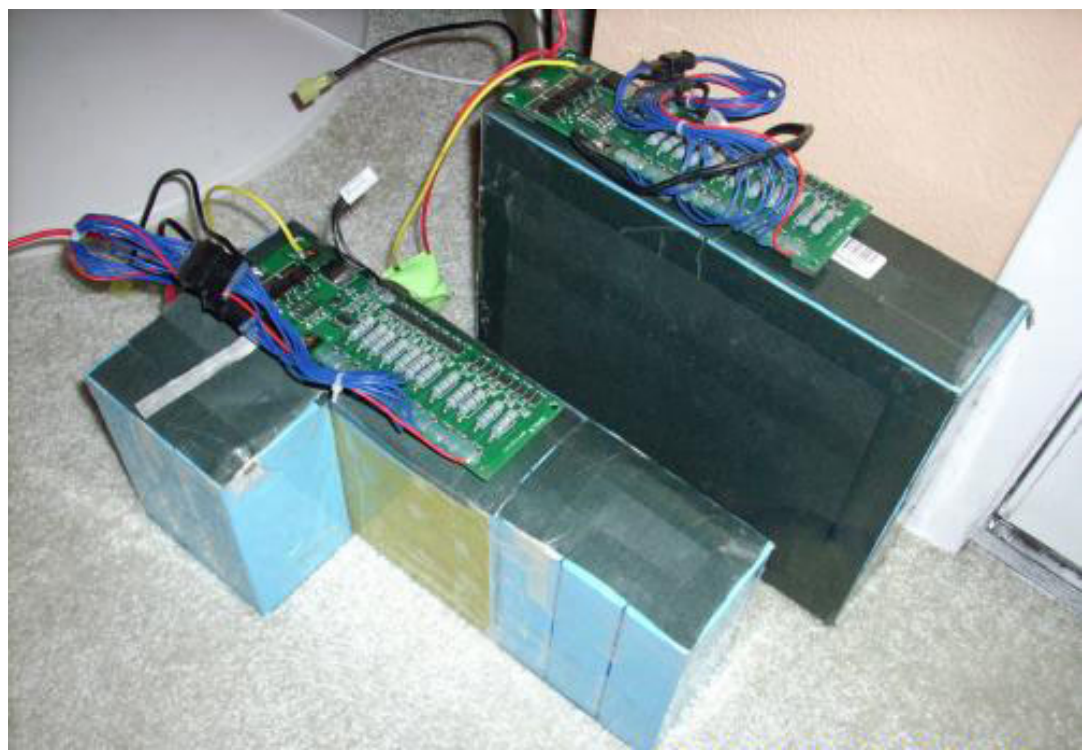

Figure 40. Shape played a large role in the damage done to the battery; the square battery on the right is the revised geometry.

The reconfiguration was to make the battery flatter than the shape the batteries initially arrived in; if this configuration was used during the initial testing then the battery may not have contacted the exchange system and the system may have been completed.

The largest component donated for this project was the $\mathrm{ABC}-150$ unit from Aerovironments Inc. It had one issue when we got it, it had no way to monitor the power being delivered to the battery, normally there is a computer port connecting the $\mathrm{ABC}-150$ to a program on the computer for monitoring, this prototype model was not built to support variable programming or computer monitoring it was designed for a single program that was loaded onto the memory, the old program was for lead acid batteries, which draw low current over long periods of time. This is why Aerovironments had to rewrite the program, the lithium batteries required a special charging cycle, $80-90 \%$ of the current was delivered in the first 25 minutes, and the remaining amperage was to be delivered over the course of five minutes. The program we received was for a $1 / 2$ capacity 
charge and would be changed to the higher rate charge when we asked. The important thing to remember about lithium iron phosphate batteries is that the charged voltage is very temper mental, if you attempt to put a high amount of electrical current into the battery when its $95 \%$ full it can cause the cells to swell, which can damage prismatic batteries' laminated arrangement. The batteries used in this system were laminated prismatic batteries; any delamination of the anodes to the separator sheets, figure 41 , would cause a cell failure or diminished capacity.

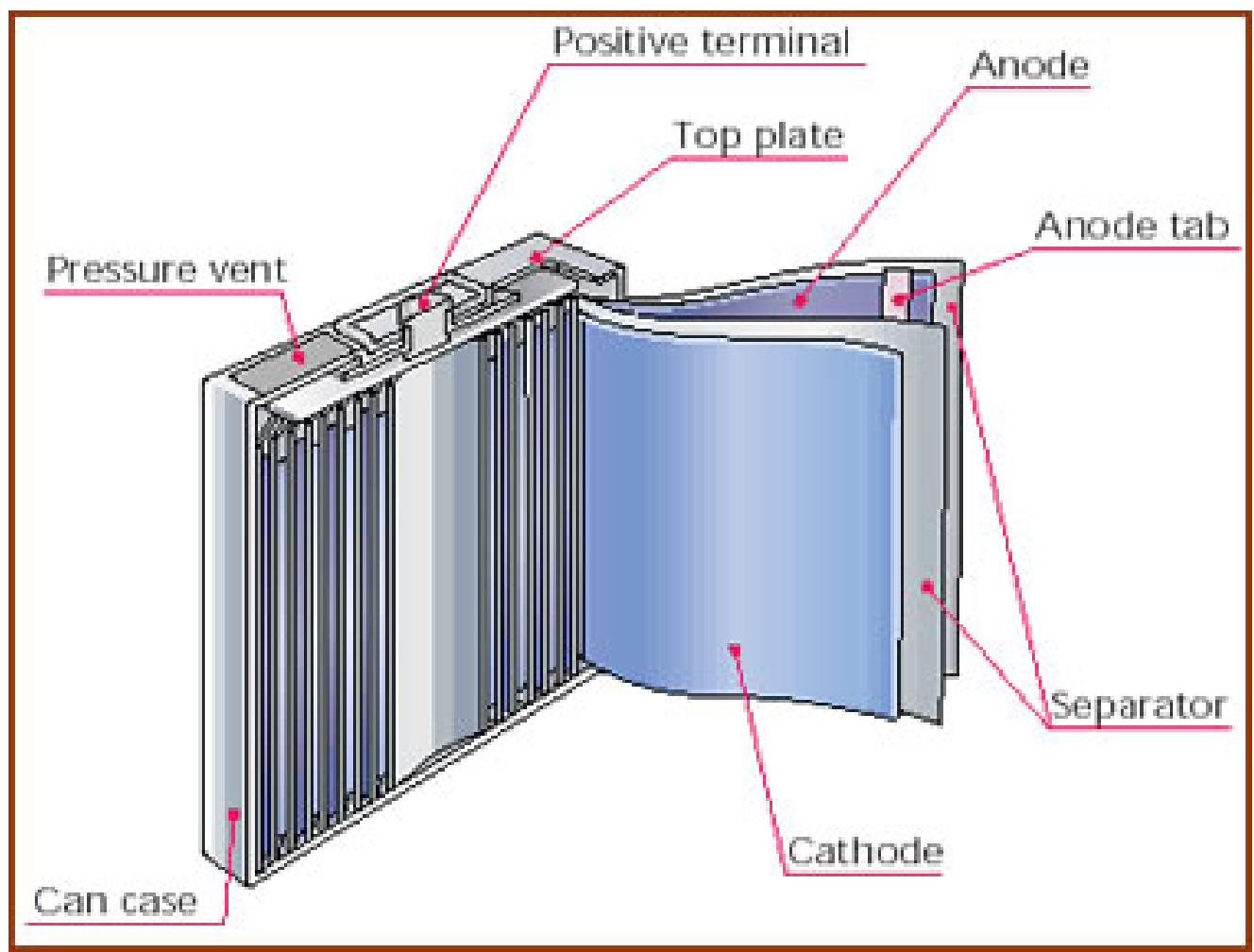

Figure 41. The typical structure of a lithium type cell consists of separators, anodes, and cathodes as the bulk of a battery's mass [34].

Cell failures are the bane of electric vehicles as they eliminate the power delivered from a string of cells, indicated by an S. A 5 cell pack in series is notated by $5 \mathrm{~S}$, this is the method in which voltage is increased in batteries, strings of cells at the desired 
voltage are also known as a pack. Multiple packs make up a completed battery and are indicated by a P. The battery that the van was using was using an $80 \mathrm{~S} 2 \mathrm{P}$ arrangement; this means there were two packs of 80 cells totaling 240 volts. If one of the 80 cells fails from a pack then that entire pack fails, the BMS will eliminate the current output from that string. There were two packs in this system meaning the system could have a pack fail and still operate just with less travel distance. Proper charging of these batteries is extremely important in order to ensure an effective service life.

Another problem that I ran into after testing the system was the fact that the batteries we ordered from china were 240 volts, the electric van took a 212 volt battery pack originally, and unfortunately the differences between the original battery and the lithium batteries were too severe. The original charged battery came in at 230VDC when tested on an open circuit, when under load they put out 212-215VDC. The batteries that I ordered for this project ended up with a 300VDC open circuit voltage and a 250VDC loaded voltage. The pack that was ordered was almost 40VDC over the original system. These batteries were ordered this way because they came in at a 50\% cost reduction when compared to ordering a $212 \mathrm{~V}$ battery. I later found out that this change in cost was associated with the fact that they just put $10-48 \mathrm{~V} 50 \mathrm{Ah}$ electric bicycle batteries together, a product that Shenzen Tech produces a lot of. They also made a new BMS to handle the larger voltage and amperage. During the collision with the system the BMS for the van was damaged as well, the BMS was repaired when the battery was sent back to the manufacturer. 
The major problem occurred when the testing of the battery with the Van's 1989 electric drive system. The controller made a few beeps indicating that something may be wrong with the system. The controller has an overcharge protection system built into it, [35] making the utilization of these batteries at this voltage impossible. I attempted to remove cells from the battery to drop the voltage but the battery management system wasn't allowing the system to function at that point.

At completing this minor system testing I realized that major modifications had to be made to the system in order to make it operate in a functional and safe manner. Being that this was the end of my available time for working on building the system I continued on with coating analysis and looked at exploring other options for the van and a rapid battery exchange system. During my corrosion analysis I redeveloped the idea to work with electric bikes or rapid charging because by this time I found that rapid charging technology had finally caught up to the needs of this system.

\subsection{Rapid Battery Exchange - Electric Bike System.}

Understanding that the electric van system probably wouldn't be able to work in the allotted time frame is what pushed me to develop the idea for the system being implemented on an electric bike. While it was initially formulated as a method of showing proof of concept for the system it quickly developed into a better solution for student transportation than the electric van's system.

The system for the bike relied on electrical connections with small surface areas for the battery that were sprung steel connecting with aluminum, one soft and one hard 
material. The result was that the surface area of the contact relied on the position of the battery on the rack, due to aluminums ability to deform. There was a millimeter of movement on the rack and this distance was the difference between the bike handling 50 amps of power and 1 amp of power. The resistance build up was so great that the wires powering the system began to heat up and eventually the heat was great enough to melt the plastic in contact with the wires on the battery; the plastic completely melted and began filling the wires. As mentioned the wires had to be modified by soldering the wires into a small aluminum spacer that the spring steel contacts attached to it, figure 42 .

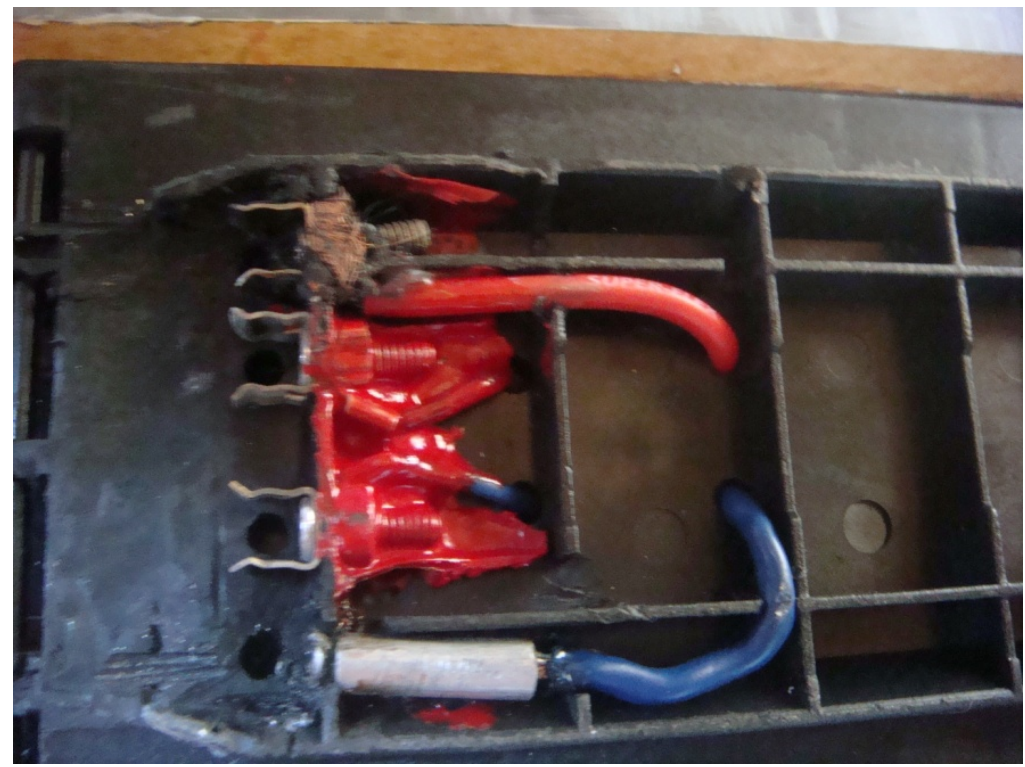

Figure 42. The connector portion of the battery showing the difference from the old attachment style (red wire) and the new attachment style (blue wire).

A solution that I came up with for ensuring the low resistance of the connection was to use a conductive grease, being that I was having a problem with the bike and that I needed it fixed I looked into a conductive grease. Most stores carry dielectric grease which is non conductive so I developed a conductive grease with the use of powdered graphite and a high quality automotive and household grease. The grease made it possible 
for the battery to have the millimeter of play and continue to power the bicycle. Upon further research I realized that graphite grease is a commercially made product to ensure electrical contacts remain connected; however this would have done little good as it would have had to be shipped to me and I needed to fix the bike in a shorter time span as it was my means of getting to school efficiently.

Yet another problem associated with the bike was the power delivery from the battery to the power switch. The original switch for the system was a 120VAC 20A switch; the maximum power that this switch could take was 2400 Watts. The problem was that I was running a DC battery at $48 \mathrm{~V}$ with more amperage than a $120 \mathrm{~V}$ AC line. After realizing that the contacts are not rated for 50 amps I obtained a battery terminator switch that provided me with a 2000A current capacity. This switch also implemented an extra security measure of requiring a key to operate.

As mentioned before, in order to obtain a battery for the electric bike I sacrificed a battery from the electric van; while it was not what I would have liked to do I could not justify the cost of a smaller battery being three times as expensive per unit of energy. Two lithium packs rated at 48V 25 ah were made from the cells in the large pack.

It was mentioned that the battery had a high center of gravity, the original battery design was to place the batteries lower on the bike but the bike was lacking the necessary mounting points for proper installation of a system like this.

When attempting to use the BMS that I built the bike would shut off if any power was delivered to the motor. It turned out that the BMS was intended to supply 15 amps of 
current continuously, the controller I had on the bike delivered 50 amps continuously, meaning it overdrew the BMS every time I twisted the throttle potentiometer. I ended up bypassing the BMS on the electric bike by soldering a separate ground wire to the negative port on the battery. The MOSFETS on the BMS have since been replaced to 100 amp capacity and the BMS is currently being used in place of the bypass wire. 


\section{CHAPTER SEVEN}

\section{CONCLUSIONS}

Protective coatings have a significant effect on the performance characteristics of rapid battery exchange systems that are intended to remain exposed to the environment. This study observed the properties of different coatings that would be applied to a rapid battery exchange system when exposed to a corrosive environment, a constant delamination force, and high pressure impacts that may occur during system use. This study also investigated the production and feasibility of implementing rapid battery exchange systems for automobiles and pedal assist electric bicycles.

1. The salt spray test used in this study indicated that samples with thicker, higher molecular weight coatings were less susceptible to corrosion. Results suggest that an epoxy coating samples with at least $1 \mathrm{~mm}$ thickness or higher and powder coating with a thickness above $0.5 \mathrm{~mm}$ would provide optimal corrosion prevention for the specified battery exchange systems. While the results may not have been easily predictable they are consistent and reproducible.

2. Ultrasonic testing is an unreliable method of obtaining a consistent reading of corrosion depth in corroded samples.

3. Delamination testing indicated that samples with consistent molecular structure were the least susceptible to delamination. Results suggest that powder coating of any thickness tested would not delaminate; epoxy with 
thicknesses $1 \mathrm{~mm}$ thick and above would also have minimal or no delamination.

4. Powder coating and epoxy coatings above $1 \mathrm{~mm}$ thick were not susceptible to exfoliation corrosion while $0.5 \mathrm{~mm}$ thick epoxy and all thicknesses of vinyl resin were.

5. Impact testing indicated that samples with lower molecular weight would exhibit the most deformation distance. Results suggest that vinyl resin paint with a $1 \mathrm{~mm}$ thickness would produce largest deformation distance.

6. Powder coating exhibited the most optimal visual deformation with the presence of small folds in the material, indicating that it is tough enough to withstand deformation however soft enough that it won't generate a flaw that would impede system performance.

7. Powder coating would be the best coating to protect rapid battery exchange system from the environment. However due to the inability to re-apply powder coating and the cost associated with reapplication a combination of powder coating and epoxy resin paint must be utilized. Epoxy resin paint should only be used when the coating is compromised.

8. Rapid battery exchange systems are a form of energy replacement for electric vehicles that could work if complex aiming mechanisms are used to aid in the exchange process in order to eliminate any safety issue.

9. Rapid battery exchange systems would be better placed in commuter pedal assist electric bicycle systems as the mode of transportation is more suited to each person's needs. 
10. Pedal assist electric bicycle systems would allow the use of constantly available transportation to school and around town while severely decreasing the users annual $\mathrm{CO} 2$ output.

While this study only resulted in one working battery exchange system it did find that rapid battery exchange systems were entirely suitable for electric vehicles. With proper modification, more funds, and more time the van system would have been completed and then coated by using powder coating. Not coating the implemented system would have resulted in the rapid corrosion of the system, leaving vehicles utilizing the system stranded. Following the completion of this project the electric bicycles coated battery sustained irreparable damage to the powder coating on the battery box. Epoxy paint was utilized in the repair of the damaged areas and has been effective in preventing corrosion thus far. 


\section{CHAPTER EIGHT}

\section{RECCOMENDATIONS FOR FUTURE WORK}

The methods of coating the rapid battery exchange system were convenient, inexpensive, and provided good resistance to environmental damage. Due to cold rolled steels ability to corrode when exposed to air or water, an alternative material with better corrosion resistant properties, such as aluminum or stainless steel might be used for the system to reduce the chance of damage occurring if a protective coating failed. These materials were not used initially due to their high $\mathrm{CO} 2$ footprint but the $\mathrm{CO} 2$ savings I obtained from choosing a cold rolled carbon steel may be eliminated over the lifetime of the unit for repairs to the system (epoxy paints emit CFC's as they are in aerosol form, powder coating requires a lot of electricity for application and thermosetting). The coating tests would not need to be redone as all of the corrosion preventative methods are applicable to all metals through the use of material specific primers.

The method of exchanging the battery would be modified to incorporate an electric aiming device that is powered off of a solar system with a small lead acid battery bank; this would eliminate any future collisions of the system. Implementing this work may prove trivial as Renault, a French car manufacturer, has put 1.5 billion dollars into rapid battery exchange systems over the last year and a half. Not only do they have a working system that uses electronic aiming, they have adapted nine of their cars to work with the system. Their system is currently being implemented into Hawaii, Australia, Israel, and the San Francisco bay area. A system could be implemented into San Luis 
Obispo and other transportation carpool models could be implemented to provide efficient transportation to students and teachers that reside out of town.

The electric bike system could utilize a smaller battery that would be positioned lower on the rack, effectively lowering the center of gravity of the bike, making it more suitable for all students as the rack would still be functional for carrying school materials. Schwinn recently released a new line of pedal assist electric bicycles that actually utilize rapid battery exchange in a similar way to the system I designed and built.

A large scale pedal assist electric bike system could be built on campus by collaborating with Schwinn in regards to construction and engineering specific parts of the system. I began the process of determining costs associated with development of battery racks or plug in bicycle racks that cal poly could use to displace people who commute by car. Implementing this type of a system would significantly reduce the $\mathrm{CO} 2$ emissions in San Luis Obispo if implemented properly and would act as an excellent example of engineering for sustainability. 


\section{REFERENCES}

1. Walker, Kenly . "Hybrid Sales On Track To Set U.S. Record - CBS News." Breaking News Headlines: Business, Entertainment \& World News - CBS News. 23 May 2009

2. Clayton, Deb. "The History of Genesee, MI, Ch. 1, Steam Transportation on Land and Water." USGenNet. The First and Only Nonprofit Historical-Genealogical Web Hosting Service on the Internet! History, Historical, Family History, Genealogy, Genealogical. Family Values. History and Genealogy. Genealogy and History. ISP. 14 Mar. 2009

3. BTS I Table 1-11: Number of U.S. Aircraft, Vehicles, Vessels, and Other Conveyances." RITA I Bureau of Transportation Statistics (BTS). 18 Sep. 2008

4. Climate Change - Climate Economics I U.S. EPA." U.S. Environmental Protection Agency. 23 Oct. 2008

5. DOE - Fossil Energy: Clean Coal \& Natural Gas Power Systems." DOE - Fossil Energy: Office of Fossil Energy Home Page. 23 May 2009

6. Goettemoeller, Jeffrey; Adrian Goettemoeller (2007), Sustainable Ethanol: Biofuels, Biorefineries, Cellulosic Biomass, Flex-Fuel Vehicles, and Sustainable Farming for Energy Independence, Praire Oak Publishing, Maryville, Missouri, pp. 42, ISBN 978-0-9786293-0-4

7. American Council for an Energy-Efficient Economy, "America's Greenest Car of 2008." 23 May 2009

8. Gas Pipeline. "U.S. Natural Gas Prices." United States Department of Energy. 23 May 2009

9. State. "Electric Power Monthly - Average Retail Price of Electricity to Ultimate Customers by End-Use Sector, by State." Energy Information Administration EIA - Official Energy Statistics from the U.S. Government. 28 May 2009

10. Eberhard, Martin. Marc Tarpenning "The 21st Century Electric Car." (2006)

11. Christense, John, Venkat Srinivasan, and John Newman. "Optimization of Lithium Titanate Electrodes for High-Power Cells." Journal of Electrochemistry 153.3 (2006): 560-565.

12. Sherwood, Larry; Les Nelson, Fred Morse, Jeff Wolfe, Chris O’Brien (2006). "US Solar Industry - Year In Review - 2006". Solar Energy Industries Association (SEIA) \& The Prometheus Institute for Sustainable Development. Retrieved on 2008-10-20

13. Muljadi, E.; Pasupulati, S.; Ellis, A.; Kosterov, D. "Method of equivalencing for a large wind power plant with multiple turbine representation." Conversion and Delivery of Electrical Energy in the 21st Century 1.1 (2008): 1-9.

14. L. Hirsch, Robert, Roger Bezdek, Robert Wendling . "PEAKING OF WORLD OIL PRODUCTION: IMPACTS, MITIGATION, \& RISK MANAGEMENT.". 1 Feb. 2005: 1-91.

15. Major uses of benzene, based on information from U.S. International Trade Commission Publication 3590 
16. "Kyoto Protocol: Status of Ratification". United Nations Framework Convention on Climate Change. 2009-01-14. Retrieved on 2009-05-06

17. EIA - Emissions of Greenhouse Gases in the U.S. 2007-Carbon Dioxide Emissions." Energy Information Administration - EIA - Official Energy Statistics from the U.S. Government. 20 June 2009

18. Bouwman, Mirjan E An environmental assessment of the bicycle and other transport systems, University of Groningen, Netherlands, 2000

19. Semmens, John. "Gas about public transit.(COMMENTARY)."Washington Times, The 11 Jan. 2008: 1-3.

20. Research and Innovating Technology Administration, Bureau of Transportation Statistics, "Table 3-14: Average Cost of Owning and Operating an Automobile"

21. "Do and don't battery table."Welcome to Battery University. 20 June 2009

22. "GridWorks: Overview of the Electric Grid." Energetics Meetings and Events. 21 June 2009

23. "Trolley Buses." San Francisco Municipal Transportation Agency (SFMTA, Muni, DPT). 20 June 2009

24. Forklifts: Operational and Environmental Impacts. Solid and hazardous waste education center. 2006. 20 june 2009

25. "Mercedes Says They Tried EV Battery Swapping and It Didn’t Work I Car industry." The Green Optimistic - alternative energy news, environmental awareness. 23 June 2009

26. "Prismatic type | Lithium Ion Batteries I Batteries, Power supplies | Panasonic Industrial Solutions Global." Panasonic Industrial Solutions Global. 23 June 2009

27. Battery Charging Systems : ENERGY STAR." Home : ENERGY STAR. 23 June 2009

28. AeroVironment, Inc.: EV Test Systems: ABC-150 Detail."AeroVironment, Inc. : Unmanned Aircraft Systems, Clean Energy Technology, Electric Vehicle Charging Systems, Electric Vehicle Test Systems. 23 Mar. 2009

29. Mcmaster carr, Linear ball bearings, Mcmaster Carr website. 30 Apr 2009

30. Topeak MTX rack systems. Topeak website. 20 June 2009

31. "ASTM B117." Salt Spray Chambers, Salt Fog Chambers and Cyclic Corrosion Test Chambers. 20 June 2009

32. Odian, George. Principles of Polymerization. New York: Wiley-Interscience, 2004.

33. Crosslinking Reagents Technical Handbook, Thermo Scientific pierce. 2008

34. "Product $>$ Products list $>$ Lithium Ion Rechargeable Battery $>$ Knowledge of battery $>$ Structure of lithium ion rechargeable battery."NEC-TOKIN WEB SITE. 23 Apr. 2009

35. DeLuca, W.H.; Tummillo, A.F.; Kulaga, J.E.; Webster, C.E.; Gillis, K.R.; Hogrefe, R.L., .. "Performance Evaluation of Advanced Battery Technologies for Electric Vehicle Applications." Energy Conversion Engineering Conference 3.1217 (1990): 314-319. 


\section{APPENDIX A}

\section{Salt Spray Test Conditions}

All samples underwent the same corrosion test conditions though three groups of samples were made to show pseudo replication.

Table A1. Salt Spray Test Conditions for 100 Day Test

\begin{tabular}{|c|c|c|c|c|}
\hline Day & $\begin{array}{l}\text { Temperatures } \\
\text { in exposed } \\
\text { zones }\end{array}$ & 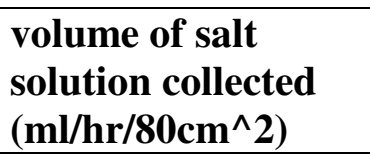 & $\begin{array}{l}\text { specific gravity of } \\
\text { solution }\end{array}$ & $\mathbf{p H}$ \\
\hline 1 & 95.1 & 1.02 & 1.029 & 6.8 \\
\hline 2 & 95.1 & 1.02 & 1.031 & 6.8 \\
\hline 3 & 95.1 & 1.01 & 1.034 & 6.8 \\
\hline 4 & 95.1 & 1.02 & 1.033 & 6.8 \\
\hline 5 & 95 & 1.02 & 1.029 & 6.8 \\
\hline 6 & 95.1 & 1.02 & 1.03 & 6.9 \\
\hline 7 & 94.9 & 1.02 & 1.029 & 6.8 \\
\hline 8 & 95.1 & 1.03 & 1.031 & 6.8 \\
\hline 9 & 95.1 & 1.02 & 1.032 & 6.8 \\
\hline 10 & 95.1 & 1.02 & 1.032 & 6.8 \\
\hline 11 & 95.2 & 1.02 & 1.035 & 6.9 \\
\hline 12 & 95.1 & 1.03 & 1.033 & 6.9 \\
\hline 13 & 95.2 & 1.02 & 1.034 & 6.9 \\
\hline 14 & 95.2 & 1.01 & 1.036 & 6.9 \\
\hline 15 & 95.1 & 1.02 & 1.033 & 6.9 \\
\hline 16 & 95.1 & 1.02 & 1.032 & 6.9 \\
\hline 17 & 95.1 & 1.02 & 1.033 & 6.9 \\
\hline 18 & 95.1 & 1.03 & 1.034 & 7 \\
\hline 19 & 95 & 1.02 & 1.031 & 6.9 \\
\hline 20 & 95.1 & 1.02 & 1.033 & 6.9 \\
\hline 21 & 95.2 & 1.02 & 1.035 & 7 \\
\hline 22 & 95.2 & 1.02 & 1.029 & 7 \\
\hline 23 & 95 & 1.02 & 1.034 & 6.9 \\
\hline 24 & 95.1 & 1.02 & 1.033 & 7 \\
\hline 25 & 95.1 & 1.02 & 1.031 & 6.9 \\
\hline 26 & 95.1 & 1.03 & 1.033 & 7 \\
\hline 27 & 95.1 & 1.02 & 1.029 & 7 \\
\hline 28 & 95.2 & 1.02 & 1.031 & 7 \\
\hline 29 & 95.2 & 1.02 & 1.034 & 7 \\
\hline
\end{tabular}




\begin{tabular}{|c|c|c|c|c|}
\hline 30 & 95.3 & 1.02 & 1.029 & 6.9 \\
\hline 31 & 95.1 & 1.02 & 1.033 & 7 \\
\hline 32 & 95.1 & 1.02 & 1.035 & 7 \\
\hline 33 & 95.1 & 1.02 & 1.031 & 7 \\
\hline 34 & 95.1 & 1.02 & 1.029 & 7 \\
\hline 35 & 95.2 & 1.02 & 1.033 & 7 \\
\hline 36 & 95.3 & 1.03 & 1.033 & 7.1 \\
\hline 37 & 95.1 & 1.02 & 1.035 & 7.1 \\
\hline 38 & 95.1 & 1.02 & 1.034 & 7.1 \\
\hline 39 & 95.1 & 1.01 & 1.029 & 7.1 \\
\hline 40 & 95.2 & 1.02 & 1.033 & 7.2 \\
\hline 41 & 95.1 & 1.02 & 1.031 & 7.1 \\
\hline 42 & 95.1 & 1.03 & 1.032 & 6.5 \\
\hline 43 & 95.1 & 1.03 & 1.029 & 6.5 \\
\hline 44 & 95.1 & 1.02 & 1.034 & 6.5 \\
\hline 45 & 95 & 1.02 & 1.035 & 6.5 \\
\hline 46 & 95.1 & 1.02 & 1.033 & 6.5 \\
\hline 47 & 95.1 & 1.01 & 1.035 & 6.5 \\
\hline 48 & 95.1 & 1.02 & 1.031 & 6.5 \\
\hline 49 & 95.1 & 1.02 & 1.033 & 6.5 \\
\hline 50 & 95.1 & 1.01 & 1.034 & 6.5 \\
\hline 51 & 95 & 1.02 & 1.035 & 6.6 \\
\hline 52 & 95 & 1.03 & 1.029 & 6.5 \\
\hline 53 & 95 & 1.02 & 1.031 & 6.5 \\
\hline 54 & 95.2 & 1.02 & 1.032 & 6.6 \\
\hline 55 & 95 & 1.02 & 1.033 & 6.5 \\
\hline 56 & 95.1 & 1.03 & 1.034 & 6.5 \\
\hline 57 & 95.1 & 1.02 & 1.031 & 6.6 \\
\hline 58 & 95.1 & 1.02 & 1.035 & 6.6 \\
\hline 59 & 95.1 & 1.02 & 1.029 & 6.6 \\
\hline 60 & 95.1 & 1.02 & 1.031 & 6.6 \\
\hline 61 & 95.1 & 1.02 & 1.028 & 6.6 \\
\hline 62 & 95.1 & 1.02 & 1.029 & 6.6 \\
\hline 63 & 95.1 & 1.02 & 1.031 & 6.6 \\
\hline 64 & 95.3 & 1.02 & 1.033 & 6.6 \\
\hline 65 & 95.1 & 1.02 & 1.029 & 6.6 \\
\hline 66 & 95.1 & 1.04 & 1.03 & 6.6 \\
\hline 67 & 95.2 & 1.02 & 1.031 & 6.7 \\
\hline 68 & 95.2 & 1.02 & 1.033 & 6.7 \\
\hline 69 & 95.1 & 1.03 & 1.034 & 6.7 \\
\hline 70 & 95.1 & 1.02 & 1.035 & 6.7 \\
\hline
\end{tabular}




\begin{tabular}{|r|r|r|r|r|}
\hline 71 & 95.1 & 1.02 & 1.029 & 6.6 \\
\hline 72 & 95.1 & 1.04 & 1.031 & 6.7 \\
\hline 73 & 95.1 & 1.02 & 1.031 & 6.7 \\
\hline 74 & 95.1 & 1.03 & 1.033 & 6.7 \\
\hline 75 & 95.4 & 1.02 & 1.034 & 6.7 \\
\hline 76 & 95.1 & 1.02 & 1.032 & 6.7 \\
\hline 77 & 95.4 & 1.03 & 1.032 & 6.8 \\
\hline 78 & 95.1 & 1.02 & 1.031 & 6.9 \\
\hline 79 & 95.1 & 1.01 & 1.033 & 6.8 \\
\hline 80 & 95.1 & 1.02 & 1.035 & 6.8 \\
\hline 81 & 95.1 & 1.02 & 1.033 & 6.8 \\
\hline 82 & 95.1 & 1.02 & 1.031 & 6.8 \\
\hline 83 & 95.1 & 1.04 & 1.029 & 6.8 \\
\hline 84 & 94.9 & 1.02 & 1.034 & 6.8 \\
\hline 85 & 95.1 & 1.01 & 1.037 & 6.7 \\
\hline 86 & 95.1 & 1.02 & 1.039 & 6.8 \\
\hline 87 & 95.1 & 1.02 & 1.031 & 6.8 \\
\hline 88 & 95.1 & 1.03 & 1.034 & 6.8 \\
\hline 89 & 95 & 1.02 & 1.038 & 6.9 \\
\hline 90 & 95.1 & 1.04 & 1.031 & 6.9 \\
\hline 91 & 95.1 & 1.02 & 1.034 & 6.8 \\
\hline 92 & 95.1 & 1.03 & 1.038 & 6.9 \\
\hline 93 & 95 & 1.02 & 1.029 & 6.9 \\
\hline 94 & 95 & 1.02 & 1.031 & 6.9 \\
\hline 95 & 95.1 & 1.02 & 1.035 & 6.9 \\
\hline 96 & 95.1 & 1.01 & 1.033 & 6.9 \\
\hline 97 & 95.1 & 1.02 & 1.031 & 6.9 \\
\hline 98 & 95.1 & 1.02 & 1.035 & 6.9 \\
\hline 99 & 95.1 & 1.02 & 1.029 & 6.9 \\
\hline 100 & 95 & 1.01 & 1.034 & 7 \\
\hline & & & & \\
\hline
\end{tabular}




\section{APPENDIX B}

\section{Corrosion Data}

Table B1. Measured Corrosion Depth of Salt Spay Test Samples

\begin{tabular}{|c|c|c|c|c|}
\hline Sample \# & $\begin{array}{l}\text { Thickness } \\
\text { (mm) }\end{array}$ & $\begin{array}{l}\text { Corrosion } \\
\text { Depth Average } \\
\text { Vinyl Resin } \\
(\mathrm{mm})\end{array}$ & $\begin{array}{l}\text { Corrosion } \\
\text { Depth Average } \\
\text { Epoxy resin } \\
(\mathrm{mm})\end{array}$ & $\begin{array}{l}\text { Corrosion } \\
\text { Depth Average } \\
\text { Powder Coat } \\
(\mathrm{mm})\end{array}$ \\
\hline 1 & 0.5 & 0.89 & 0.2 & 0.05 \\
\hline 2 & 0.5 & 0.65 & 0.25 & 0.04 \\
\hline 3 & 0.5 & 0.57 & 0.2 & 0.05 \\
\hline 4 & 0.5 & 0.88 & 0.15 & 0.05 \\
\hline 5 & 0.5 & 0.76 & 0.19 & 0.05 \\
\hline 6 & 0.5 & 0.4 & 0.15 & 0.03 \\
\hline 7 & 0.5 & 1.1 & 0.21 & 0 \\
\hline 8 & 0.5 & 1.2 & 0.24 & 0 \\
\hline 9 & 0.5 & 1.2 & 0.23 & 0.02 \\
\hline 10 & 1 & 0.48 & 0.05 & 0 \\
\hline 11 & 1 & 0.64 & 0.04 & 0 \\
\hline 12 & 1 & 0.5 & 0.06 & 0.02 \\
\hline 13 & 1 & 0.6 & 0.06 & 0 \\
\hline 14 & 1 & 0.55 & 0.06 & 0 \\
\hline 15 & 1 & 0.52 & 0.25 & 0 \\
\hline 16 & 1 & 0.76 & 0.05 & 0.03 \\
\hline 17 & 1 & 0.66 & 0.02 & 0 \\
\hline 18 & 1 & 0.78 & 0.09 & 0 \\
\hline 19 & 1.5 & 0.4 & 0 & 0 \\
\hline 20 & 1.5 & 0.35 & 0 & 0 \\
\hline 21 & 1.5 & 0.4 & 0 & 0.02 \\
\hline 22 & 1.5 & 0.44 & 0 & 0 \\
\hline 23 & 1.5 & 0.42 & 0.05 & 0 \\
\hline 24 & 1.5 & 0.52 & 0 & 0 \\
\hline 25 & 1.5 & 0.34 & 0 & 0 \\
\hline 26 & 1.5 & 0.34 & 0 & 0 \\
\hline 27 & 1.5 & 0.34 & 0 & 0.02 \\
\hline
\end{tabular}




\section{APPENDIX C}

Corrosion Statistical Significance

\section{General Linear Model: Corrosion Depth versus Coating type, Thickness}

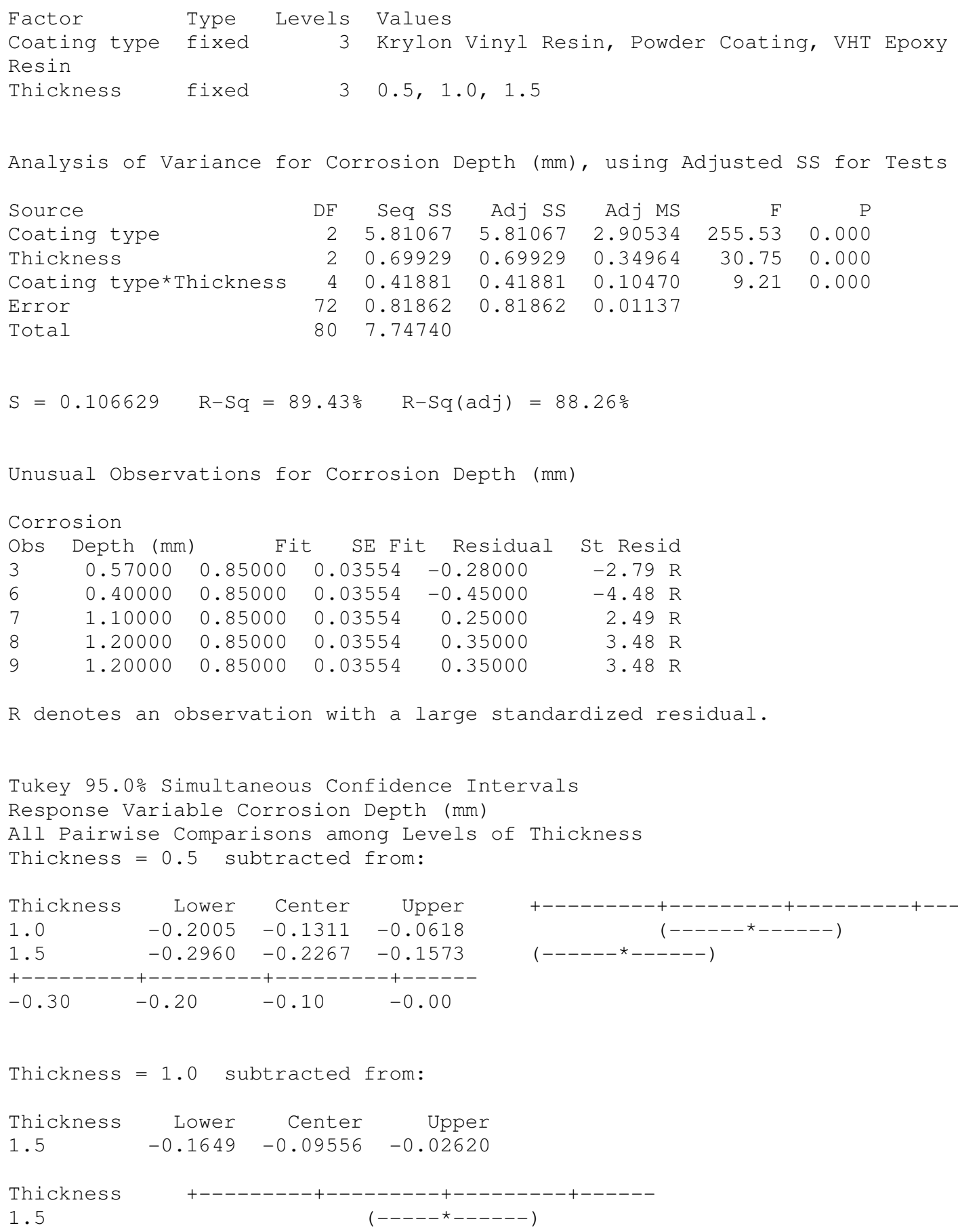




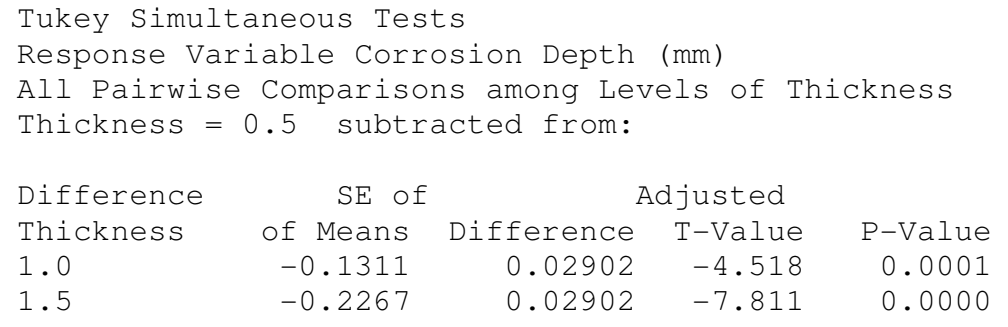




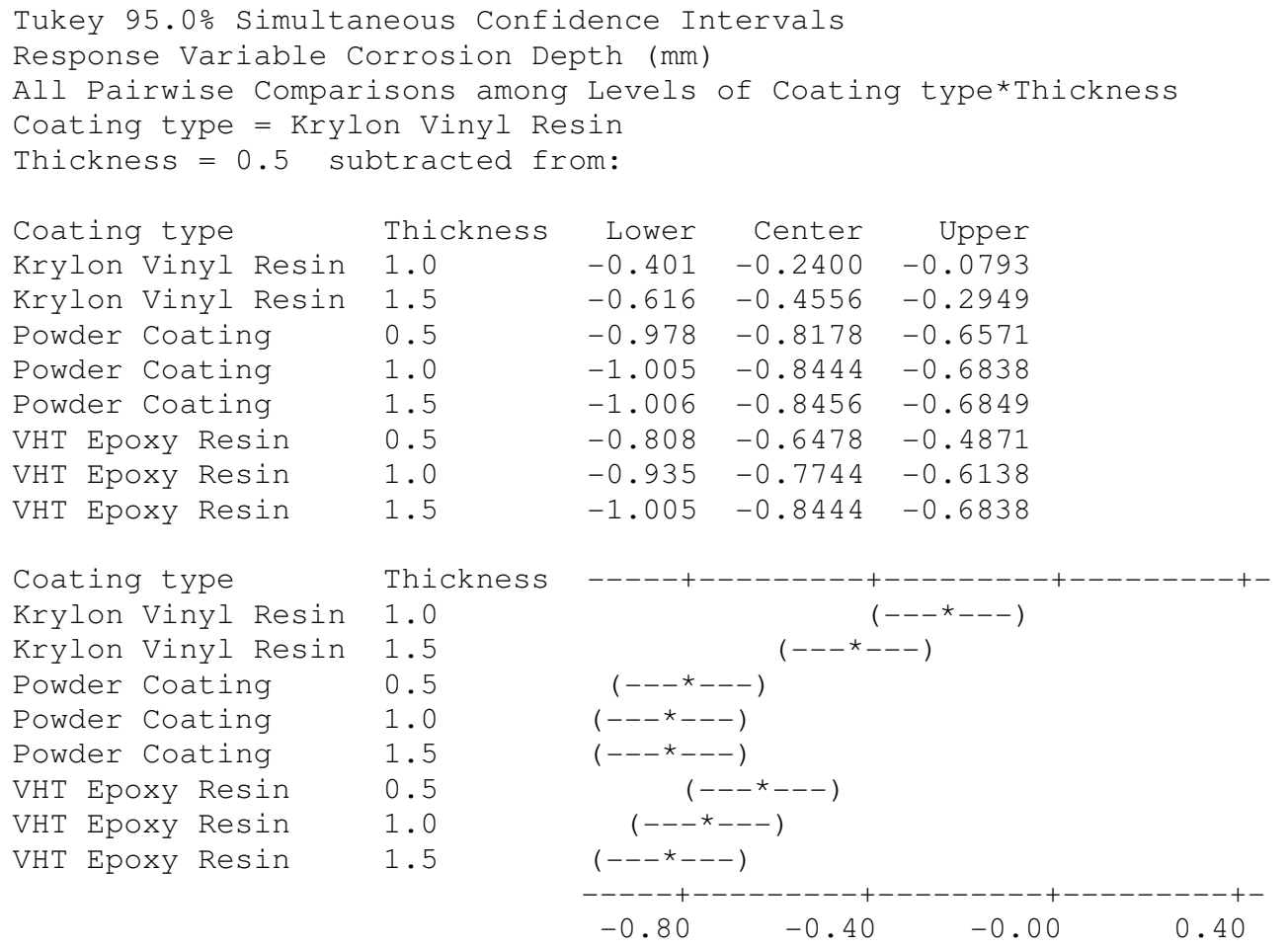

Coating type $=$ Krylon Vinyl Resin

Thickness $=1.0$ subtracted from:

\begin{tabular}{|c|c|c|c|c|}
\hline Coating type & Thickness & Lower & Center & Upper \\
\hline Krylon Vinyl Resin & 1.5 & -0.3762 & -0.2156 & -0.0549 \\
\hline Powder Coating & 0.5 & -0.7384 & -0.5778 & -0.4171 \\
\hline Powder Coating & 1.0 & -0.7651 & -0.6044 & -0.4438 \\
\hline Powder Coating & 1.5 & -0.7662 & -0.6056 & -0.4449 \\
\hline VHT Epoxy Resin & 0.5 & -0.5684 & -0.4078 & -0.2471 \\
\hline VHT Epoxy Resin & 1.0 & -0.6951 & -0.5344 & -0.3738 \\
\hline VHT Epoxy Resin & 1.5 & -0.7651 & -0.6044 & -0.4438 \\
\hline Coating type & Thickness & \multirow{2}{*}{\multicolumn{3}{|c|}{$\begin{array}{r}--------+--------\cdot \\
(---\star---)\end{array}$}} \\
\hline Krylon Vinyl Resin & 1.5 & & & \\
\hline Powder Coating & 0.5 & \multicolumn{3}{|c|}{$\left(---\star_{---}\right)$} \\
\hline Powder Coating & 1.0 & \multicolumn{3}{|c|}{$(---\star---)$} \\
\hline Powder Coating & 1.5 & \multicolumn{3}{|c|}{$(---*---)$} \\
\hline VHT Epoxy Resin & 0.5 & \multicolumn{3}{|c|}{$\left(---\star_{---}\right)$} \\
\hline VHT Epoxy Resin & 1.0 & \multicolumn{3}{|c|}{$(---\star---)$} \\
\hline VHT Epoxy Resin & 1.5 & \multicolumn{3}{|c|}{$(---\star---)$} \\
\hline & & \multicolumn{3}{|l|}{-0.80} \\
\hline
\end{tabular}

Coating type $=$ Krylon Vinyl Resin

Thickness $=1.5$ subtracted from:

$\begin{array}{llrrr}\text { Coating type } & \text { Thickness } & \text { Lower } & \text { Center } & \text { Upper } \\ \text { Powder Coating } & 0.5 & -0.5229 & -0.3622 & -0.2016 \\ \text { Powder Coating } & 1.0 & -0.5495 & -0.3889 & -0.2282 \\ \text { Powder Coating } & 1.5 & -0.5507 & -0.3900 & -0.2293 \\ \text { VHT Epoxy Resin } & 0.5 & -0.3529 & -0.1922 & -0.0316\end{array}$




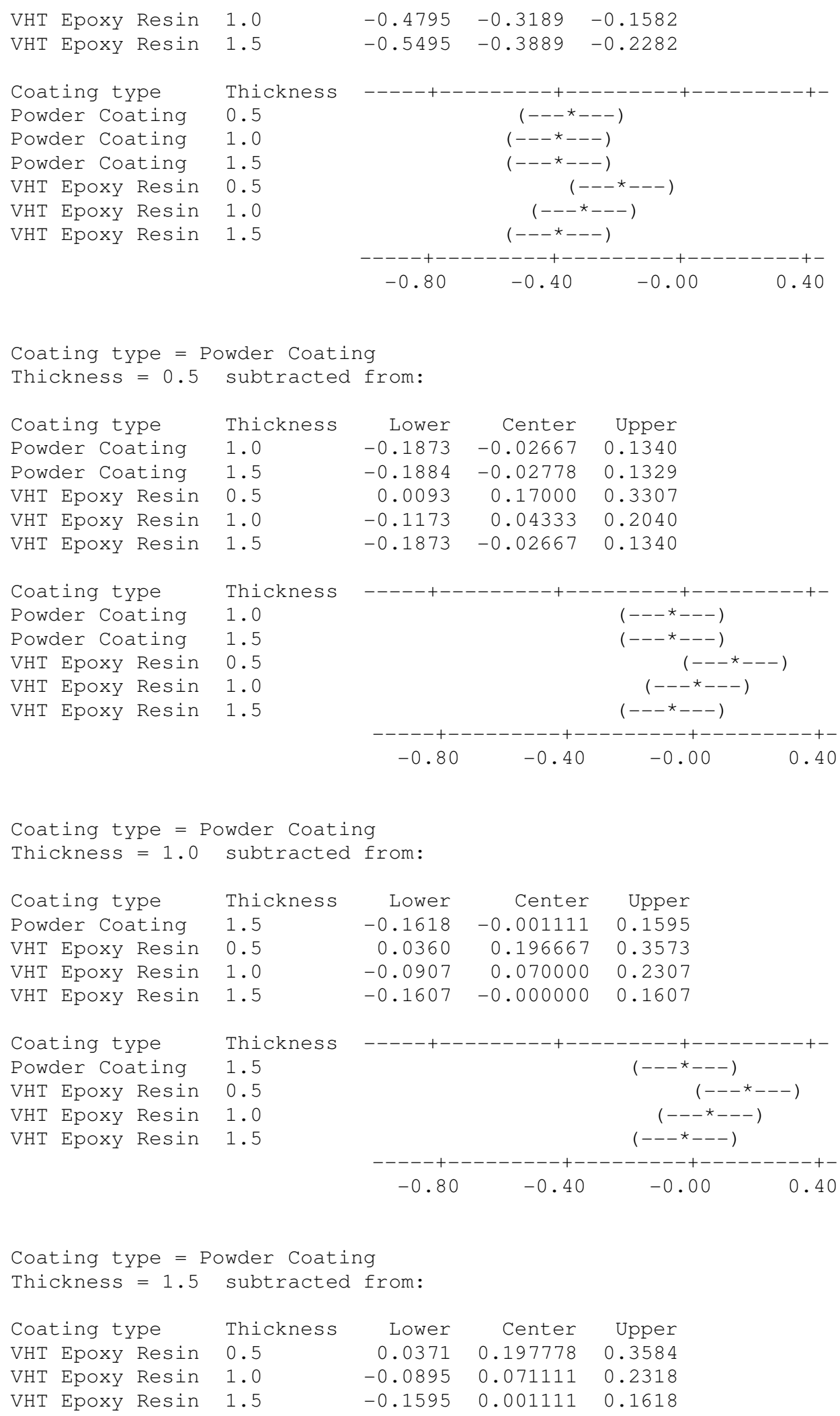




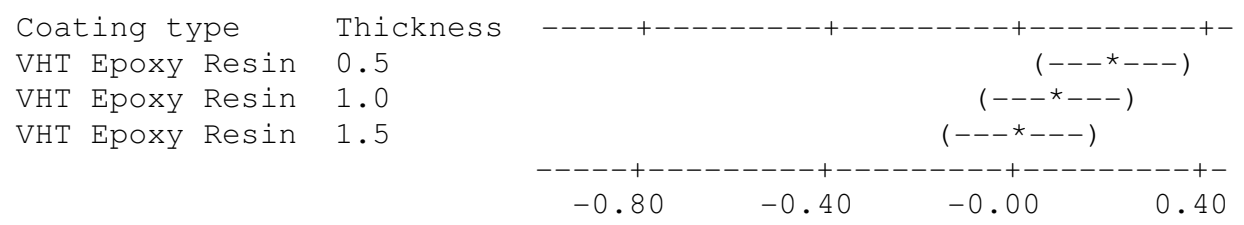

Coating type $=$ VHT Epoxy Resin

Thickness $=0.5$ subtracted from:

Coating type Thickness Lower Center Upper

$\begin{array}{lllll}\text { VHT Epoxy Resin } 1.0 & -0.2873 & -0.1267 & 0.03399\end{array}$

$\begin{array}{lllll}\text { VHT Epoxy Resin } 1.5 & -0.3573 & -0.1967 & -0.03601\end{array}$

Coating type Thickness

VHT Epoxy Resin 1.0

VHT Epoxy Resin 1.5

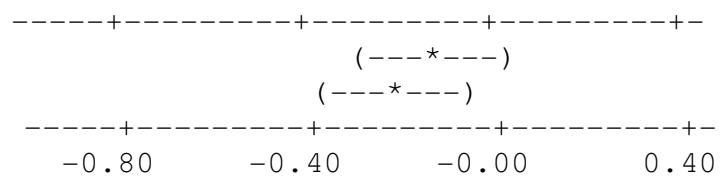

Coating type $=$ VHT Epoxy Resin

Thickness $=1.0$ subtracted from:

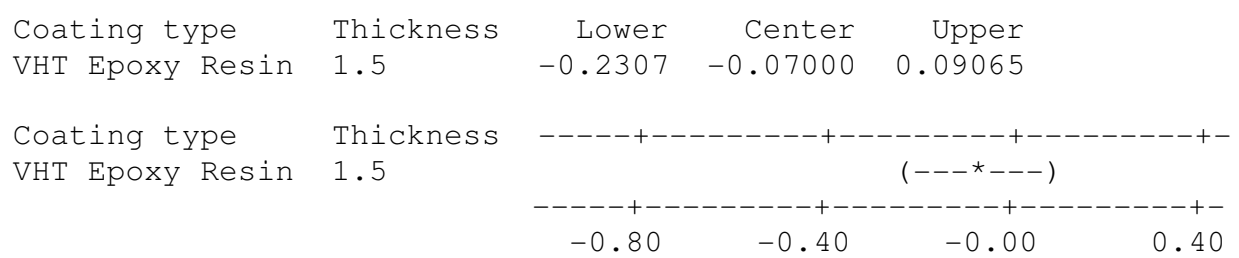

Tukey Simultaneous Tests

Response Variable Corrosion Depth (mm)

All Pairwise Comparisons among Levels of Coating type*Thickness

Coating type $=$ Krylon Vinyl Resin

Thickness $=0.5$ subtracted from:

\begin{tabular}{|c|c|c|c|c|c|}
\hline Difference & of & Adjusted & & & \\
\hline Coating type & Thickness & of Means & Difference & T-Value & P-Value \\
\hline Krylon Vinyl Resin & 1.0 & -0.2400 & 0.05027 & -4.77 & 0.0003 \\
\hline Krylon Vinyl Resin & 1.5 & -0.4556 & 0.05027 & -9.06 & 0.0000 \\
\hline Powder Coating & 0.5 & -0.8178 & 0.05027 & -16.27 & 0.0000 \\
\hline Powder Coating & 1.0 & -0.8444 & 0.05027 & $-16 \cdot 80$ & 0.0000 \\
\hline Powder Coating & 1.5 & -0.8456 & 0.05027 & -16.82 & 0.0000 \\
\hline VHT Epoxy Resin & 0.5 & -0.6478 & 0.05027 & -12.89 & 0.0000 \\
\hline VHT Epoxy Resin & 1.0 & -0.7744 & 0.05027 & -15.41 & 0.0000 \\
\hline JHT Epoxy Resin & 1.5 & -0.8444 & 0.05027 & -16.80 & 0.0000 \\
\hline
\end{tabular}

Coating type $=$ Krylon Vinyl Resin

Thickness $=1.0$ subtracted from:

\begin{tabular}{|c|c|c|c|c|c|}
\hline Difference & of & Adjusted & & & \\
\hline Coating type & Thickness & of Means & Difference & T-Value & P-Value \\
\hline Krylon Vinyl Resin & 1.5 & -0.2156 & 0.05027 & -4.29 & 0.0017 \\
\hline Powder Coating & 0.5 & -0.5778 & 0.05027 & $-11 \cdot 49$ & 0.0000 \\
\hline Powder Coating & 1.0 & -0.6044 & 0.05027 & -12.03 & 0.0000 \\
\hline Powder Coating & 1.5 & -0.6056 & 0.05027 & -12.05 & 0.0000 \\
\hline VHT Epoxy Resin & 0.5 & -0.4078 & 0.05027 & -8.11 & 0.0000 \\
\hline VHT Epoxy Resin & 1.0 & -0.5344 & 0.05027 & -10.63 & 0.0000 \\
\hline VHT Epoxy Resin & 1.5 & -0.6044 & 0.05027 & -12.03 & 0.0000 \\
\hline
\end{tabular}




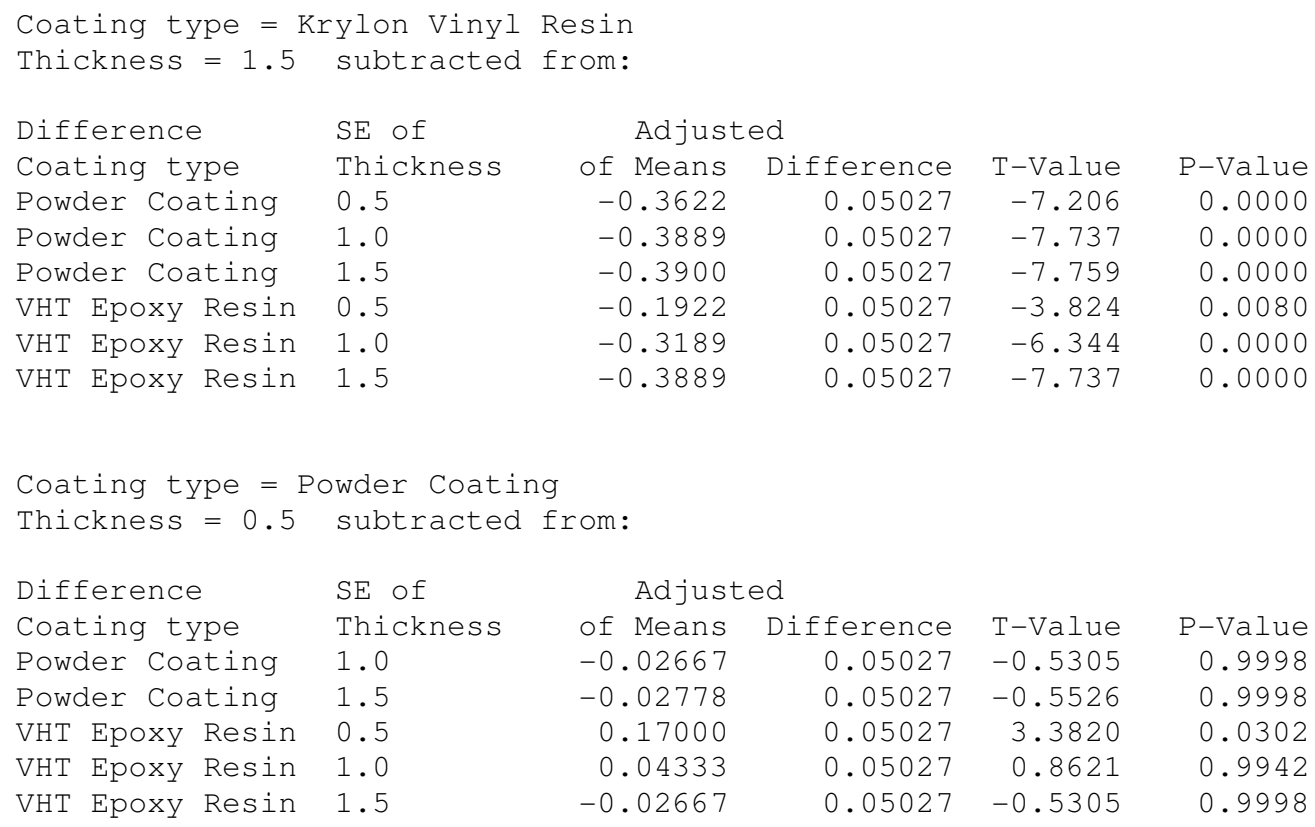

Coating type $=$ Powder Coating

Thickness $=1.0$ subtracted from:

\begin{tabular}{llrrrr} 
Difference & SE of & \multicolumn{2}{c}{ Adjusted } & \\
Coating type & Thickness & of Means & Difference & T-Value & P-Value \\
Powder Coating & 1.5 & -0.001111 & 0.05027 & -0.02210 & 1.0000 \\
VHT Epoxy Resin & 0.5 & 0.196667 & 0.05027 & 3.91256 & 0.0061 \\
VHT Epoxy Resin & 1.0 & 0.070000 & 0.05027 & 1.39261 & 0.8970 \\
VHT Epoxy Resin & 1.5 & -0.000000 & 0.05027 & -0.00000 & 1.0000
\end{tabular}

Coating type $=$ Powder Coating

Thickness $=1.5$ subtracted from:

\begin{tabular}{|c|c|c|c|c|c|}
\hline Difference & SE of & Adjust & & & \\
\hline Coating type & Thickness & of Means & Difference & T-Value & P-Value \\
\hline VHT Epoxy Resin & 0.5 & 0.197778 & 0.05027 & 3.93467 & 0.0056 \\
\hline VHT Epoxy Resin & 1.0 & 0.071111 & 0.05027 & 1.41471 & 0.8885 \\
\hline VHT Epoxy Resin & 1.5 & 0.001111 & 0.05027 & 0.02210 & 1.0000 \\
\hline $\begin{array}{l}\text { oating type }= \\
\text { hickness }=0.5\end{array}$ & $\begin{array}{l}\text { IT Epoxy Re } \\
\text { subtractec }\end{array}$ & om: & & & \\
\hline Difference & $\mathrm{SE}$ of & Adjust & & & \\
\hline Coating type & Thickness & of Means & Difference & T-Value & P-Value \\
\hline VHT Epoxy Resin & 1.0 & -0.1267 & 0.05027 & -2.520 & 0.2401 \\
\hline VHT Epoxy Resin & 1.5 & -0.1967 & 0.05027 & -3.913 & 0.0061 \\
\hline
\end{tabular}

Coating type = VHT Epoxy Resin

Thickness $=1.0$ subtracted from:

Difference SE of Adjusted

Coating type Thickness of Means Difference T-Value P-Value

$\begin{array}{llllll}\text { VHT Epoxy Resin } 1.5 & -0.07000 & 0.05027 & -1.393 & 0.8970\end{array}$ 


\section{APPENDIX D}

\section{Delamination Data}

Table D1. Measured Coating Delamination

\begin{tabular}{|l|r|r|}
\hline Coating Type & $\begin{array}{l}\text { Coating } \\
\text { thickness }\end{array}$ & $\begin{array}{l}\text { Deformation } \\
\text { (in^2) }\end{array}$ \\
\hline Krylon Vinyl Resin & 0.5 & 1.9 \\
\hline Krylon Vinyl Resin & 0.5 & 2 \\
\hline Krylon Vinyl Resin & 0.5 & 2 \\
\hline Krylon Vinyl Resin & 1 & 1.8 \\
\hline Krylon Vinyl Resin & 1 & 1.9 \\
\hline Krylon Vinyl Resin & 1 & 1.8 \\
\hline Krylon Vinyl Resin & 1.5 & 1.6 \\
\hline Krylon Vinyl Resin & 1.5 & 1.5 \\
\hline Krylon Vinyl Resin & 1.5 & 1.5 \\
\hline VHT Epoxy Resin & 0.5 & 0.2 \\
\hline VHT Epoxy Resin & 0.5 & 0.3 \\
\hline VHT Epoxy Resin & 0.5 & 0.2 \\
\hline VHT Epoxy Resin & 1 & 0.05 \\
\hline VHT Epoxy Resin & 1 & 0.05 \\
\hline VHT Epoxy Resin & 1 & 0 \\
\hline VHT Epoxy Resin & 1.5 & 0 \\
\hline VHT Epoxy Resin & 1.5 & 0 \\
\hline VHT Epoxy Resin & 1.5 & 0 \\
\hline Powder Coating & 0.5 & 0 \\
\hline Powder Coating & 0.5 & 0 \\
\hline Powder Coating & 0.5 & 0 \\
\hline Powder Coating & 1 & 0 \\
\hline Powder Coating & 1 & 0 \\
\hline Powder Coating & 1.5 & 0 \\
\hline Powder Coating & & 0 \\
\hline Powder Coating & 1.5 & 0 \\
\hline Powder Coating & & 0 \\
\hline & 1.5 & 0 \\
\hline
\end{tabular}




\section{APPENDIX E}

\section{Delamination Statistical Significance}

\section{General Linear Model: Delamination versus Coating Type, Coating thic}

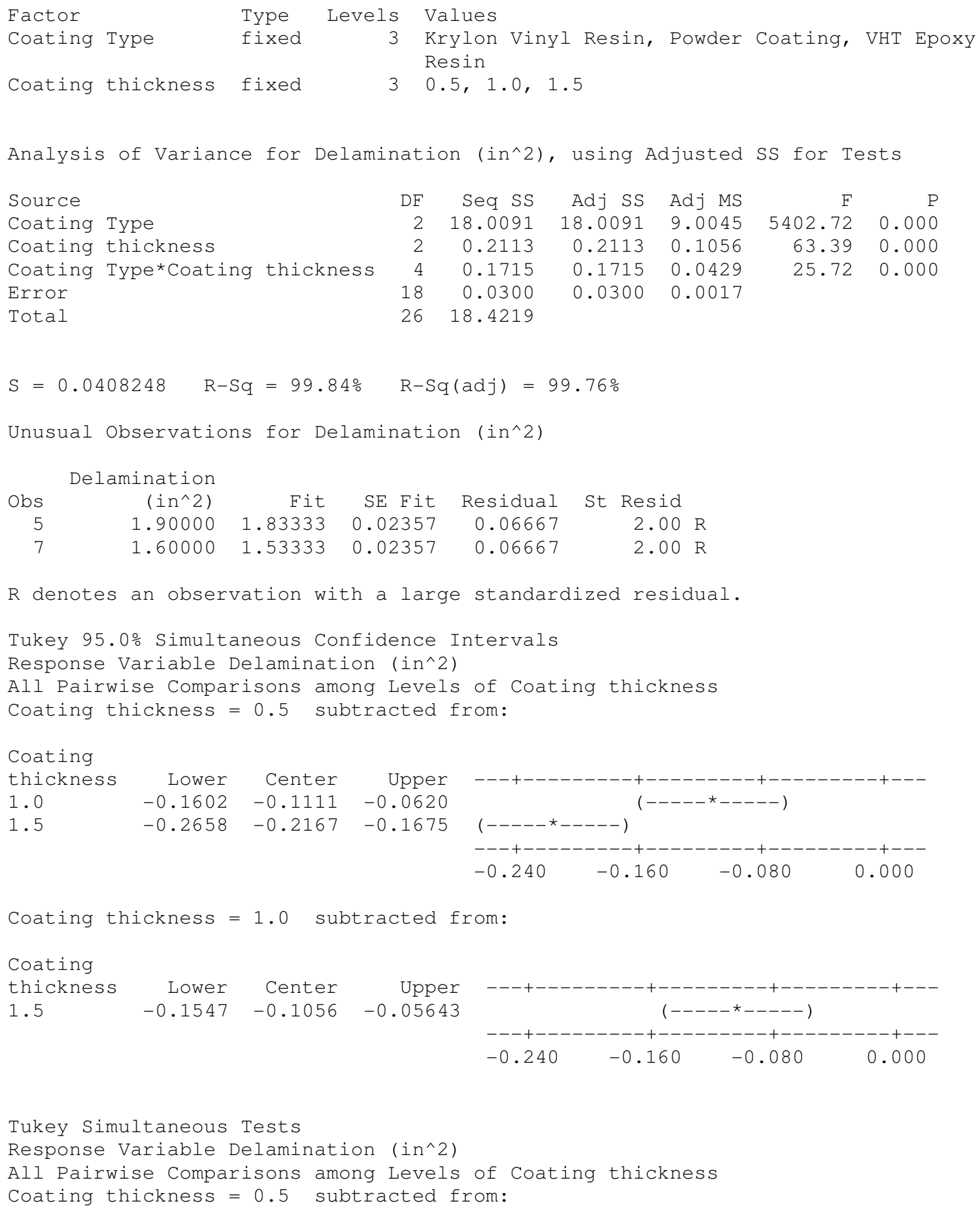

Tukey Simultaneous Tests Response Variable Delamination (in^2)

All Pairwise Comparisons among Levels of Coating thickness

Coating thickness $=0.5$ subtracted from: 


$\begin{array}{lrrrr}\begin{array}{l}\text { Coating } \\ \text { thickness }\end{array} & \begin{array}{r}\text { Difference } \\ \text { of Means }\end{array} & \begin{array}{r}\text { SE of } \\ \text { Difference }\end{array} & \text { T-Value } & \begin{array}{r}\text { Adjusted } \\ \text { P-Value }\end{array} \\ 1.0 & -0.1111 & 0.01925 & -5.77 & 0.0001 \\ 1.5 & -0.2167 & 0.01925 & -11.26 & 0.0000 \\ & & & & \\ \text { Coating thickness }=1.0 & \text { subtracted from: } & \\ \text { Coating } & \text { Difference } & \text { SE of } & & \text { Adjusted } \\ \text { thickness } & \text { of Means } & \text { Difference } & \text { T-Value } & \text { P-Value } \\ 1.5 & -0.1056 & 0.01925 & -5.485 & 0.0001\end{array}$

Tukey 95.0\% Simultaneous Confidence Intervals Response Variable Delamination (in^2)

All Pairwise Comparisons among Levels of Coating Type Coating Type $=$ Krylon Vinyl Resin subtracted from:

Coating Type Lower Center Upper

Powder Coating $\quad-1.827-1.778 \quad-1.729$

VHT Epoxy Resin $-1.732-1.683-1.634$

Coating Type

Powder Coating

VHT Epoxy Resin

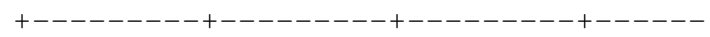

*)

$(\star)$

$+---------+---------+---------+------$

$\begin{array}{llll}-1.80 & -1.20 & -0.60 & 0.00\end{array}$

Coating Type = Powder Coating subtracted from:

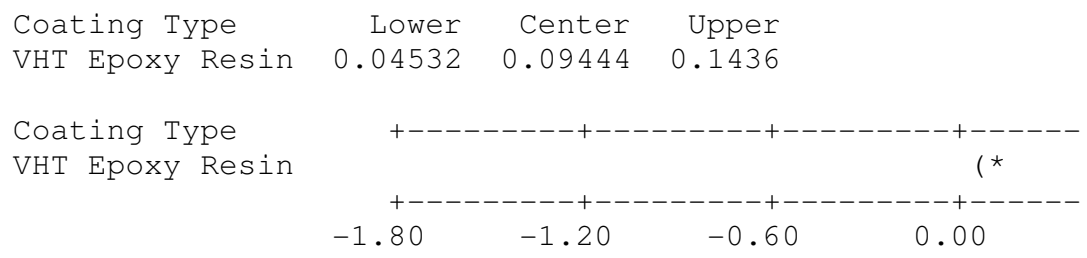

Tukey Simultaneous Tests

Response Variable Delamination (in^2)

All Pairwise Comparisons among Levels of Coating Type

Coating Type $=$ Krylon Vinyl Resin subtracted from:

$\begin{array}{lrrrr} & \text { Difference } & \text { SE of } & & \text { Adjusted } \\ \text { Coating Type } & \text { of Means } & \text { Difference } & \text { T-Value } & \text { P-Value } \\ \text { Powder Coating } & -1.778 & 0.01925 & -92.38 & 0.0000 \\ \text { VHT Epoxy Resin } & -1.683 & 0.01925 & -87.47 & 0.0000\end{array}$

Coating Type = Powder Coating subtracted from:

$\begin{array}{lrrrr} & \text { Difference } & \text { SE of } & \text { Adjusted } \\ \text { Coating Type } & \text { of Means } & \text { Difference } & \text { T-Value } & \text { P-Value } \\ \text { VHT Epoxy Resin } & 0.09444 & 0.01925 & 4.907 & 0.0003\end{array}$

Tukey 95.0\% Simultaneous Confidence Intervals

Response Variable Delamination (in^2)

All Pairwise Comparisons among Levels of Coating Type*Coating thickness Coating Type $=$ Krylon Vinyl Resin

Coating thickness $=0.5$ subtracted from: Coating 


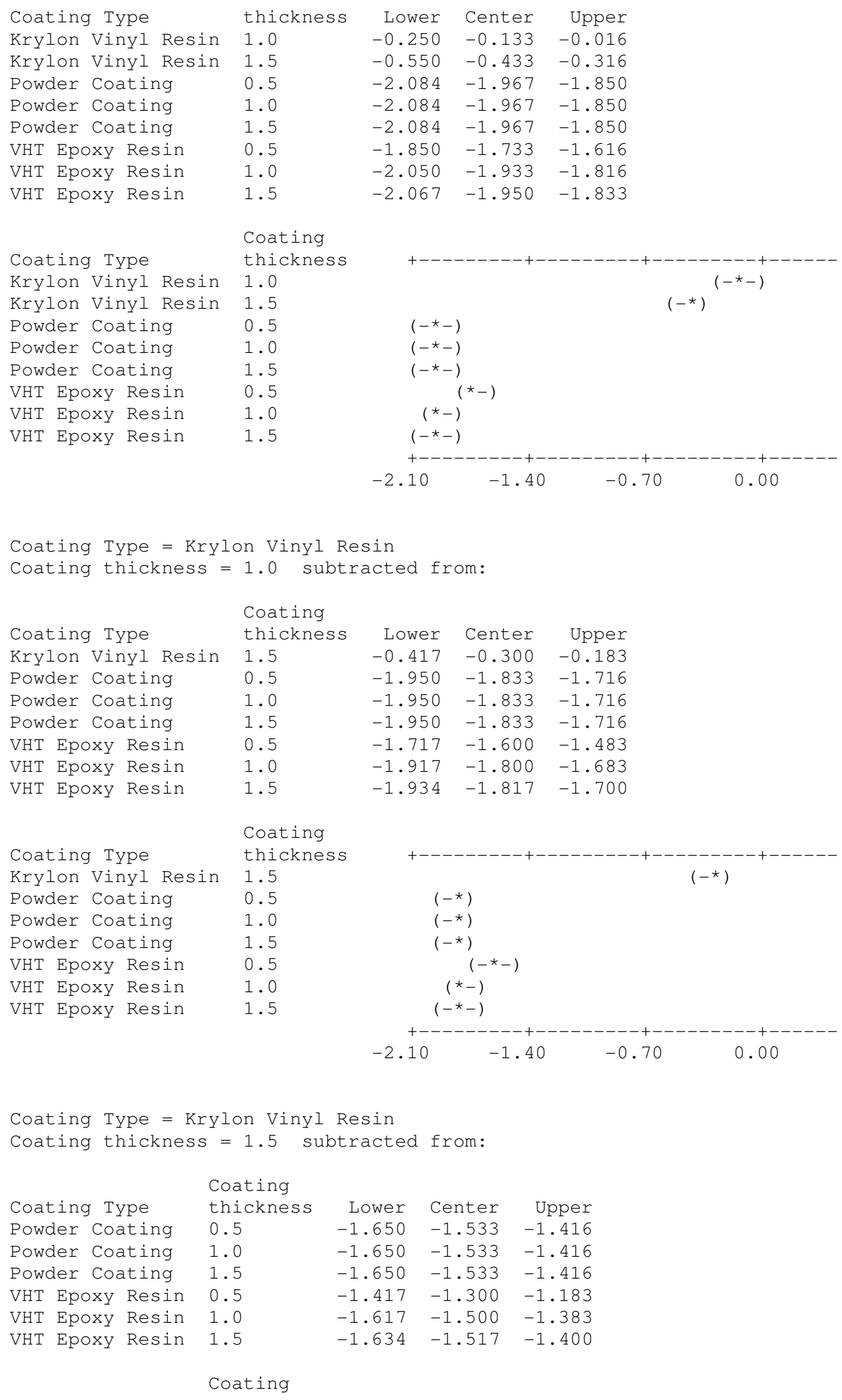




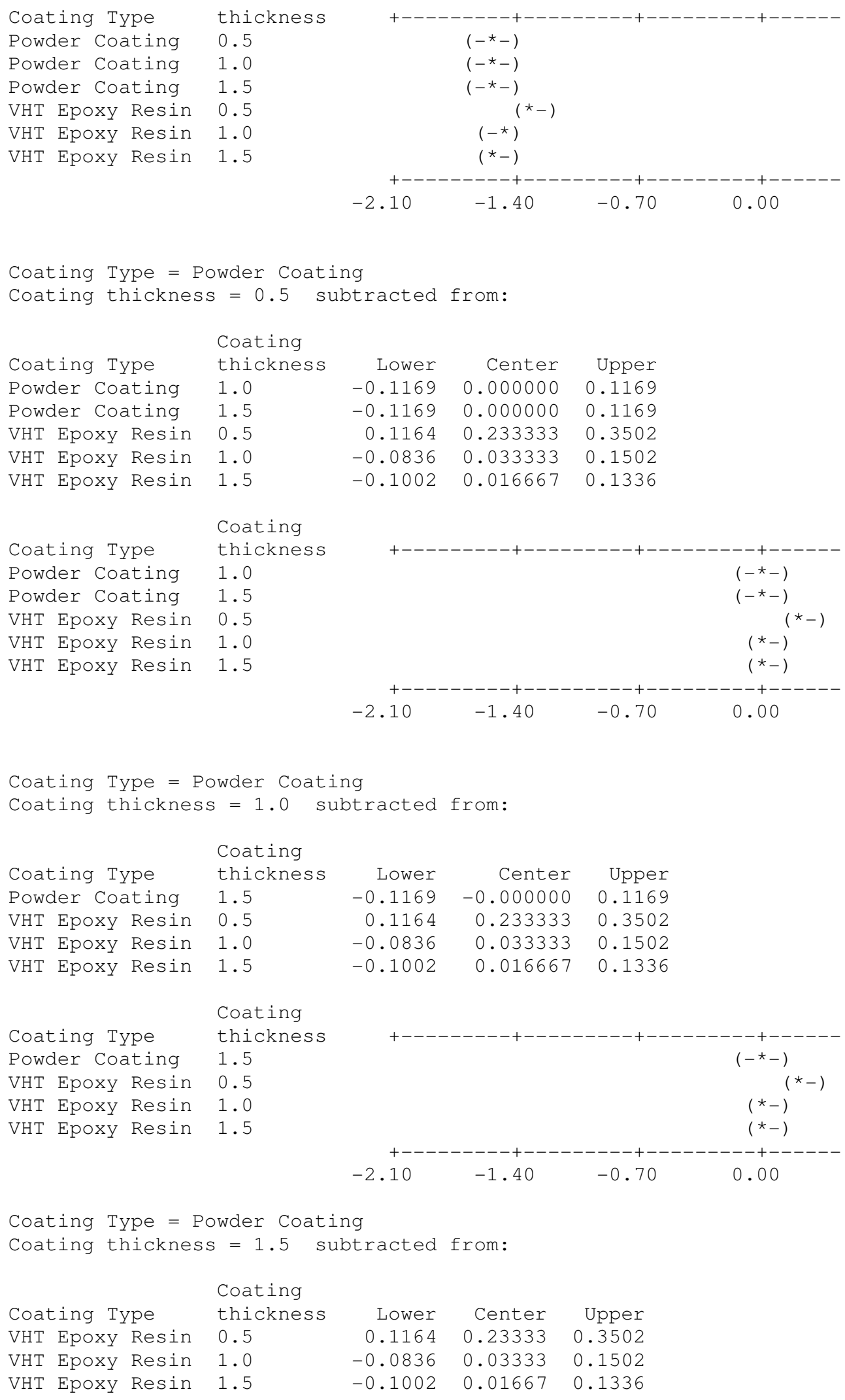




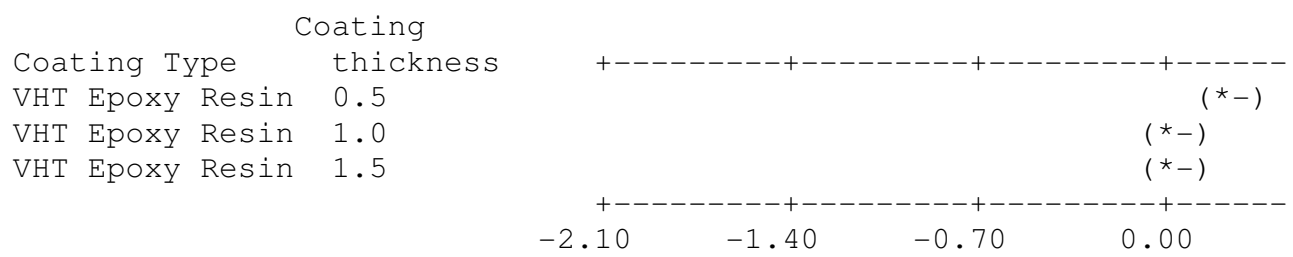

Coating Type = VHT Epoxy Resin

Coating thickness $=0.5$ subtracted from:

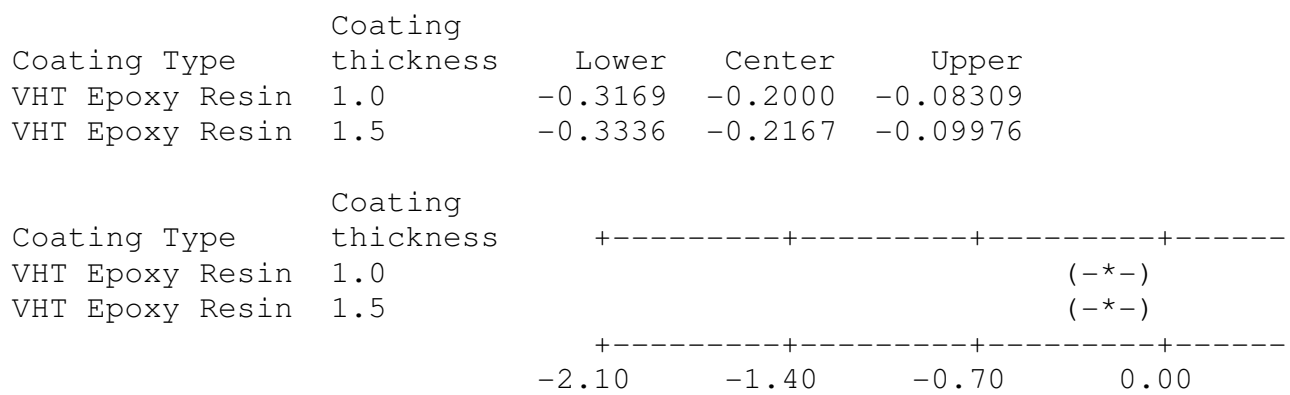

Coating Type = VHT Epoxy Resin

Coating thickness $=1.0$ subtracted from:

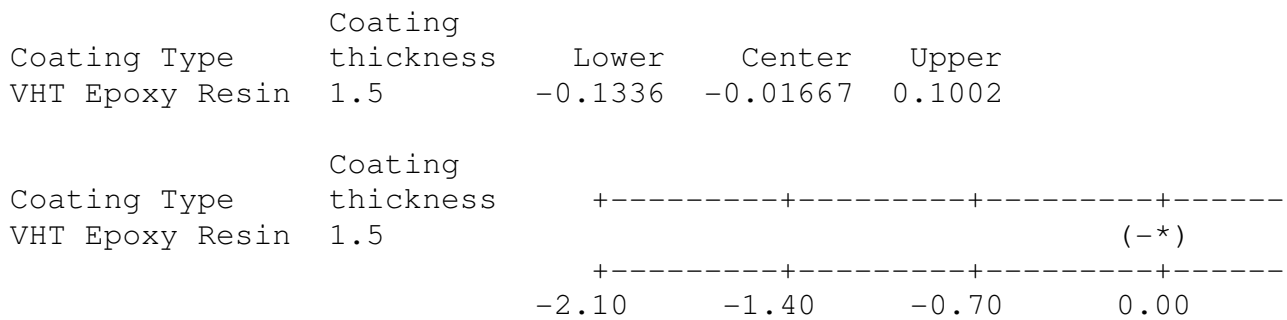

Tukey Simultaneous Tests

Response Variable Delamination (in^2)

All Pairwise Comparisons among Levels of Coating Type*Coating thickness Coating Type = Krylon Vinyl Resin

Coating thickness $=0.5$ subtracted from:

$\begin{array}{llrrrr}\text { Coating Type } & \begin{array}{l}\text { Coating } \\ \text { thickness }\end{array} & \begin{array}{r}\text { Difference } \\ \text { of Means }\end{array} & \begin{array}{r}\text { SE of } \\ \text { Difference }\end{array} & \begin{array}{r}\text { T-Value } \\ \text { P-Value }\end{array} \\ \text { Krylon Vinyl Resin } & 1.0 & -0.133 & 0.03333 & -4.00 & 0.0185 \\ \text { Krylon Vinyl Resin } & 1.5 & -0.433 & 0.03333 & -13.00 & 0.0000 \\ \text { Powder Coating } & 0.5 & -1.967 & 0.03333 & -59.00 & 0.0000 \\ \text { Powder Coating } & 1.0 & -1.967 & 0.03333 & -59.00 & 0.0000 \\ \text { Powder Coating } & 1.5 & -1.967 & 0.03333 & -59.00 & 0.0000 \\ \text { VHT Epoxy Resin } & 0.5 & -1.733 & 0.03333 & -52.00 & 0.0000 \\ \text { VHT Epoxy Resin } & 1.0 & -1.933 & 0.03333 & -58.00 & 0.0000 \\ \text { VHT Epoxy Resin } & 1.5 & -1.950 & 0.03333 & -58.50 & 0.0000\end{array}$

Coating Type $=$ Krylon Vinyl Resin

Coating thickness $=1.0$ subtracted from:

$\begin{array}{llrrrr} & \begin{array}{l}\text { Coating } \\ \text { thickness }\end{array} & \begin{array}{r}\text { Difference } \\ \text { of Means }\end{array} & \begin{array}{r}\text { SE of } \\ \text { Difference }\end{array} & \begin{array}{r}\text { T-Value } \\ \text { Adjusted } \\ \text { P-Value }\end{array} \\ \text { Krylon Vinyl Resin } & 1.5 & -0.300 & 0.03333 & -9.00 & 0.0000 \\ \text { Powder Coating } & 0.5 & -1.833 & 0.03333 & -55.00 & 0.0000 \\ \text { Powder Coating } & 1.0 & -1.833 & 0.03333 & -55.00 & 0.0000 \\ \text { Powder Coating } & 1.5 & -1.833 & 0.03333 & -55.00 & 0.0000\end{array}$




$\begin{array}{llllll}\text { VHT Epoxy Resin } & 0.5 & -1.600 & 0.03333 & -48.00 & 0.0000 \\ \text { VHT Epoxy Resin } & 1.0 & -1.800 & 0.03333 & -54.00 & 0.0000 \\ \text { VHT Epoxy Resin } & 1.5 & -1.817 & 0.03333 & -54.50 & 0.0000\end{array}$

Coating Type = Krylon Vinyl Resin

Coating thickness $=1.5$ subtracted from:

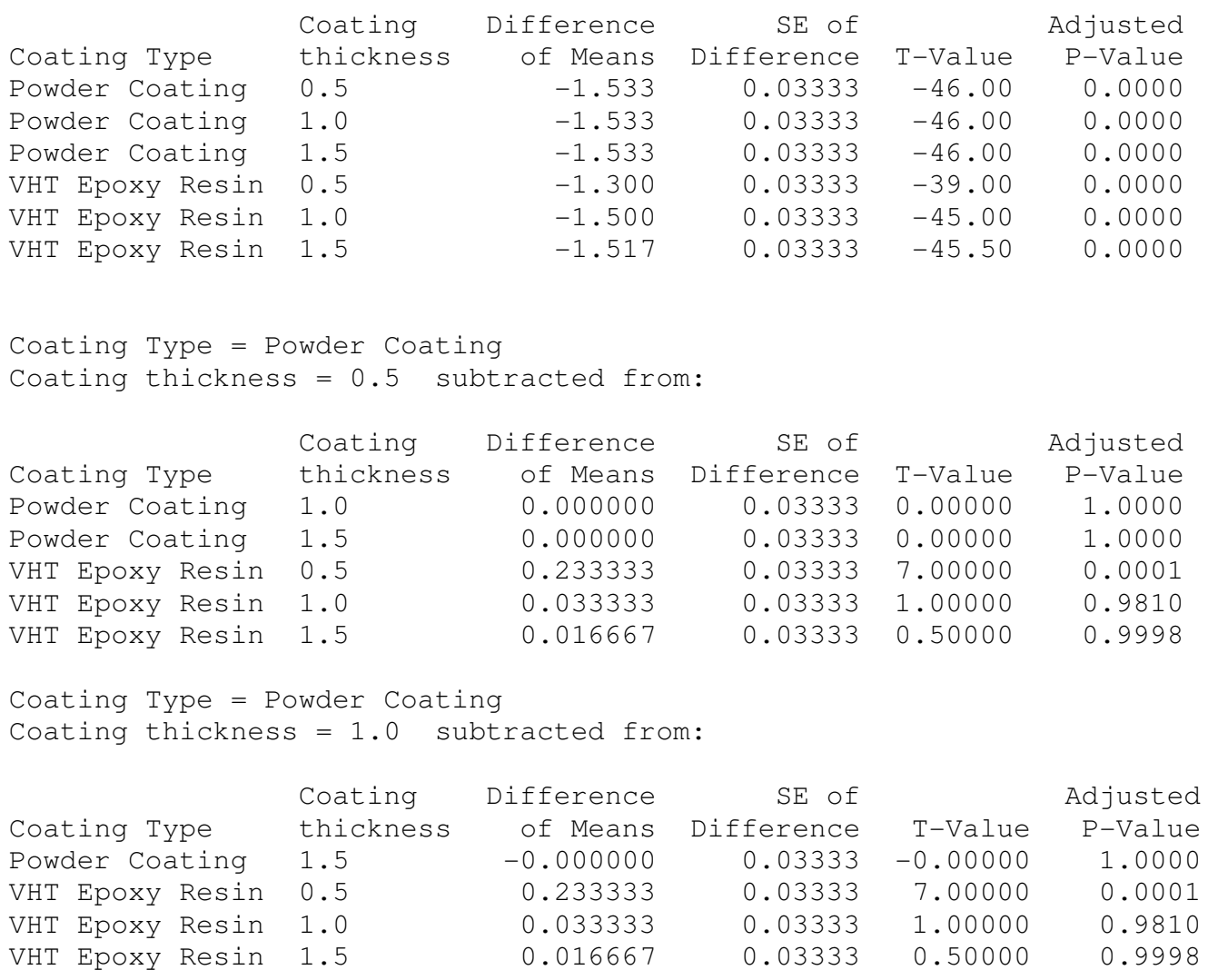

Coating Type $=$ Powder Coating

Coating thickness $=1.5$ subtracted from:

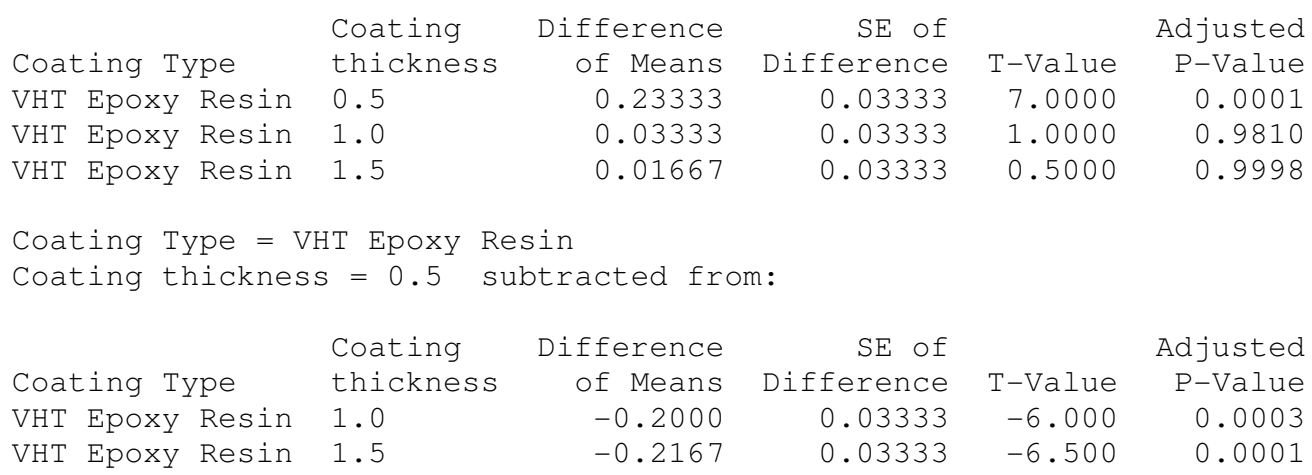

Coating Type = VHT Epoxy Resin

Coating thickness $=1.0$ subtracted from:

\begin{tabular}{|c|c|c|c|c|c|}
\hline & $\begin{array}{l}\text { Coating } \\
\text { thickness }\end{array}$ & $\begin{array}{r}\text { Difference } \\
\text { of Means }\end{array}$ & $\begin{array}{r}\text { SE of } \\
\text { Difference }\end{array}$ & $\mathrm{T}-\mathrm{V}$ & $\begin{array}{l}\text { Adjusted } \\
\text { P-Value }\end{array}$ \\
\hline in & 1.5 & -0.01667 & 0.03333 & -0.5000 & 0.9998 \\
\hline
\end{tabular}




\section{APPENDIX F}

\section{Deformation Data}

Table F1. Deformation Distances of Impact Testing

\begin{tabular}{|l|r|r|r|}
\hline Coating type & $\begin{array}{l}\text { Coating } \\
\text { thickness }\end{array}$ & \multicolumn{1}{l|}{$\begin{array}{l}\text { weight } \\
\text { (gf) }\end{array}$} & \multicolumn{1}{l|}{$\begin{array}{l}\text { Deformation } \\
\text { distance (m) }\end{array}$} \\
\hline Krylon Vinyl Resin & 1 & 300 & 160.1 \\
\hline Krylon Vinyl Resin & 1 & 300 & 155.4 \\
\hline Krylon Vinyl Resin & 1 & 300 & 167.1 \\
\hline Krylon Vinyl Resin & 1 & 500 & 230.5 \\
\hline Krylon Vinyl Resin & 1 & 500 & 251.9 \\
\hline Krylon Vinyl Resin & 1 & 500 & 255.4 \\
\hline Krylon Vinyl Resin & 1 & 2000 & 384.2 \\
\hline Krylon Vinyl Resin & 1 & 2000 & 376 \\
\hline Krylon Vinyl Resin & 1 & 2000 & 385.1 \\
\hline VHT Epoxy Resin & 1 & 300 & 92.3 \\
\hline VHT Epoxy Resin & 1 & 300 & 90.1 \\
\hline VHT Epoxy Resin & 1 & 300 & 97.4 \\
\hline VHT Epoxy Resin & 1 & 500 & 109.5 \\
\hline VHT Epoxy Resin & 1 & 500 & 121.6 \\
\hline VHT Epoxy Resin & 1 & 500 & 116.8 \\
\hline VHT Epoxy Resin & 1 & 2000 & 194.7 \\
\hline VHT Epoxy Resin & 1 & 2000 & 185.3 \\
\hline VHT Epoxy Resin & 1 & 2000 & 165.6 \\
\hline Powder Coating & 1 & 300 & 131.4 \\
\hline Powder Coating & 1 & 300 & 124.6 \\
\hline Powder Coating & 1 & 300 & 129.8 \\
\hline Powder Coating & 1 & 500 & 171.5 \\
\hline Powder Coating & 1 & 500 & 168.9 \\
\hline Powder Coating & 1 & 500 & 162.2 \\
\hline Powder Coating & 1 & 2000 & 298.1 \\
\hline Powder Coating & 1 & 2000 & \\
\hline Powder Coating & 1 & 2000 & \\
\hline
\end{tabular}




\section{APPENDIX G}

\section{Deformation Statistical Significance}

\section{General Linear Model: Deformation dist versus Coating type, weight (gf)}

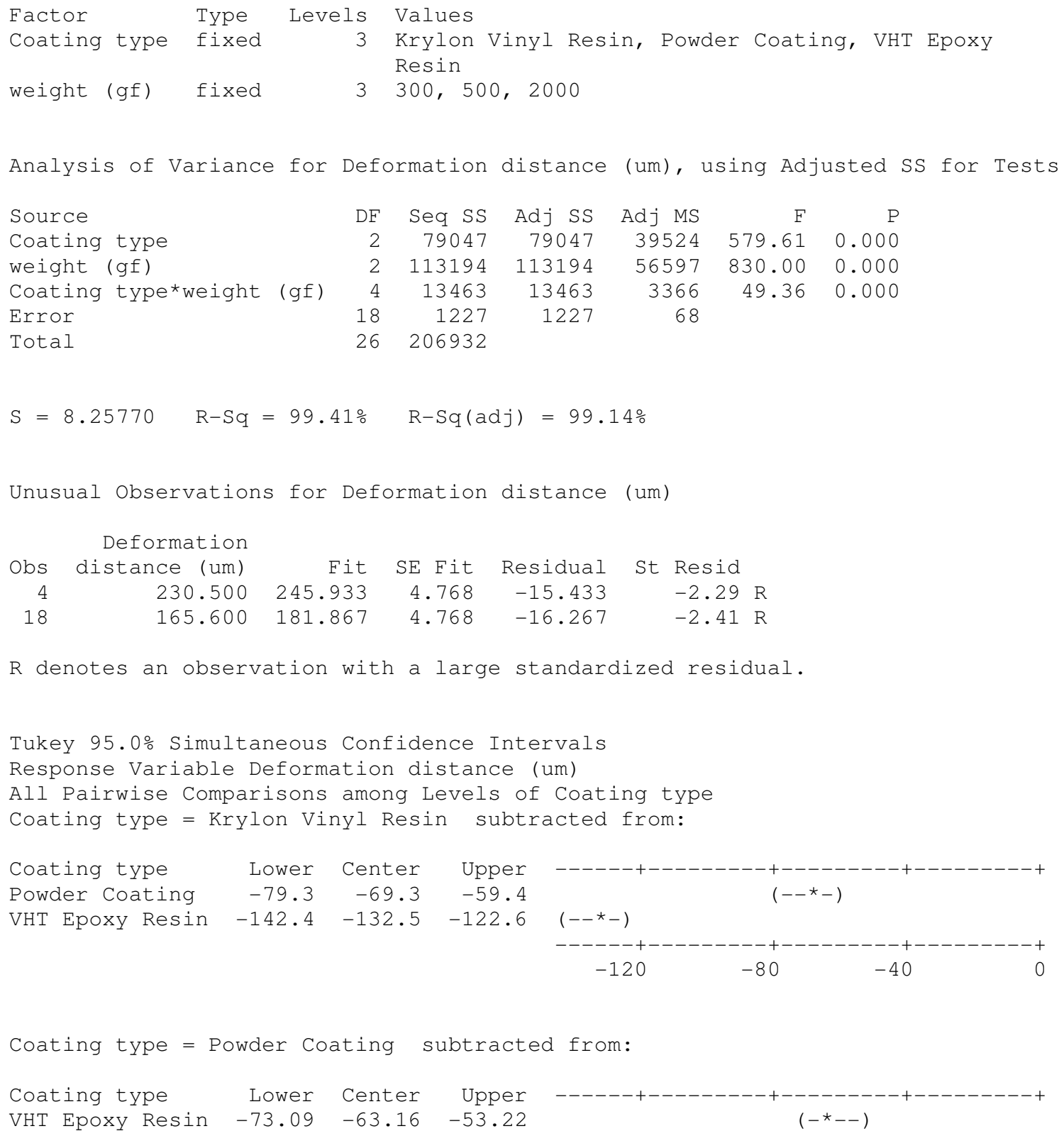

Tukey Simultaneous Tests

Response Variable Deformation distance (um)

All Pairwise Comparisons among Levels of Coating type

Coating type = Krylon Vinyl Resin subtracted from: 


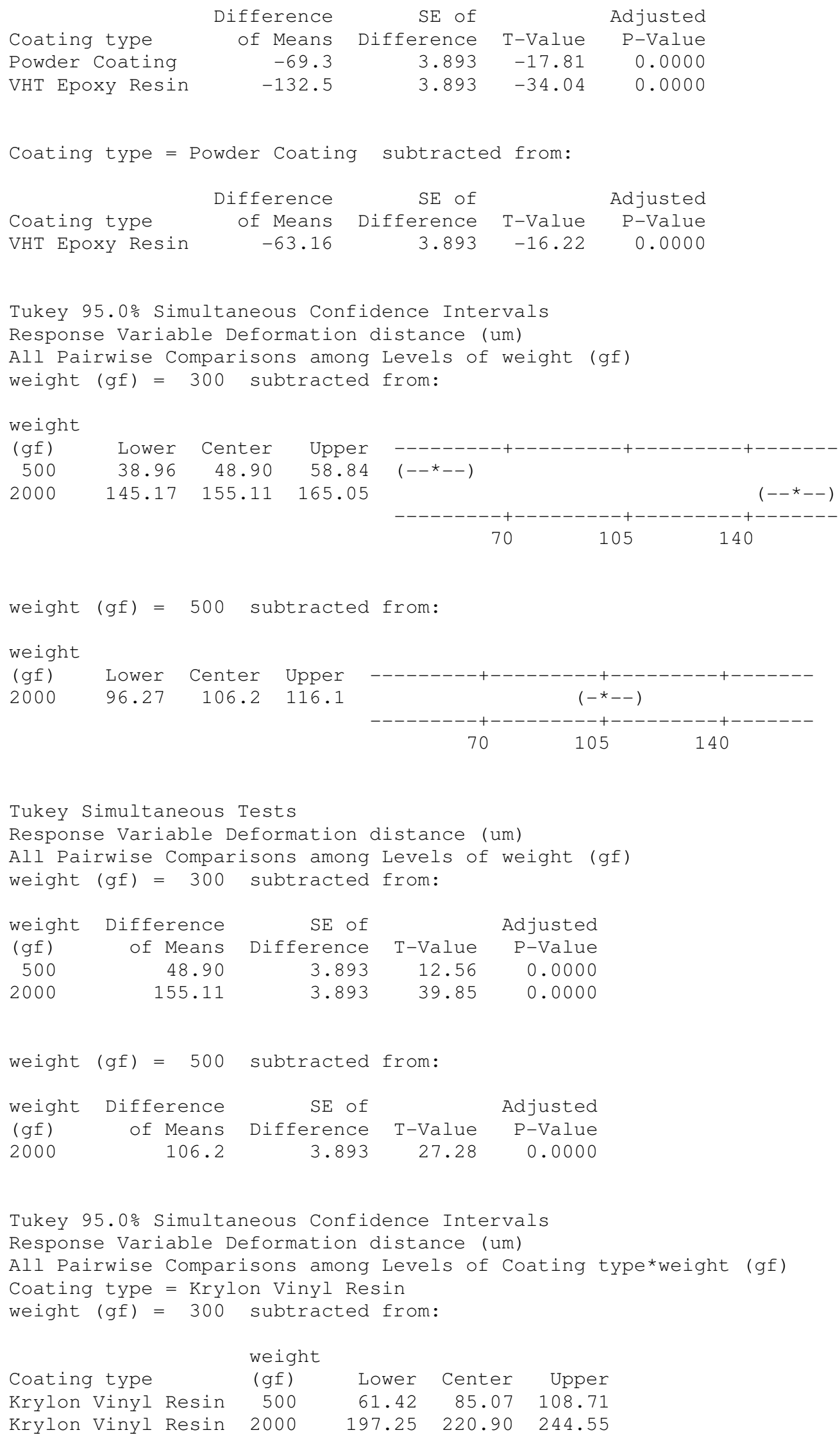




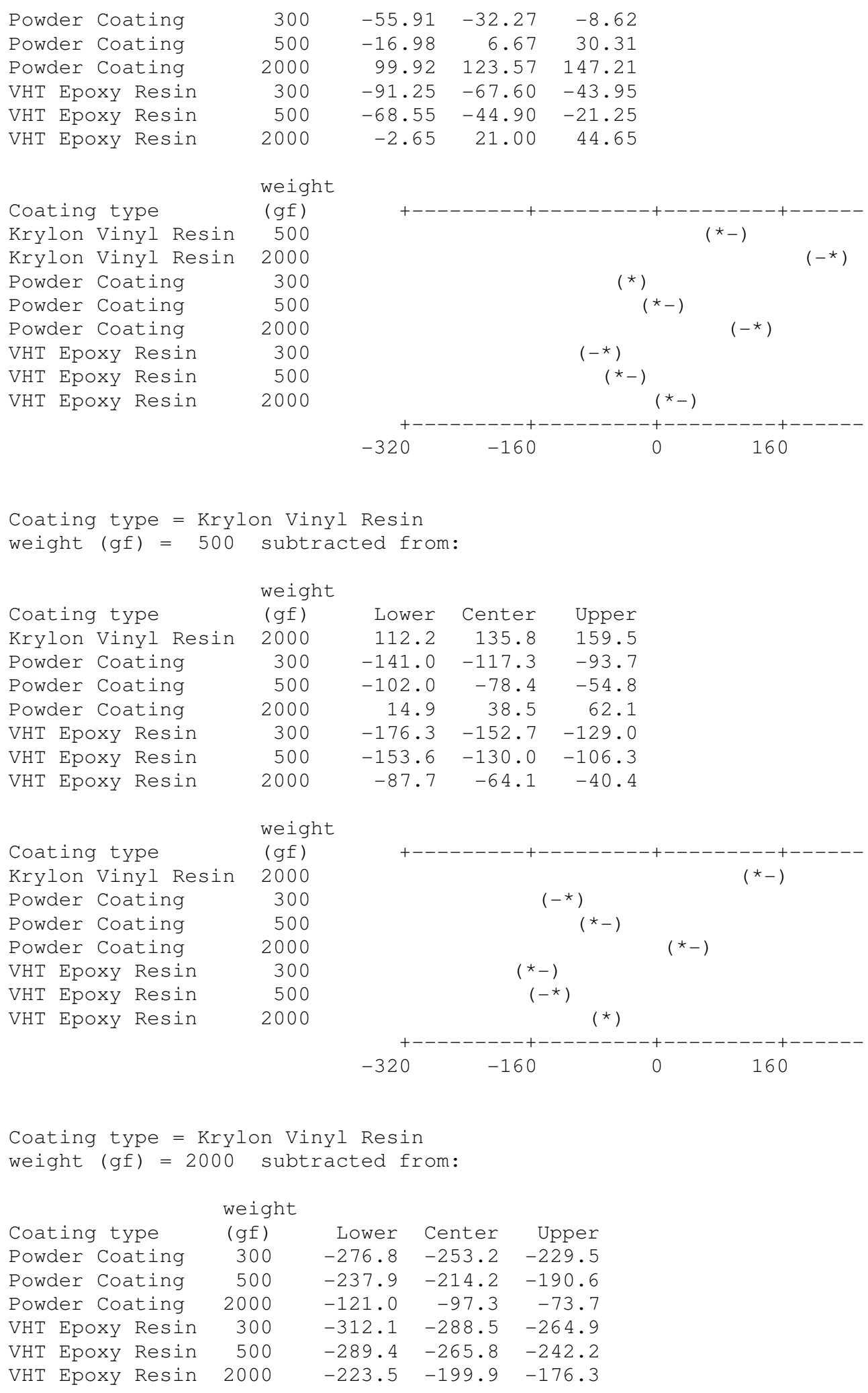




$\begin{array}{lr}\text { Coating type } & \begin{array}{r}\text { weight } \\ (\text { gf) }\end{array} \\ \text { Powder Coating } & 300 \\ \text { Powder Coating } & 500 \\ \text { Powder Coating } & 2000 \\ \text { VHT Epoxy Resin } & 300 \\ \text { VHT Epoxy Resin } & 500 \\ \text { VHT Epoxy Resin } & 2000\end{array}$

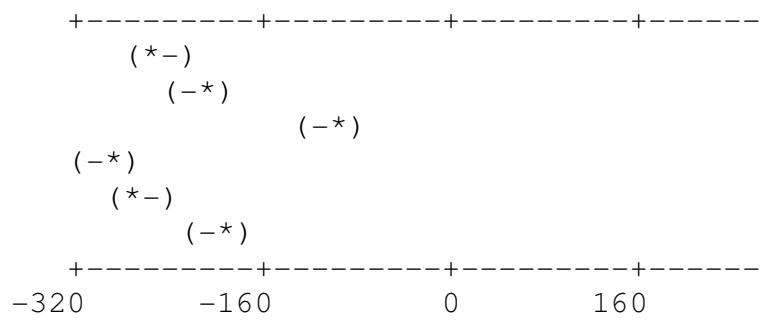

Coating type $=$ Powder Coating

weight $(g f)=300$ subtracted from:

$\begin{array}{lr}\text { Coating type } & \begin{array}{r}\text { weight } \\ \text { (gf) }\end{array} \\ \text { Powder Coating } & 500 \\ \text { Powder Coating } & 2000 \\ \text { VHT Epoxy Resin } & 300 \\ \text { VHT Epoxy Resin } & 500 \\ \text { VHT Epoxy Resin } & 2000 \\ & \\ & \\ & \text { weight } \\ \text { Coating type } & (\text { gf) } \\ \text { Powder Coating } & 500 \\ \text { Powder Coating } & 2000 \\ \text { VHT Epoxy Resin } & 300 \\ \text { VHT Epoxy Resin } & 500 \\ \text { VHT Epoxy Resin } & 2000\end{array}$

$\begin{array}{rrr}\text { Lower } & \text { Center } & \text { Upper } \\ 15.29 & 38.93 & 62.58 \\ 132.19 & 155.83 & 179.48 \\ -58.98 & -35.33 & -11.69 \\ -36.28 & -12.63 & 11.01 \\ 29.62 & 53.27 & 76.91\end{array}$

VHT Epoxy Resin

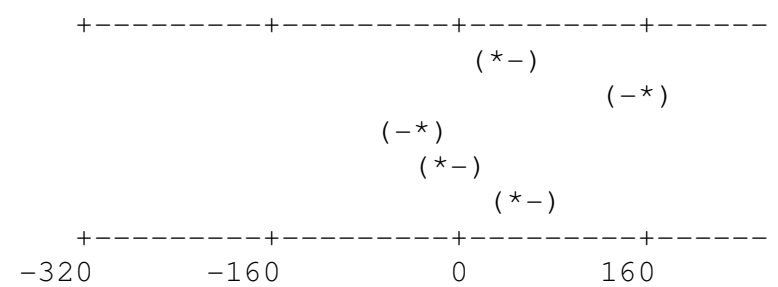

Coating type $=$ Powder Coating

weight $(\mathrm{gf})=500$ subtracted from:

$\begin{array}{lr}\text { Coating type } & \begin{array}{r}\text { weight } \\ (g f)\end{array} \\ \text { Powder Coating } & 2000 \\ \text { VHT Epoxy Resin } & 300 \\ \text { VHT Epoxy Resin } & 500 \\ \text { VHT Epoxy Resin } & 2000 \\ & \\ & \text { weight } \\ & (g f) \\ \text { Coating type } & 2000 \\ \text { Powder Coating } & 300 \\ \text { VHT Epoxy Resin } & 500 \\ \text { VHT Epoxy Resin } & 5000 \\ \text { VHT Epoxy Resin } & 2000\end{array}$

$\begin{array}{rrr}\text { Lower } & \text { Center } & \text { Upper } \\ 93.25 & 116.90 & 140.55 \\ -97.91 & -74.27 & -50.62 \\ -75.21 & -51.57 & -27.92 \\ -9.31 & 14.33 & 37.98\end{array}$

VHT Epoxy Resin

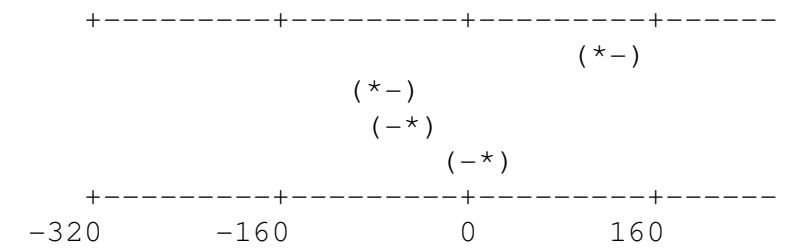

Coating type $=$ Powder Coating

weight $(g f)=2000$ subtracted from:

$\begin{array}{lrrrr} & \text { weight } & & \\ \text { Coating type } & (\text { gf }) & \text { Lower } & \text { Center } & \text { Upper } \\ \text { VHT Epoxy Resin } & 300 & -214.8 & -191.2 & -167.5 \\ \text { VHT Epoxy Resin } & 500 & -192.1 & -168.5 & -144.8 \\ \text { VHT Epoxy Resin } & 2000 & -126.2 & -102.6 & -78.9\end{array}$




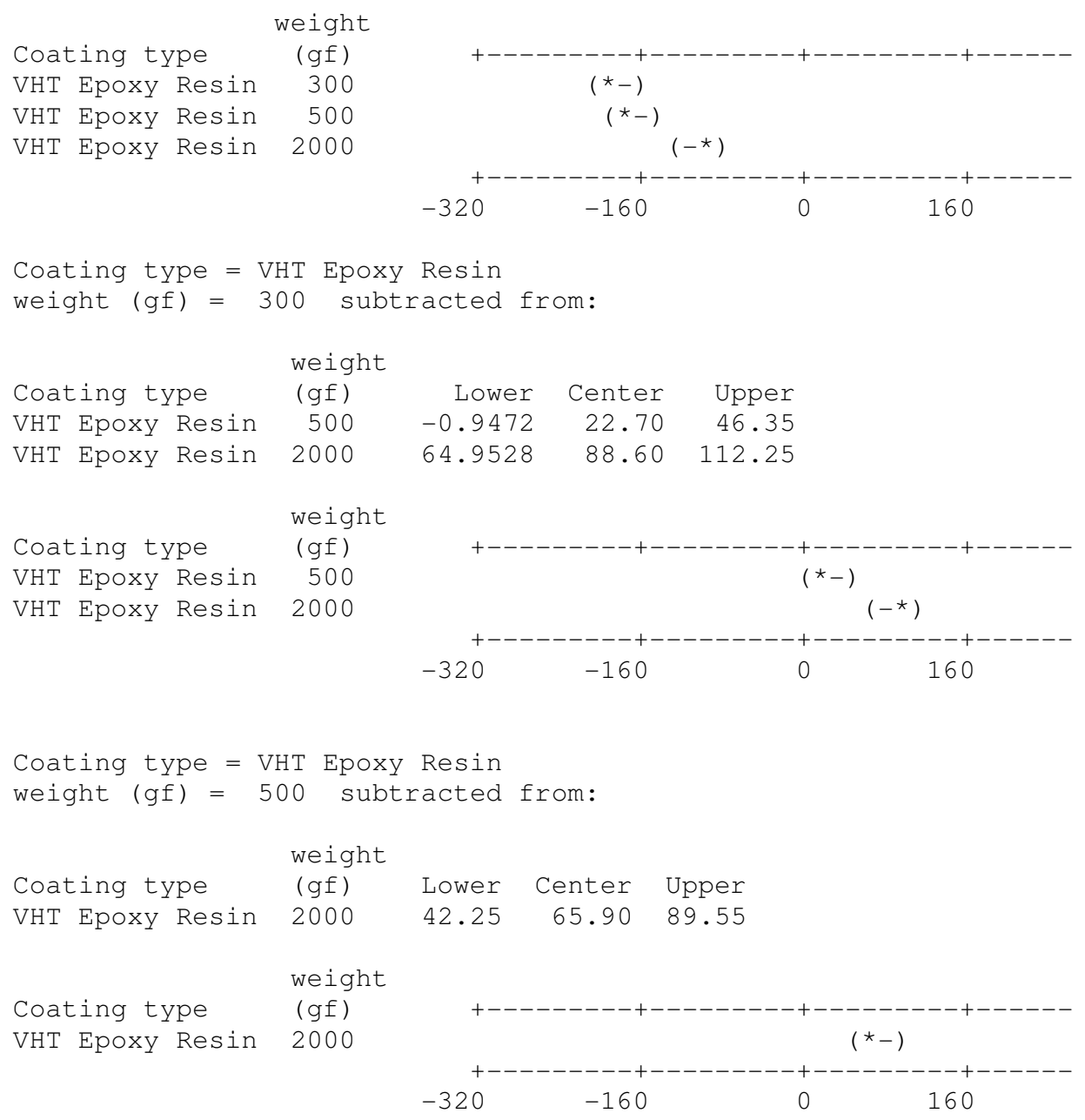

Tukey Simultaneous Tests

Response Variable Deformation distance (um)

All Pairwise Comparisons among Levels of Coating type*weight (gf)

Coating type $=$ Krylon Vinyl Resin

weight $(g f)=300$ subtracted from:

\begin{tabular}{|c|c|c|c|c|c|}
\hline Coating type & $\begin{array}{l}\text { weight } \\
\text { (gf) }\end{array}$ & $\begin{array}{r}\text { Difference } \\
\text { of Means }\end{array}$ & $\begin{array}{r}\text { SE of } \\
\text { Difference }\end{array}$ & T-Value & $\begin{array}{l}\text { Adjusted } \\
\text { P-Value }\end{array}$ \\
\hline Krylon Vinyl Resin & 500 & 85.07 & 6.742 & 12.62 & 0.0000 \\
\hline Krylon Vinyl Resin & 2000 & 220.90 & 6.742 & 32.76 & 0.0000 \\
\hline Powder Coating & 300 & -32.27 & 6.742 & -4.79 & 0.0037 \\
\hline Powder Coating & 500 & 6.67 & 6.742 & 0.99 & 0.9823 \\
\hline Powder Coating & 2000 & 123.57 & 6.742 & 18.33 & 0.0000 \\
\hline VHT Epoxy Resin & 300 & -67.60 & 6.742 & -10.03 & 0.0000 \\
\hline VHT Epoxy Resin & 500 & -44.90 & 6.742 & -6.66 & 0.0001 \\
\hline VHT Epoxy Resin & 2000 & 21.00 & 6.742 & 3.11 & 0.1046 \\
\hline
\end{tabular}

Coating type $=$ Krylon Vinyl Resin

weight $(g f)=500$ subtracted from:

$\begin{array}{lcrrrr} & \text { weight } & \text { Difference } & \text { SE of } & & \text { Adjusted } \\ \text { Coating type } & (\text { gf) } & \text { of Means } & \text { Difference } & \text { T-Value } & \text { P-Value } \\ \text { Krylon Vinyl Resin } & 2000 & 135.8 & 6.742 & 20.15 & 0.0000 \\ \text { Powder Coating } & 300 & -117.3 & 6.742 & -17.40 & 0.0000\end{array}$




$\begin{array}{lrrrrr}\text { Powder Coating } & 500 & -78.4 & 6.742 & -11.63 & 0.0000 \\ \text { Powder Coating } & 2000 & 38.5 & 6.742 & 5.71 & 0.0006 \\ \text { VHT Epoxy Resin } & 300 & -152.7 & 6.742 & -22.64 & 0.0000 \\ \text { VHT Epoxy Resin } & 500 & -130.0 & 6.742 & -19.28 & 0.0000 \\ \text { VHT Epoxy Resin } & 2000 & -64.1 & 6.742 & -9.50 & 0.0000\end{array}$

Coating type $=$ Krylon Vinyl Resin weight $(g f)=2000$ subtracted from:

$\begin{array}{lrrrrr}\text { Coating type } & \begin{array}{r}\text { weight } \\ \text { (gf) }\end{array} & \begin{array}{r}\text { Difference } \\ \text { of Means }\end{array} & \begin{array}{r}\text { SE of } \\ \text { Difference }\end{array} & \begin{array}{r}\text { T-Value } \\ \text { P-Value }\end{array} \\ \text { Powder Coating } & 300 & -253.2 & 6.742 & -37.55 & 0.0000 \\ \text { Powder Coating } & 500 & -214.2 & 6.742 & -31.77 & 0.0000 \\ \text { Powder Coating } & 2000 & -97.3 & 6.742 & -14.44 & 0.0000 \\ \text { VHT Epoxy Resin } & 300 & -288.5 & 6.742 & -42.79 & 0.0000 \\ \text { VHT Epoxy Resin } & 500 & -265.8 & 6.742 & -39.42 & 0.0000 \\ \text { VHT Epoxy Resin } & 2000 & -199.9 & 6.742 & -29.65 & 0.0000\end{array}$

Coating type $=$ Powder Coating

weight $(g f)=300$ subtracted from:

$\begin{array}{lrrrrr} & \text { weight } & \text { Difference } & \text { SE of } & & \text { Adjusted } \\ \text { Coating type } & \text { (gf) } & \text { Of Means } & \text { Difference } & \text { T-Value } & \text { P-Value } \\ \text { Powder Coating } & 500 & 38.93 & 6.742 & 5.774 & 0.0005 \\ \text { Powder Coating } & 2000 & 155.83 & 6.742 & 23.112 & 0.0000 \\ \text { VHT Epoxy Resin } & 300 & -35.33 & 6.742 & -5.240 & 0.0014 \\ \text { VHT Epoxy Resin } & 500 & -12.63 & 6.742 & -1.874 & 0.6379 \\ \text { VHT Epoxy Resin } & 2000 & 53.27 & 6.742 & 7.900 & 0.0000\end{array}$

Coating type $=$ Powder Coating

weight $(g f)=500$ subtracted from:

$\begin{array}{lrrrrr} & \text { weight } & \text { Difference } & \text { SE of } & & \text { Adjusted } \\ \text { Coating type } & \text { (gf) } & \text { of Means } & \text { Difference } & \text { T-Value } & \text { P-Value } \\ \text { Powder Coating } & 2000 & 116.90 & 6.742 & 17.34 & 0.0000 \\ \text { VHT Epoxy Resin } & 300 & -74.27 & 6.742 & -11.01 & 0.0000 \\ \text { VHT Epoxy Resin } & 500 & -51.57 & 6.742 & -7.65 & 0.0000 \\ \text { VHT Epoxy Resin } & 2000 & 14.33 & 6.742 & 2.13 & 0.4872\end{array}$

Coating type $=$ Powder Coating

weight $(g f)=2000$ subtracted from:

\begin{tabular}{|c|c|c|c|c|c|}
\hline Coating type & $\begin{array}{l}\text { weight } \\
\text { (gf) }\end{array}$ & $\begin{array}{l}\text { Difference } \\
\text { of Means }\end{array}$ & $\begin{array}{r}\text { SE of } \\
\text { Difference }\end{array}$ & T-Value & $\begin{array}{l}\text { Adjusted } \\
\text { P-Value }\end{array}$ \\
\hline VHT Epoxy Resin & 300 & -191.2 & 6.742 & -28.35 & 0.0000 \\
\hline VHT Epoxy Resin & 500 & $-168 \cdot 5$ & 6.742 & -24.99 & 0.0000 \\
\hline VHT Epoxy Resin & 2000 & -102.6 & 6.742 & $-15 \cdot 21$ & 0.0000 \\
\hline \multicolumn{6}{|c|}{$\begin{array}{l}\text { Coating type }=\text { VHT Epoxy Resin } \\
\text { weight }(g f)=300 \text { subtracted from: }\end{array}$} \\
\hline Coating type & $\begin{array}{l}\text { weight } \\
\text { (gf) }\end{array}$ & $\begin{array}{r}\text { Difference } \\
\text { of Means }\end{array}$ & $\begin{array}{r}\text { SE of } \\
\text { Difference }\end{array}$ & T-Value & $\begin{array}{r}\text { Adjusted } \\
\text { P-Value }\end{array}$ \\
\hline VHT Epoxy Resin & 500 & 22.70 & 6.742 & 3.367 & 0.0652 \\
\hline VHT Epoxy Resin & 2000 & 88.60 & 6.742 & 13.141 & 0.0000 \\
\hline $\begin{array}{l}\text { Coating type }=V \\
\text { weight }(g f)=5\end{array}$ & $\begin{array}{rr}\mathrm{HT} & \text { Epo } \\
0 & \text { su }\end{array}$ & $\begin{array}{l}\text { Resin } \\
\text { acted fron }\end{array}$ & & & \\
\hline ating ty & $\begin{array}{l}\text { weight } \\
\text { (gf) }\end{array}$ & $\begin{array}{l}\text { Difference } \\
\text { of Means }\end{array}$ & $\begin{array}{r}\text { SE of } \\
\text { Difference }\end{array}$ & T-Value & $\begin{array}{l}\text { Adjusted } \\
\text { P-Value }\end{array}$ \\
\hline VHT Epoxy Resin & 2000 & 65.90 & 6.742 & 9.774 & 0.0000 \\
\hline
\end{tabular}

